Portland State University

PDXScholar

$1-1-2012$

\title{
Site Fidelity, Associations and Long-Term Bonds of Short-Finned Pilot Whales off the Island of Hawai i
}

Sabre D. Mahaffy

Portland State University

Follow this and additional works at: https://pdxscholar.library.pdx.edu/open_access_etds Let us know how access to this document benefits you.

\section{Recommended Citation}

Mahaffy, Sabre D., "Site Fidelity, Associations and Long-Term Bonds of Short-Finned Pilot Whales off the Island of Hawai'i" (2012). Dissertations and Theses. Paper 320.

https://doi.org/10.15760/etd.320

This Thesis is brought to you for free and open access. It has been accepted for inclusion in Dissertations and Theses by an authorized administrator of PDXScholar. Please contact us if we can make this document more accessible: pdxscholar@pdx.edu. 
Site Fidelity, Associations and Long-Term Bonds of Short-Finned Pilot Whales off the Island of Hawai' $\mathrm{i}$

\section{by}

Sabre D. Mahaffy

A thesis submitted in partial fulfillment of the

requirements for the degree of

Master of Science

in

Biology

Thesis Committee:

Deborah Duffield, Chair

Robin W. Baird

Bradley A. Buckley

Portland State University

2012 


\begin{abstract}
Short-finned pilot whales (Globicephala macrorhynchus) are the most frequently sighted odontocete in a long-term study in Hawai 'i (representing $23.8 \%$ of all odontocete sightings from directed research efforts), yet little has been published on this species in Hawaiian waters. Studies elsewhere have suggested that short-finned pilot whales travel in stable mixed-sex groups composed of strongly associated individuals; however temporal analyses of social structure are lacking. To examine site fidelity, association patterns and temporal relationships, I analyzed data from 267 directed research and opportunistic encounters of short-finned pilot whales off the island of Hawai'i from 2003 through 2007. Sightings occurred year-round. Analysis of sighting depths in relation to effort indicated short-finned pilot whales are strongly associated with the island slope, with no sightings in water $>2,700 \mathrm{~m}$ deep despite effort to $\sim 5,000 \mathrm{~m}$. Using only goodquality photos, I identified 448 distinctive individuals; of these, 305 (68.1\%) were seen more than once and $250(55.8 \%)$ were seen in $>1$ year. Sighting histories varied from 129 sightings per individual (median=3) over the course of the study, suggesting only some individuals exhibit high site fidelity. Degree of residency was assessed using multiyear site fidelity to the study area; individuals seen $\geq 5$ times in $\geq 3$ years were considered core residents (154 individuals), individuals who fell below these criteria but that were seen more than once were termed residents (150 individuals) and those seen on a single occasion were termed visitors (142 individuals). Only $71.9 \%$ of the whales were linked by association into a single social network, suggesting the possibility of multiple populations using the study area. Individuals demonstrated preferential associations and community division was strongly supported by average-linkage hierarchical cluster
\end{abstract}


analysis of the association data. Nine longitudinally-stable social units composed of key individuals (seen together $\geq 8$ times in $\geq 4$ years) and their constant companions (seen together $\geq 5$ times in $\geq 3$ years) were identified (unit membership 5-16, median $=10.5$; mean unit association index: 0.62-0.90). Qualitative assignment of age and sex classes to unit members indicated that some segregation between adult males and female/calf pairs may occur. Temporal analysis using standardized lagged association rates of individuals grouped in the same encounter produced a best-fit model where dyads gradually disassociated over time while individuals grouped in the same day produced a model where dyads remained in association, suggesting companions not documented during an encounter are likely still present in the study area. Differential patterns of residency and site fidelity were unexpected and may be indicative of multiple populations around the main Hawaiian Islands. Additionally, the presence of a core resident population demonstrating strong, long-term site fidelity and associations off the island of Hawai' $i$ may warrant special management considerations. Evidence of fisheries-related injuries in addition to anthropogenic threats such as high levels of commercial and recreational vessel traffic, targeted tourist activities, and commercial and sports troll fisheries indicate that additional research is needed to evaluate potential threats to this island-associated population. 


\section{Dedication}

To my parents, John and Jolyn Mahaffy. This is for you.

And to the short-finned pilot whales of Hawai'i, thank you for the snapshots into your world. 


\section{Acknowledgements}

I want to extend my deepest gratitude to my co-advisors, Dr. Deborah Duffield and Dr. Robin Baird. Deb, your enthusiasm for marine mammal science is infectious and it was such a pleasure to be a part of your lab. Thank you for your friendship and support. Robin: thank you for introducing me to the world of Hawaiian odontocetes, for sharing your knowledge and expertise, and for emphasizing the importance of holding research to the highest standard. Working with you has been an invaluable experience.

I would also like to thank Daniel J. McSweeney and the Wild Whale Research Foundation for the wealth of photos contributed to this study. Dan has been photographing odontocetes off the leeward side of the island of Hawai' $i$ for close to three decades and his collaboration has greatly expanded the scope of this study. I would also like to thank all of the researchers and volunteers in the field who assisted in the collection of photos used in this study, particularly Gregory S. Schorr, Daniel L. Webster, and Robin W. Baird - I wouldn't have a project without you.

Annie B. Douglas generously provided confirmation of all matches that resulted from a mark change (and many that did not) and both Robin Baird and Annie Douglas were excellent resources in the area of photo-identification. Uko Gorter kindly illustrated a map of pilot whale distribution for this study.

Funding for fieldwork was provided by Daniel J. McSweeney and the Wild Whale Research Foundation, Cascadia Research Collective, Southwest Fisheries Science Center, Pacific Islands Fisheries Science Center, and Chief of Naval Operations/Environmental Readiness Division. 
Finally, I would like to thank my parents, whose unwavering support and enthusiasm throughout the length of my project made every challenge seem surmountable. Your confidence gave me strength. And to Jason, for sacrificing many a Saturday afternoon to work on an Excel spreadsheet, and for always having a fresh cup of tea waiting... 


\section{Table of Contents}

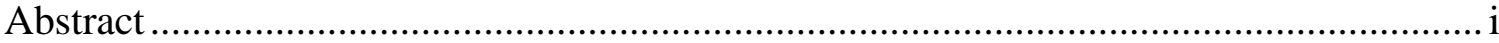

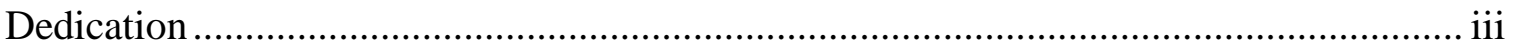

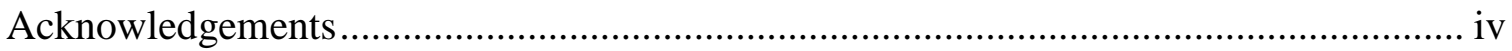

List of Tables ................................................................................................... viii

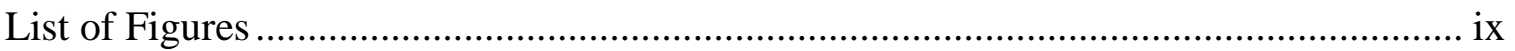

Short-finned pilot whale adult female with calf off the island of Hawai' $i$...................... xii

CHAPTER 1: Background/ Literature Review ...............................................................1

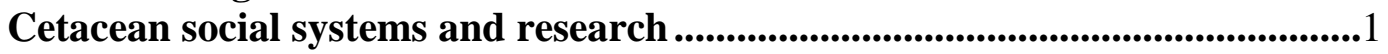

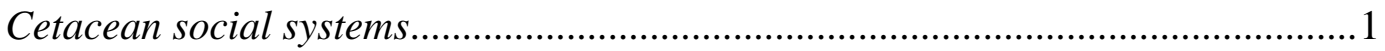

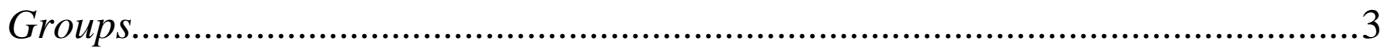

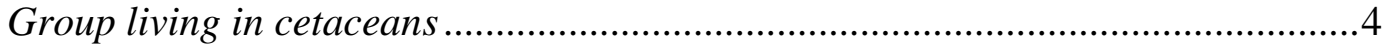

Residency, site fidelity, and habitat usage .......................................................

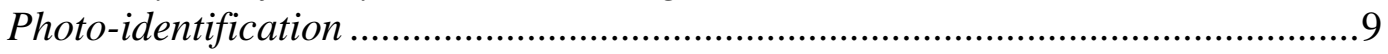

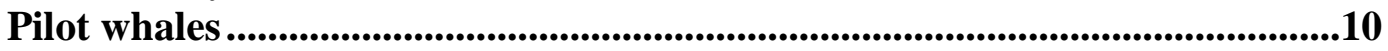

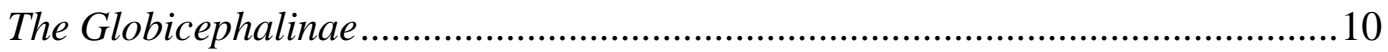

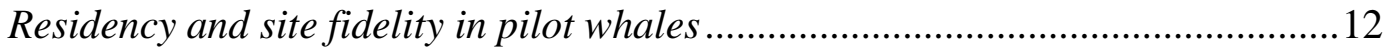

Depth distribution and movements in relation to prey ........................................13

Defining groups - comparisons to other studies ............................................. 14

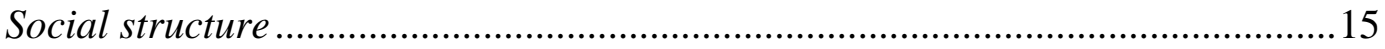

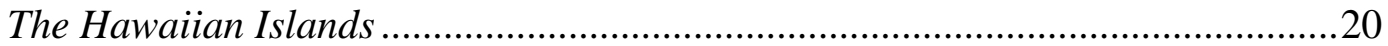

CHAPTER 2: High site fidelity, strong associations and long-term bonds: shortfinned pilot whales off the island of Hawai'i .....................................................23

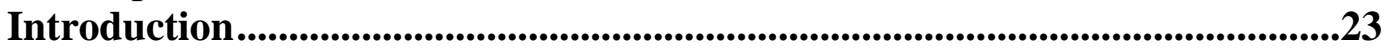

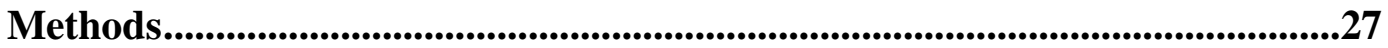

Field methods .............................................................................27

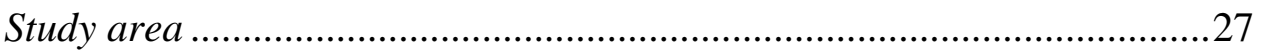

Effort ........................................................................................27

Wild Whale Research Foundation: opportunistic effort and encounters ..28

Directed research encounters ..............................................................28

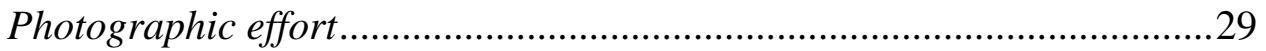

Photo-identification....................................................................................30

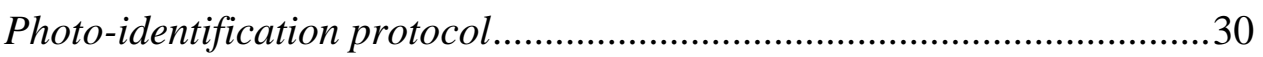

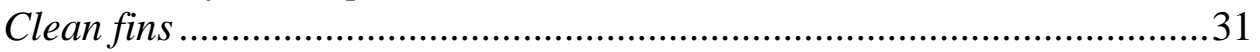

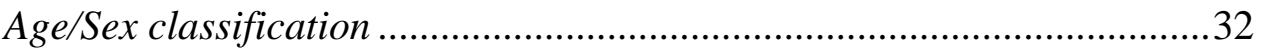

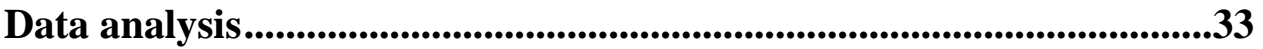

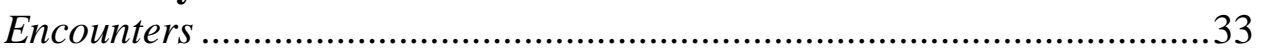

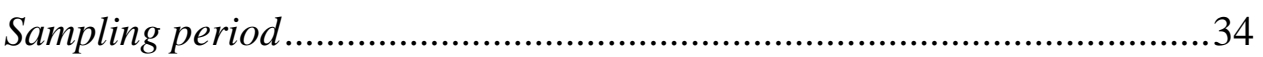

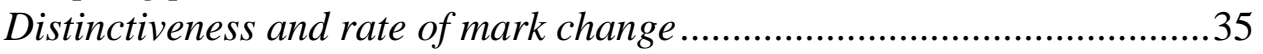

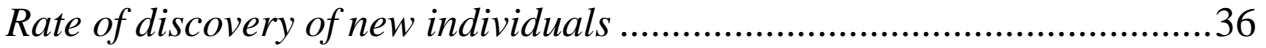

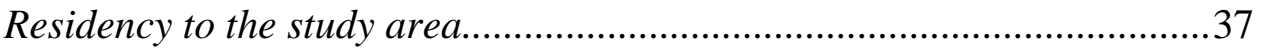

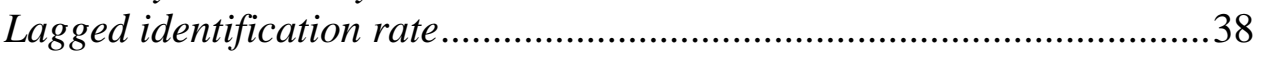

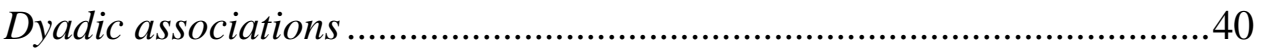

Social differentiation and precision analysis........................................42 


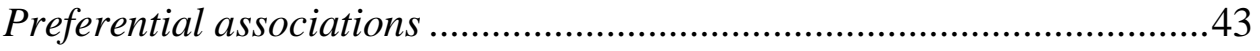

Detecting community structure ...........................................................45

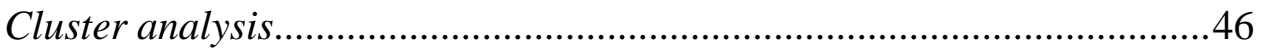

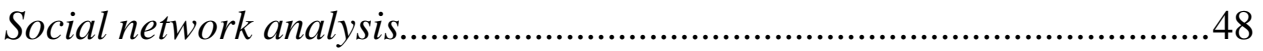

Temporal aspects of social structure ..................................................50

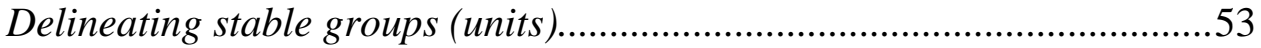

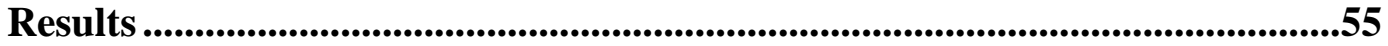

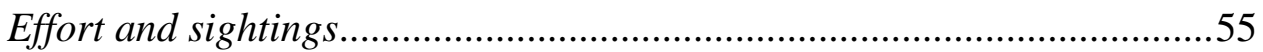

Assessing encounter coverage ...........................................................58

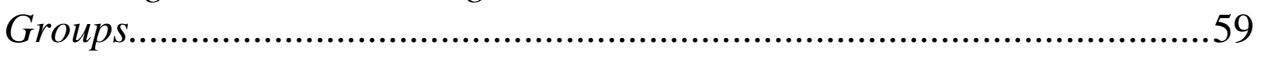

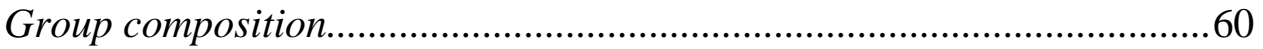

Distinctiveness and rate of mark change ..............................................60

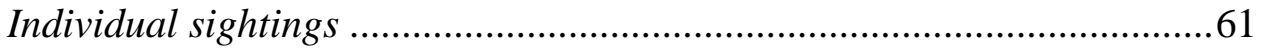

Rate of discovery of new individuals ..................................................6...63

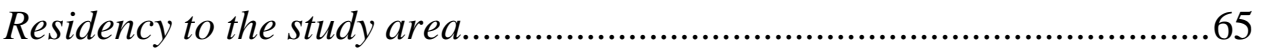

Lagged identification rate ....................................................................67

Social differentiation and precision analysis......................................69

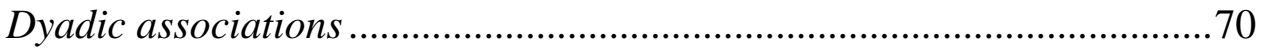

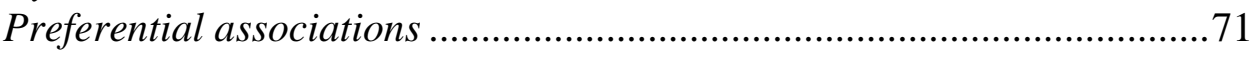

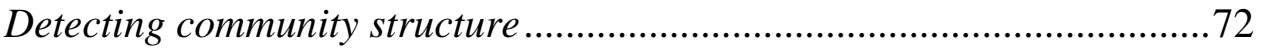

Hierarchical cluster analysis and network analysis...............................73

Temporal aspects of social structure .....................................................76

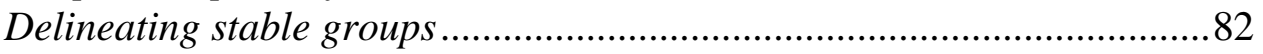

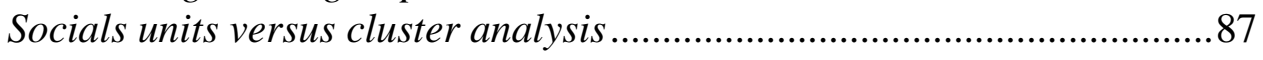

Discussion...............................................................................................................................993

Residency, site fidelity and differential patterns of habitat usage off the

island of Hawai 'i.................................................................................... 93

Preliminary evidence of population structure .........................................96

Depth distribution and movements: potential influences of prey abundance

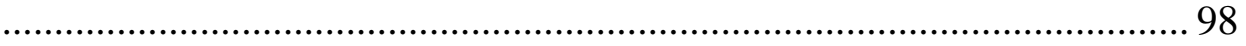

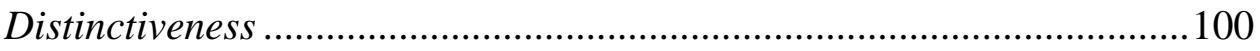

Mark changes.................................................................................101

Characteristics of the individual: examining differences in association

patterns and gregariousness ........................................................... 103

Detecting community structure: hierarchical cluster analysis and temporal methods..........................................................................105

Detecting community structure: comparisons to other studies................107

Interpreting the social and ecological significance of clusters and units 109

Implications for conservation and management..................................112

Literature Cited .......................................................................................115

Appendix A: Group size ................................................................................................128

Appendix B: Evolving fingerprints: working with natural markings ...........130

Appendix C: Distinctiveness of the study population and the influence of photo-identification on fine-scale and population-wide analysis.......132 


\section{List of Tables}

Table 2.1. Coverage ratings for directed research and opportunistic encounters off the island of Hawai' $i$ from 2003 through 2007. Coverage ratings were assigned to provide a metric of how completely groups were sampled (Ottensmeyer \& Whitehead 2003)....... 34

Table 2.2. Exponential models available in SOCPROG 2.4 that can be fitted to the LIRs using maximum likelihood and binomial loss. Models describe movements of individuals in and out of one study area; model equations and possible interpretations were taken from the SOCPROG 2.4 manual (Whitehead 2009).

Table 2.3. Exponential models available in SOCPROG 2.4 that can be fitted to the LARs and SLARs using maximum likelihood and binomial loss. Models allow for quantitative analysis of the lagged association rate(s); possible interpretations are also given.

Table 2.4. Exponential models fitted to the entire dataset using maximum likelihood and binomial loss, and used to describe movements of individuals in and out of study area off the island of Hawai' $i$. The best-fit model was that with lowest $\triangle$ QAIC value; standard errors were obtained using 1,000 bootstrap replications.

Table 2.5. Tests for non-random associations among distinctive short-finned pilot whales seen $\geq 5$ times off the island of Hawai' $i$; permutation tests performed in SOCPROG 2.4 were used to test for short-term and long-term preferred or avoided associations and for differences in individual gregariousness. $P$-values $>0.95$ are considered significant.... 72

Table 2.6. Exponential models fitted to the entire dataset using maximum likelihood and binomial loss and used to describe long-term associations (SLAR, g') of distinctive individuals off the island of Hawai' $i$. Associations were defined as individuals grouped within an encounter; the best-fit model was that with lowest $\Delta \mathrm{QAIC}$ value. .77

Table 2.7. Exponential models fitted to the entire dataset using maximum likelihood and binomial loss, and used to describe long-term associations of distinctive individuals off the island of Hawai' $i$ restricted to coverage $\geq 80 \%$; the best-fit model was that with lowest $\triangle$ QAIC value.

Table 2.8. Exponential models fitted to the entire dataset using maximum likelihood and binomial loss, and used to describe long-term associations of distinctive individuals off the island of Hawai' $i$ using a sampling period of a day and associations defined as individuals seen on the same day; the best-fit model was that with lowest $\triangle Q A I C$ value.

Table 2.9. Longitudinally stable social units of short-finned pilot whales off the island of Hawai' $i$ constructed from shared sighting histories and composed of key individuals and constant companions. .84

Table 2.10. Visually estimated age/sex classes of individuals within social units; see section on Age/Sex Classification for a review of terms and criteria. 


\section{List of Figures}

Figure 1. Geographic distribution of long-finned and short-finned pilot whales. Dark gray areas indicate the range of the long-finned pilot whale, light gray areas indicate the range of the short-finned pilot whale and hatched areas indicate overlapping range. Illustration by Uko Gorter

Figure 2.1. Map showing directed research effort around the main Hawaiian Islands from 2003 through 2007. Short-finned pilot whale sightings are represented by blue diamonds and survey tracklines are shown in red; the 1,000 $\mathrm{m}$ and 2,000 $\mathrm{m}$ depth contours are

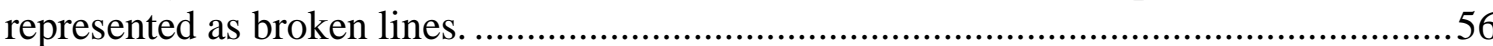

Figure 2.2. Distance from shore of short-finned pilot whale sightings (per $100 \mathrm{~h}$ effort) around the main Hawaiian Islands from 2003 through 2007

Figure 2.3. Depth distribution of short-finned pilot whale sightings (per $100 \mathrm{~h}$ effort) around the main Hawaiian Islands from 2003 through 2007

Figure 2.4. Rate of discovery of new individuals showing the cumulative number of individuals documented versus the cumulative number of identifications made (maximum of one identification per day) off the island of Hawai' $i$. Top: including a 1:1 line for comparison. Bottom: detailed view of the curve.

Figure 2.5. Social network diagram of all distinctive short-finned pilot whales documented off the island of Hawai'i from 2003 through 2007. Distances between nodes were determined using a spring-embedding algorithm to depict closeness between individuals. Core residents are shown as white circles, residents are shown as gray boxes and visitors are shown as black triangles. Note the two core residents that do not link by association to the main social network. 66

Figure 2.6. Enlargement of main social network cluster taken from Figure 2.5. Note the presence of two cut-points (clusters linked to the main component by a single individual). Removal of either individual would cause the main cluster to fragment slightly. 67

Figure 2.7. Lagged identification rate $(*)$ for short-finned pilot whales documented off the island of Hawai' $i$. The two models that best described the study population were both of emigration and remigration and are shown as completely overlapping dashed lines (Models E and F, Table 2.4). Standard error bars were produced using 1,000 bootstrap replications

Figure 2.8. Distribution of association indices for distinctive individuals seen off the island of Hawai ${ }^{6} i \geq 5$ times: a) maximum association index, and $b$ ) sum of associates for each individual.

Figure 2.9. Dendrogram constructed using average-weight linkage hierarchical cluster analysis of distinctive short-finned pilot whales documented off the island of Hawai'i on 
five or more occasions. The dashed line represents cluster division resulting from the Modularity-G method (Mod- $\mathrm{G}=0.798, \mathrm{AI}=0.048$ ); the dotted line represents cluster division resulting from the Modularity-P method (Mod-P=0.172, $\mathrm{AI}=0.174) \ldots \ldots \ldots . .75$

Figure 2.10. SLAR for short-finned pilot whales documented off Hawai'i Island using a moving average of 200,000 associations. Associations are defined as individuals grouped within an encounter. Approximate standard error bars (+/- one standard error) were produced by jackknifing on each sampling period. The best-fit model (casual acquaintances, $\mathrm{g}^{\prime}=0.046^{*} \mathrm{e}^{-0.0002 \tau}$ ) was obtained using maximum likelihood methods; the

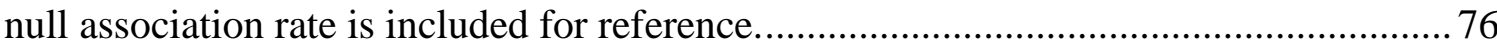

Figure 2.11. SLAR for short-finned pilot whales documented off the island of Hawai' $i$ (restricted to coverage $\geq 80 \%$ ), using a moving average of 30,000 associations. The bestfit model was constant companions, $\mathrm{g}^{\prime}=0.0429$; the null association rate is included for reference.

Figure 2.12. SLAR for short-finned pilot whales documented off the island of Hawai' $i$ using a moving average of 250,000 associations. Associations were defined as individuals seen on the same day. The best-fit model (constant companions, $\mathrm{g}^{\prime}=0.0191$ ) was obtained using maximum likelihood methods; the null association rate is included for reference.

Figure 2.13. Social network diagram depicting all distinctive individuals documented off Hawai' $i$ Island that link back to the main social network. Visitors are depicted as black triangles, residents are depicted as gray squares and core residents are depicted as white circles; individuals assigned to units are labeled with their unit designation and core residents not allocated to a social unit are labeled "NA".

Figure 2.14. Social network diagram depicting core residents documented off Hawai' $i$ Island that link back to the main social network: Unit A (red circle), Unit B1 (black plus sign), Unit B2 (light green up triangle), Unit C1 (gray hatched box), Unit C2 (light blue down triangle), Unit E (pink boxed-circle), Unit F (dark green diamond), Unit G (yellow square) and Unit $\mathrm{H}$ (orange inverted triangles). Core residents not allocated to a social unit are shown as dark blue squares.

Figure 2.15. Dendrogram reproduced from Figure 2.9 for comparison with social units consisting of key individuals and constant companions constructed using longitudinal sighting histories. Here, individuals failing to meet the criteria for key individuals or constant companions are grayed-out.

Figure 2.16. Dendrogram constructed from key individuals and constant companions documented off the island of Hawai' $i$ to illustrate differences between social unit delineation using sighting histories and cluster assignment using the eigenvector method. Solid lines represent key individuals and dotted lines represent constant companions. Maximum modularity- $G$ is indicated by a dashed line and an association index of 0.50 is indicated by a dotted line. Note: the asterisk in Cluster 1 refers to HIGm0211, the 
individual responsible for subdividing Unit $\mathrm{C}$ into $\mathrm{C} 1$ and $\mathrm{C} 2$. The individual that fell below the 0.50 criterion in Unit B1 was removed from the final analysis but is shown here for illustration. Cluster assignments here do not correspond to other figures. ......... 92 


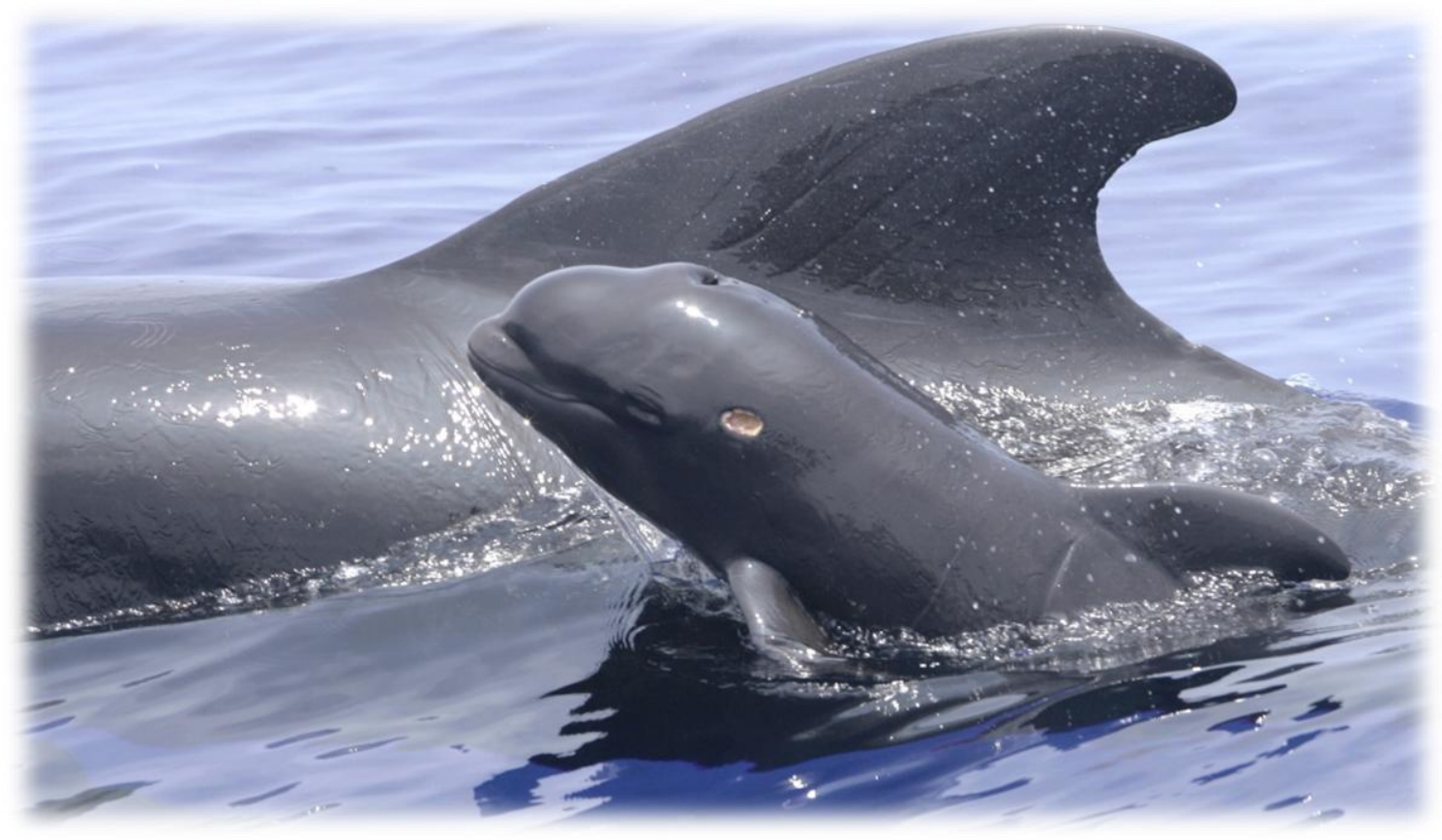

Short-finned pilot whale adult female with calf off the island of Hawai'i. Photo by Daniel J. McSweeney. 


\section{Chapter 1: Background/Literature review}

\section{Cetacean social systems and research}

\section{Cetacean social systems}

Cetaceans are a dynamic order within the class Mammalia, composed of more than 80 species of whales, dolphins and porpoises inhabiting a variety of marine and freshwater systems worldwide. The diversity of the cetacean taxon is a reflection of the physiological, ecological and behavioral adaptations necessary for a mammal to spend its life in an entirely aquatic environment while also being exposed to extreme habitats. The cetacean's ability to exploit a wide range of environmental conditions, from freezing temperatures to extreme depths, is the result of multiple selective pressures operating on an evolutionary timescale. The extent that these selective pressures have impacted the evolution of social systems in cetaceans is not fully known; however, the importance of these systems to the survivorship of a species is well known (Connor 2000). As might be expected from the diversity of habitats being exploited, cetaceans exhibit a variety of different social patterns, ranging from the solitary nature of the humpback whale, Megaptera novaeangliae (Clapham 2000), to the stable matrilineal pods observed in the killer whale, Orcinus orca (Bigg et al. 1990).

From a taxonomic perspective, social system generalities within the order Cetacea can be grouped according to the two suborders: Mysticeti and Odontoceti. With some notable exceptions, the social organizations of the suborder Mysticeti (baleen whales) are characterized by largely solitary animals lacking both long-term associations between individuals and stable cohesive groups. The mysticetes are composed of many migratory species that form loose affiliations on breeding and feeding grounds normally 
lasting on the order of hours to days (Clapham 2000). The longest observed bond is the mother-calf association (Clapham et al. 1993), and calves are known to have little contact once they disperse from their mothers after weaning (Baker et al. 1987).

By contrast, the suborder Odontoceti (toothed whales) is characterized by group living and a variety of complex social relationships (Connor 2000). Examples of these social relationships include the fission-fusion societies found in several delphinid species including the bottlenose dolphin, Tursiops spp., in which individuals associate in small, dynamic groups that change in composition over a period of hours or days (Würsig \& Würsig 1977, Wells 1986, Connor et al. 2000). Strong long-term bonds may also exist within fission-fusion societies, such as stable male-male bonds documented in bottlenose dolphins from Sarasota Bay, Florida (Wells et al.1987, Wells 1991) and Shark Bay, Australia (Smolker et al. 1992).

In contrast to fission-fusion societies, several odontocete species form long-term associations within stable social groups. For example, the sperm whale, Physeter macrocephalus, forms stable matrilineal groups termed "family units" composed of adult females and their female offspring, with males dispersing from the natal group and roving singly between groups of females (Whitehead \& Weilgart 2000). Male sperm whales leave the natal group before reaching sexual maturity and often associate with other male cohorts in "bachelor schools" before moving into higher latitudes and adopting a more solitary existence (Best 1979, Whitehead et al. 1997).

In the most extreme example of group living, several populations of killer whales in the coastal eastern North Pacific exhibit yet another type of social organization, natal group philopatry, in which individuals are organized into multigenerational matrilineal 
pods with dispersal of neither male nor female offspring (Bigg et al. 1990). Such an organization is thought to be unique to killer whales among mammalian species (with the possible exception of pilot whales, Globicephala spp.), and is likely a result of selective pressures promoting a mutually beneficial group structure (Palmeirim \& Rodrigues 1995, Baird 2000, Connor 2000). Extensive research on these populations has revealed a hierarchical social structure composed of related matrilines with differing degrees of association (Bigg et al. 1990). The fundamental social assemblage, the intra-pod group, is a single (often multigenerational) matriline consisting of an adult female and her male and female offspring (Bigg et al. 1990) where individuals are generally thought not to separate from the group for more than a few hours (Baird 2000). Intra-pod groups range from two to nine individuals (mean=4) and one to four generations (mean=3) (Bigg et al. 1990, Baird 2000). Multiple intra-pod groups or matrilines traveling in close association for more than $95 \%$ of the time are termed sub-pods, and sub-pods (1-11matrilines, mean=2) associating more than $50 \%$ of the time are collectively termed a pod (1-3subpods, mean=2).

\section{Groups}

Defining a "group" in biologically meaningful terms is essential to studies of sociobiology and ecology; however, extreme species diversity hampers the development of any comprehensive definition. In a review of the definitions of "group" used in a range of studies, Krause \& Ruxton (2002) found little consensus among essential attributes beyond that of spatio-temporal proximity, a condition that allows for possible communication, interaction and exchange of information between individuals. Following this definition, groups can exist on broad spatial scales where individuals do not receive 
the benefits from being in close proximity to other individuals. Krause \& Ruxton (2002) therefore distinguished "social groups" as groups where social interaction was a key component in grouping behavior, as opposed to simple co-occurrence related to abundant resources or favorable habitat. Connor (2000) noted also that "only mutualistic group formation promotes the formation of social bonds." Similar distinctions were made by Norris \& Schilt (1988) referring to social and non-social aggregations as grouping behavior influenced by group attraction (social aggregations) versus "physical or biotic" factors (non-social aggregations). Whitehead (2008) also used spatio-temporal proximity as a defining characteristic of "groups" (with the added condition that the majority of interactions would take place therein), but distinguished between social and nonsocial groups by referring to social groups simply as "groups" and nonsocial groups as aggregations.

\section{Group living in cetaceans}

The evolution of group living in certain cetacean species has been the subject of intense study; the development of social bonds generally is thought to represent the relative cost-benefit balance specific to local ecological conditions (reviewed by Trillmich 2009). Defense against predation, increased rate of resource acquisition, and improved survivorship of young are all thought to be driving forces in the evolution of group formation and relative stability of groups through time (Krause \& Ruxton 2002). Norris \& Schilt (1988) reasoned that for organisms living in an environment where predators can attack from three dimensions, predation would be the most influential factor in promoting group formation (see also Connor (2000)). Living in groups is particularly beneficial in species in which predators have the size advantage, as is the 
case with many odontocetes and with mysticete calves. For larger cetaceans where the main predation risk is not to the adult but to the calf; mother-calf pairs may persist for the first year or two following parturition in mysticetes, presumably to increase survivorship of the calf (Clapham et al. 1993). Large odontocetes such as the sperm whale appear to have developed an evolutionary response to threats of predation on the calves and juveniles in the group by utilizing members of the group termed "babysitters" that remain at the surface with younger individuals not yet able to dive to depth while the mothers and other adults go on deep foraging dives (Whitehead 1996). Given the low reproductive rate found in sperm whales, Whitehead \& Weilgart (2000) suggested that cooperative defense against predators may be essential to calf survivorship and an evolutionary driving force in the formation of stable family units (Whitehead 1996).

While predator avoidance thus generally favors the formation of larger groups in smaller odontocetes (i.e., by using the "dilution effect" or "confusion effect" to reduce the probability that an individual is targeted or that the predator will be able to focus in on a particular group member (Krause \& Ruxton 2002, Trillmich 2009)), group size is much more variable with respect to foraging. For example, delphinids such as dusky dolphins (Lagenorhynchus obscurus) benefit from cooperatively herding fish into easily accessible areas (Würsig \& Würsig 1979) while mammal-eating killer whales off the west coast of the United States maintain intermediate group membership levels to ensure both the most efficient capture of prey and the least amount of intra-group competition (Baird \& Dill 1996). Dispersal of adult male sperm whales from the natal group to higher latitudes is primarily thought to decrease foraging competition, thus returning to warmer waters to breed may be energetically costly and result in decreased foraging 
success, and is not undertaken until males are roughly twice the age they were when they reached sexual maturity (Best 1979, Whitehead \& Weilgart 2000).

In contrast, while odontocetes benefit from group cooperation when pursuing high-speed prey such as schooling fish or other marine mammals, mysticetes generally exploit unpredictable and patchily distributed prey easily secured and consumed entirely by a single individual. The nature and abundance of prey as a predictor of group formation and group size is also evident in feeding aggregations seen in certain populations of mysticete humpback whales where individuals will converge to cooperatively hunt a school of fish before dispersing after the feeding event (Clapham 2000). Indeed, Clapham (2000) cited several studies that indicated coordinated behavior corresponded to schooling prey, such as herring, and was less common with slow-moving prey. Clapham et al. (1993) also noted that humpback whale group size was positively correlated with the prey school size.

As mentioned above, living in groups also has several disadvantages, such as increased resource competition, risk of inbreeding and increased risk of acquiring pathogens, such as morbillivirus, the most pathogenic virus seen in cetaceans (reviewed by Bellière et al. 2010). It would therefore not be surprising that groups would have a membership threshold above which the cost-benefit ratio shifts and associations become unstable (Krause \& Ruxton 2002, Trillmich 2009). The subject of inbreeding avoidance (thought to be maintained by sex-biased dispersal from the natal group (Greenwood 1980, Connor 2000)), is particularly relevant to fish-eating killer whales in the coastal eastern North Pacific, where neither sex disperses from the natal group. Baird (2000) and Connor (2000) noted that potential costs to remaining in the natal group such as 
decreased reproductive opportunities and increased competition for food were likely minimized due to wide-spread movements and low locomotion costs, facilitating frequent opportunities to interact with other pods. Baird (2000) also suggested that both males and females may benefit from increased inclusive fitness related to prey acquisition, group defense and care of related calves.

Residency, site fidelity, and habitat usage

Patterns of residency and site fidelity are often indicative of the ecology of a population; evidence of repeated sightings in the same area can be used to establish core ranges of individuals and reveal the importance of a particular habitat. While residency is generally defined based on the amount of time spent in a predefined area (Wells \& Scott 1990), parameters used to define residency in cetacean field studies vary widely and are often influenced by the local geography of the area and access to the study population. Easily accessible study areas such as coastal waters and embayments, which naturally lend themselves to more focused and intensive field studies, tend to adopt stricter requirements for residency than offshore or open-ocean studies. Möller et al. (2002) defined individual bottlenose dolphins in Jervis Bay and Port Stephens Bay, Australia as resident, transient or occasional visitor based on sighting frequency and presence across seasons; residents were defined as individuals sighted in $\geq 10 \%$ of surveys and in multiple seasons, occasional visitors were individuals seen in $<10 \%$ of surveys but in multiple seasons and transients were essentially occasional visitors seen in a single season. A study examining the degree of residency for botos (also known as Amazon river dolphins, Inia geoffrensis) in the Mamirauá Lake system considered individuals seen in $\geq$ seven months/year and in $\geq 1$-3years as resident to the area, with 
permanent residents seen in all years of the study and partial residents seen in less than three years; individuals that did not meet the residency criteria were termed nonresidents (Martin \& da Silva 2004). Seasonal residency has been described for several large migratory whale species (e.g., Herman \& Antinoja 1977) but operational definitions of residency for presumably non-migratory open-ocean delphinids are somewhat lacking.

Residency, as defined in open-ocean systems, is more tenuous, as protected areas offering predictable and highly concentrated prey generally thought to support resident communities are likely not available (see Baird et al. 2008a); instead, studies of openocean species often rely on site fidelity, the tendency for individuals to return to or remain in the same area over time (Baird et al. 2008a). Given the relative size of areas typically surveyed during open-ocean studies (e.g., $5,000 \mathrm{~km}^{2}$ off the island of Hawai ${ }^{i} \mathrm{i}$ in McSweeney et al. (2007) versus $225 \mathrm{~km}^{2}$ in the Mamirauá Lake system in Martin \& da Silva (2004)), encounter rates would be expected to be lower in the open-ocean system based on the expanse of area being covered. Thus, residency requirements should be adjusted accordingly.

A high degree of site fidelity was found for Risso's dolphins (Grampus griseus) off the southern coast of Picos Island, Azores, using photo-identification (Hartman et al. 2008, 2009); residency to the study area (estimated from Figure 1 in Hartman et al. (2009) to be $\sim 280 \mathrm{~km}^{2}$ ) was measured using seasonal presence in the area (see below). While Risso's dolphins typically inhabit deep, offshore waters, the bathymetry off Picos Island (similar to that off the island of Hawai' $i$ ) is characterized by steep submarine canyons, affording the opportunity to encounter deep-water species in close proximity to the shoreline (Hartman et al. 2008). As survey effort varied seasonally, residency 
classification for Risso's dolphins was determined by seasonal and yearly presence over 11 seasons from May 2004 to January 2007 (Hartman et al. 2009). Over the course of the study, residents were defined as individuals sighted in $\geq 3$ years and 4-11 seasons, partial residents were those sighted in 2 years and $>1-3$ seasons and non-residents were sighted in a single year and season (Hartman et al. 2009). Such variation in residency criteria between near-shore species (e.g., Möller et al. 2002) and open-ocean delphinids (Hartman et al. 2008, 2009) preclude direct comparisons between populations.

\section{Photo-identification}

The utilization of photo-identification in behavioral and population studies has become integral to the field of cetacean research (Hammond et al.1990). Reliable and repeated identification of individuals can provide pivotal information on movement patterns, group stability and association patterns over time (Würsig \& Würsig 1977). The extensive life histories of killer whales in the coastal eastern North Pacific, for example, were gathered primarily with the aid of photo-identification techniques (Olesiuk et al.

1990). Although the natural markings used to identify individuals varies among cetacean species, the method is common to the order Cetacea and has become one of the most important tools cetacean biologists have in conducting longitudinal studies (Wells 1991). Long-term studies on individuals or populations are essential for species with long life spans (such as cetaceans) if life history and other temporal data are to be obtained (Mann 2000). Photo-identification also provides the opportunity to integrate behavioral studies in the field, such as focal and group follows, with individual life histories, a prospect that was unavailable prior to its implementation (Wells 1991). Finally, behavioral data can greatly assist with assessing anthropogenic impacts, either through direct observation or 
indirectly through analysis of temporal changes in movement or behavioral pattern (Hammond et al. 1990).

\section{Pilot whales}

\section{The Globicephalinae}

The pilot whales, genus Globicephala, belong to the most speciose family within the suborder Odontoceti, the Delphinidae. Two similar species comprise the Globicephala: the short-finned pilot whale, Globicephala macrorhynchus (Gray 1846) and the long-finned pilot whale, Globicephala melas (Traill 1809), the latter of which has three recognized subspecies based on geographic distribution (Bernard \& Reilly 1999). However, based on shared haplotypes, Oremus (2008) has suggested long-finned pilot whale sub-species should be revised.

The differences that exist between the two Globicephala species are subtle to the extent that they cannot, with high reliability, be distinguished at sea. Pilot whales are medium-sized odontocetes, with maximum recorded lengths of long-finned pilot whales being $6.3 \mathrm{~m}$ in males and $4.7 \mathrm{~m}$ in females, and $7.3 \mathrm{~m}$ in males and $5.1 \mathrm{~m}$ in females for short-finned pilot whales (Reeves et al. 2002). As the common names suggest, evaluation of the flipper length is often necessary for species identification, as is examination of the number of paired-teeth (Reeves et al. 2002). However, even external morphological identification can prove subjective due to overlapping characteristics; analysis of cranial morphology or genetic testing may be required for a definitive identification. Fortunately, as close visual examination is not always feasible in the field, geographical distribution is considered to be a reliable indicator of species when the two do not overlap (Reeves et al. 2002). 
Short-finned pilot whales have a pantropical and warm temperate distribution with a southern boundary limit around $25^{\circ} \mathrm{S}$ and northern limits around New Jersey and the central Bay of Biscay in the Atlantic Ocean and Hokkaido (Japan) and Vancouver Island (Canada) in the Pacific Ocean (Reeves et al. 2002). The distribution of longfinned pilot whales is largely complementary to that of short-finned pilot whales; longfinned pilot whales are found in cool temperate to subpolar waters with a circumpolar distribution in the Southern Hemisphere and a range in the North Atlantic Ocean between $45^{\circ}$ and $50^{\circ} \mathrm{N}$, including the Bay of Biscay and the Mediterranean Sea. It is at the southern edge of the North Atlantic distribution of long-finned pilot whales and the northern edge for that of short-finned pilot whales that species overlap occurs, and identification becomes difficult in the northern hemisphere (see Figure 1).

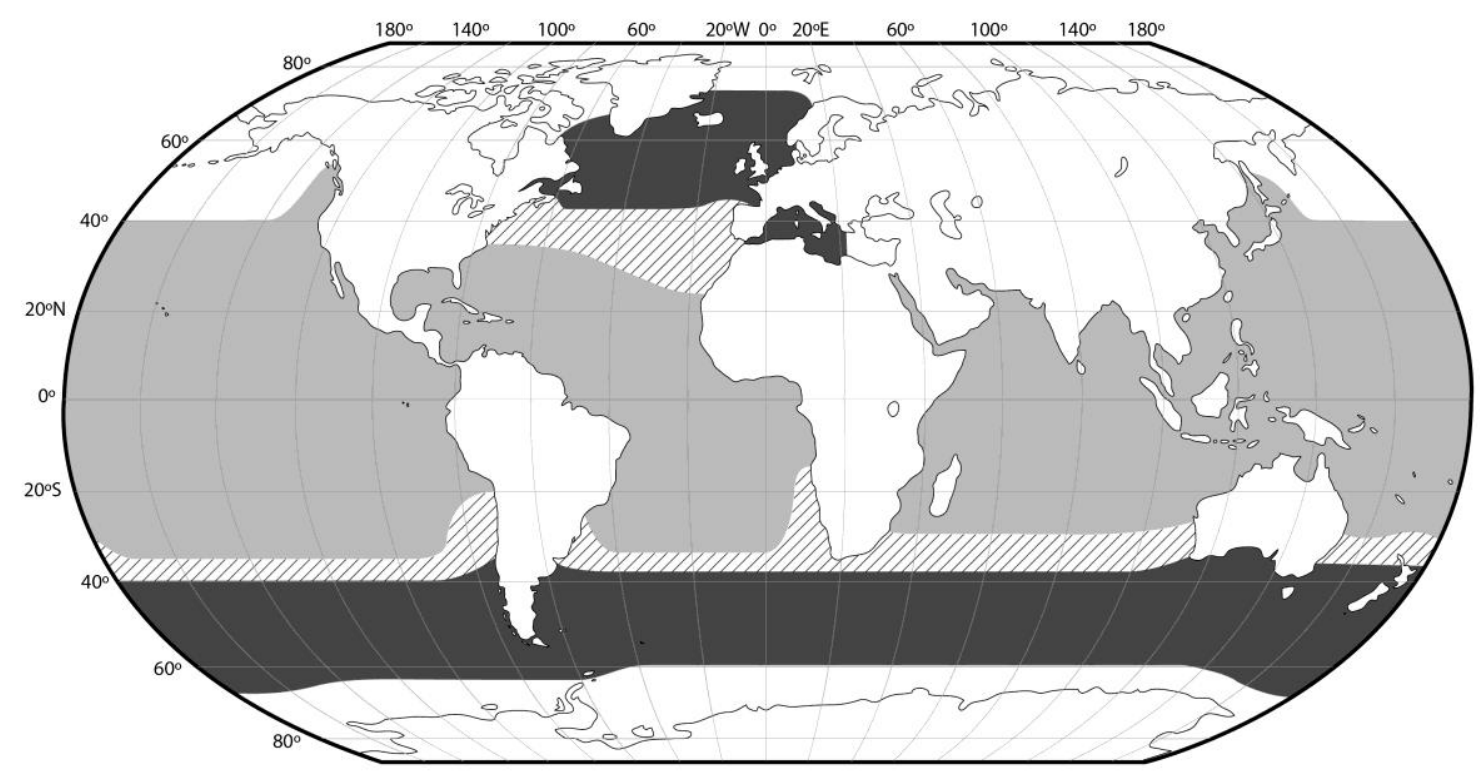

Figure 1. Geographic distribution of long-finned and short-finned pilot whales. Dark gray areas indicate the range of the long-finned pilot whale, light gray areas indicate the range of the short-finned pilot whale and hatched areas indicate overlapping range. Illustration by Uko Gorter. 


\section{Residency and site fidelity in pilot whales}

Pilot whales have a reputation for being abundant throughout their range (Olson 2009); short-finned pilot whale abundance was most recently estimated at 160,200 $(\mathrm{CV}=0.14)$ for the Eastern Tropical Pacific (Wade \& Gerrodette 1993) and 8,846 $(\mathrm{CV}=0.49)$ for the entire Exclusive Economic Zone (EEZ) surrounding the main Hawaiian Islands (Barlow 2006). Barlow (2006) also reported that short-finned pilot whales were the most commonly sighted species during a shipboard survey of the Hawaiian Islands EEZ and were estimated to be among the most abundant delphinid species in these waters. Short-finned pilot whales were also consistently among the most frequently sighted delphinids in small-vessel surveys conducted off the island of Hawai' $i$ (Baird et al. 2008c, Baird, unpublished) but were less frequently seen in similar surveys off Kaua'i and Ni'ihau (Baird et al. 2006). However, survey effort off Kaua'i and

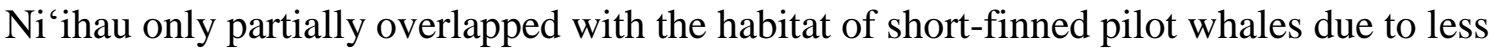
favorable sea conditions ( $47 \%$ of effort was confined to $<500 \mathrm{~m}$ depth); thus, the shallow waters surveyed are likely responsible for the depressed sighting rate. Long-finned pilot whales were reportedly one of the most frequently encountered species of cetacean in the Strait of Gibraltar (Roussel 1999).

Few resident populations of pilot whales have been documented. Using photoidentification, a year-round resident population of $\sim 372$ short-finned pilot whales has been described off the island of Tenerife (Heimlich-Boran 1993), and a population of 216 long-finned pilot whales in the Strait of Gibraltar has been described as "seasonally resident" by Verborgh et al. (2009) and "resident year round" by de Stephanis et al. (2008a, b). Seasonal site fidelity was documented in short-finned pilot whales both off 
the island of Hawai'i and off Santa Catalina Island, California (Shane \& McSweeney 1990). On-going research off California was unexpectedly limited by a severe El Niño (ENSO) event that resulted in a substantial decrease of short-finned pilot whale sightings, likely due to a decrease in abundance of market squid (Loligo opalescens), their primary prey (Shane \& McSweeney 1990). Based on the low re-sighting frequency of individuals off northern Nova Scotia, Ottensmeyer \& Whitehead (2003) reported that long-finned pilot whales were not resident to the area.

\section{Depth distribution and movements in relation to prey}

Pilot whales generally are known to consume 19 species of neritic and oceanic cephalopod species (reviewed in Clarke 1996). Seasonal inshore-offshore movements of long-finned pilot whales have been closely tied to that of their primary prey, squid; whales off Newfoundland were documented moving into bays just ahead of the arrival of shortfin squid (Illex illecebrosus) and leaving just before the exodus of squid from the area (Abend \& Smith 1999). Further, long-finned pilot whales are absent off Newfoundland in the winter season when squid are not present and have been documented in reduced numbers or absent in years when squid abundance is reduced (reviewed in Abend \& Smith 1999). The seasonal presence of long-finned pilot whales in eastern Canadian waters illustrates the influence prey abundance has on predator movement patterns and suggests that primary prey in areas where resident populations have been documented could be both abundant and stable. Long-finned pilot whales have been similarly recorded favoring depths occupied by pelagic cephalopods in the Alboran Sea (Cañadas \& Sagarminaga 2000) and demonstrated seasonal preference for deep water with steep bathymetry in the Strait of Gibraltar during summer months 
followed by a more even distribution in fall and winter months (de Stephanis et al. 2008a, b).

Defining groups - comparisons to other studies

In previous photo-identification studies of free-ranging pilot whales, researchers have defined encounters in a variety of ways; a study of long-finned pilot whales in St. Lawrence Bay, Nova Scotia required that groups be separated by a $200 \mathrm{~m}$ boundary (Ottensmeyer \& Whitehead 2003), while a study on the same species in the Mediterranean used a 1,000m chain-rule where individuals separated by a distance less than 1,000 m were considered members of the same group (Cañadas \& Sagarminaga 2000). Acknowledging that the $200 \mathrm{~m}$ delineation was somewhat arbitrary and potentially negatively-biased toward small or discrete groups, Ottensmeyer \& Whitehead (2003) noted that large groups were infrequently encountered and cited the advantage of being able to visually track all individuals within the boundary. The decision by Cañadas \& Sagarminaga (2000) to use a 1,000 m chain rule was based on observations in the field, similar to those in the present study, of cohesive as well as sparsely distributed individuals; however a more recent study on long-finned pilot whales in the Strait of Gibraltar by de Stephanis et al. (2008b) only considered whales separated by an interindividual length $\leq 5 \mathrm{~m}$ to be associated.

In a study of short-finned pilot whale social structure Heimlich-Boran (1993) initially considered all individuals within $250 \mathrm{~m}$ of one another to be part of the same group (leaving encounters with sparsely distributed individuals undefined); however, group designations were revised such that any groups containing the same individual were collapsed into a common sighting for the day. Preliminary photo-identification 
studies on short-finned pilot whales by Shane \& McSweeney (1990) and Miyashita et al. (1990) did not provide formal definitions for groups, though the mention of "cohesive pods" suggested individuals in close proximity were considered grouped. Such variation in group delineation reflects differing field conditions and makes cross-study comparisons difficult; however, useful inferences may still be drawn if common analyses are used.

Social structure

The pilot whale was one of the odontocete species most exploited by the whaling industry and long-finned pilot whales are still taken regularly in traditional drive fisheries in the Faroe Islands (Bloch et al. 1993). Considerable research has been conducted on long-finned pilot whales in the North Atlantic due to the wealth of specimens generated by the whaling practices (Amos et al. 1991, 1993a, b, Fullard et al. 2000). Results of genetic analysis (nuclear DNA 'fingerprints' and microsatellites obtained from sampling each individual killed within a group or "grind") have revealed a multigenerational group composition consisting of maternally related males and females that rarely if ever, interbreed (Amos et al. 1991, 1993a, b, Fullard et al. 2000). Based on the results, Amos et al. (1993) and Fullard et al. (2000) suggested that grinds represent persistent familial units similar to that of killer whales in the coastal eastern North Pacific (Bigg et al. 1990). Additional studies of groups taken in drive fisheries, such as those examining trace metals (Caurant et al. 1993, 1994), organochlorine concentrations (Aguilar et al. 1993), protein polymorphisms (Andersen 1988, 1993) and intestinal helminth communities (Balbuena \& Raga 1994) have also demonstrated inter-group differences consistent with longitudinally stable behavioral groups. However, the limitations of 
using a cross-sectional view of group composition to describe longitudinal aspects of pilot whale social structure have raised concerns (Ottensmeyer \& Whitehead 2003, Oremus 2008), and it has been suggested that the research could benefit from the addition of mitochondrial (mtDNA) analysis (Oremus 2008).

Oremus (2008) analyzed mtDNA and microsatellites from samples of long-finned pilot whales taken from mass stranding events around New Zealand to help address whether groups observed at sea represented longitudinally stable "extended matrilineal groups" as suggested by Amos et al. (1993) and Fullard et al. (2000), or whether they represented ephemeral associations between groups of smaller, stable matrilines as suggested by Ottensmeyer \& Whitehead (2003) (see discussion below). In contrast to the "extended matrilineal groups" reported in the Faroese drive fisheries studies, results of the mass stranding analysis indicated that stranded groups were composed of multiple unrelated matrilines, suggesting a complimentary study on the Faroese drive fishery would be beneficial to resolve this discrepancy. Results from the mass stranding analysis did reveal some similarities to the Faroese studies; sexually mature male and female offspring were identified within stranded groups and breeding within the group was determined to be rare (Oremus 2008). Evidence of long-finned pilot whale groups containing multiple unrelated matrilines where individuals demonstrate some degree of natal group philopatry prompted Oremus (2008) to suggest that long-finned pilot whales have a social structure distinct from sperm whales or the coastal eastern North Pacific population of killer whales.

Genetic analyses on short-finned pilot whales culled off the Japanese coast were conducted by Kasuya et al. (1988) and were found to contain two discrete forms: a 
"northern form" and a "southern form," also distinguished by phenotypic and morphologic differences in body size and pigmentation. Wada (1988) identified significant differences in gene frequencies between the two forms but further analysis indicated that the forms were genetically-isolated stocks operating at the inter-population level.

Limitations of genetic analysis have been complemented by photo-identification studies on long-finned pilot whales off Nova Scotia (Ottensmeyer \& Whitehead 2003) and in the Mediterranean (de Stephanis et al. 2008b), and on short-finned pilot whales in Hawai'i (Shane \& McSweeney 1990) and the Canary Islands (Heimlich-Boran 1993). Ottensmeyer \& Whitehead's (2003) study described the social structure of the longfinned pilot whales in St. Lawrence Bay, Nova Scotia (a study area of $85 \mathrm{~km}^{2}$ ) as a blend of short-term associates and constant companions; many of the associations observed in the field were determined to be ephemeral and would degrade over the period of a week, with a subset of individuals forming long-term associations. Social units of long-finned pilot whales consisting of "key individuals," and their "constant companions" were constructed following the method outlined in Christal et al. (1998), in which individuals seen on at least four occasions with each sighting separated by a minimum of 30 days were selected as key individuals and constant companions were those that had similar sighting histories (seen on the same day as the key individual on at least three occasions, separated by a minimum of 30 days). Of the 322 distinctive individuals documented during the study, less than half (41.0\%) were re-sighted more than once over the two-year period and the majority of those re-sightings (72.4\%) occurred in only one season. While the low re-sighting rate suggested the study population was not resident to the area, it 
could also suggest that the population was quite large and that sampling effort was insufficient to get good coverage of all individuals. The low re-sighting rate also made obtaining detailed information on social structure difficult; only 35 individuals were seen on more than four occasions and were included in many of the analyses. Preferential associations were found among the 35 individuals seen on more than four occasions and $92 \%$ were found in association with at least one other individual more than $50 \%$ of the time. Seven behavioral units were defined ranging from one to six distinctive individuals; an average unit size of eight stable companions was estimated after adjusting for the presence of less distinctive individuals.

Although Ottensmeyer \& Whitehead (2003) provided evidence for associations over a period of two years, the individuals represented a subset of those termed "shortterm associates," and existed in much smaller units than the extended matrilineal groups proposed in the Faroe Islands using genetic analysis (Amos et al. 1991, 1993b). The fact that the average unit size for stable associates in St. Lawrence Bay was less than half of the average group size encountered in the field supports the assertion that encountered groups are themselves ephemeral but contain smaller stable social units. However, the nature of photo-identification requires a longitudinal data set in order to make in-depth population inferences, and from Ottensmeyer \& Whitehead's (2003) conclusion it is reasonable to suggest their study would have benefited from a longer time frame.

Heimlich-Boran (1993) conducted a 22-month photo-identification study on short-finned pilot whales in the Canary Islands archipelago, off the island of Tenerife. Over the course of the study, Heimlich-Boran (1993) identified 495 individuals and delineated 46 "pods" using a distance coefficient to measure co-occurrence. Heimlich- 
Boran (1993) was able to distinguish differing patterns of occurrence among individuals which he termed residents and visitors. Visitors were classified as individuals seen on a single occasion and in the presence of individuals that had also not been documented previously; residents therefore referred to any individual that did not fit the criteria of visitor. Analyses were performed to ensure that those labeled visitors had a probability of being re-sighted equal to that of residents, and that the distinction between groups was not artificial or a result of sampling error.

Resident groups demonstrating preferential associations throughout the study period were termed "pods" and were composed of individuals of mixed age and sex (Heimlich-Boran 1993). Association preferences differed depending on individuals present in the area; within their own pods, females considered to be "mothers" based on calf presence most strongly associated with other "mothers" and associated the least with adult males; however, on occasions during which several pods were observed traveling together, "mothers" most strongly associated with adult males from neighboring pods (Heimlich-Boran 1993). The strongest associations observed both within pods and among neighboring pods were among adult males, suggesting that adult males form the most consistent associations. Heimlich-Boran (1993) used the data from this study to suggest that males remain in their natal pods while seeking mating opportunities outside of the natal group.

Finally, although several studies have employed the term "pods" in reference to pilot whales (e.g., Amos et al. 1991, Heimlich-Boran 1993), Oremus (2008) cautioned against its application. Originally coined by Bigg et al. (1990) to designate longitudinally stable groups of killer whales in the coastal eastern North Pacific, the term 
"pod" implies a specific type of social structure which has not been fully resolved in pilot whales. Ottensmeyer \& Whitehead (2003) have elected to call stable groups of longfinned pilot whales defined using shared sighting histories "units", and this study follows that nomenclature.

\section{The Hawaiian Islands}

The Hawaiian archipelago is situated in the central tropical Pacific Ocean and is one of the most isolated island chains in the world. It is composed of eight main islands and a variety of atolls, which are smaller uninhabited islands and reefs that are commonly referred to as the Northwestern Hawaiian Islands (Figure 2.1). The archipelago is a popular tourist destination and waterways around the main islands often are congested with commercial and private vessel traffic. Hawai ${ }^{i} i$ also is the site of annual naval warfare exercises and naval sonar testing. The waters around the main Hawaiian Islands are home to 24 documented cetacean species, including the short-finned pilot whale that has been documented off each of the main islands (Barlow 2006).

Cetaceans exist in a dynamic underwater environment that lacks the traditional physical barriers used in terrestrial systems to delineate populations; consequently, geopolitical boundaries often serve as proxies for defining populations (Baird et al. 2009). However, research on well-studied populations such as common bottlenose dolphins (Tursiops truncatus) and lesser-known species such as false killer whales (Pseudorca crassidens) has shown substantial differences in habitat usage, ecology and social structure, suggesting research from one population is not necessary indicative of another (Wells 1986, Baird et al. 2008b).

With the recent exceptions of false killer whales, spinner dolphins and common 
bottlenose dolphins, one stock is currently recognized for each species found within the Hawaiian EEZ, a management boundary that extends 200nm from shore and encircles the Hawaiian Islands (Carretta et al. 2011). However, photo-identification and genetic analyses of several species around the main Hawaiian Islands indicates current stock designations may not be appropriate (Baird et al. 2008a, b, 2009, McSweeney et al. 2009, Aschettino et al. 2011, Courbis 2011). A multi-island comparison of photo-identified common bottlenose dolphins showed fidelity to individual islands and no inter-island movements, suggesting the existence of multiple resident populations (Baird et al. 2009) and this was confirmed with genetic analyses (Martien et al. 2011). Photographic analysis of population structure in melon-headed whales (Peponocephala electra) provided evidence for two populations in Hawaiian waters that differ in ecology and habitat use: a small resident population off the island of Hawai'i occupying shallow waters, and a larger non-resident population found in deeper waters (Aschettino et al. 2011).

For management purposes, Stock Assessment Reports (SARs) prepared by the National Marine Fisheries Service (NMFS) have divided short-finned pilot whales into two stocks within the Pacific U.S. EEZ; those in Hawaiian waters and those off the west coast of the United States (Washington, California and Oregon) (Carretta et al. 2011). The Potential Biological Removal (PBR) is defined by NMFS as the maximum number of individuals that can be sustainably removed from a stock; this level was calculated at 52 individuals for the short-finned pilot whale stock in Hawai' $i$, which is less than the estimated mortality and serious injury rate of 0.7 individuals per year (Carretta et al. 2011). 
As mentioned earlier, the short-finned pilot whale is thought to exhibit natal group philopatry, a social system that could effectively divide the population into discrete groups. Short-finned pilot whales within the Hawaiian EEZ are currently are recognized as a single stock; however, the demonstration of population substructure could greatly influence future management decisions. Consequently, further research is needed on this population for both conservation risk assessment and to establish basic ecology needed to evaluate future threats. The focus of my research was therefore to examine association patterns, site fidelity and residency for short-finned pilot whales off the island of Hawai' $i$ that could be used to inform the population structure of this species within the main Hawaiian Islands. My results and conclusions are presented in Chapter 2 in manuscript form. 


\section{Chapter 2. High site fidelity, strong associations and long-term bonds: short-finned pilot whales off the island of Hawai'i}

\section{Introduction}

Social structure can influence the ecology, genetics and population biology of a species (Wilson 1975, Whitehead 2008b), thus understanding social organization in cetaceans has important implications for management and conservation. Bigg (1982) used associations of photo-identified individuals to define killer whale (Orcinus orca) populations in the coastal eastern North Pacific, and Wells (1986) used patterns of association among photo-identified common bottlenose dolphins (Tursiops truncatus) near Sarasota, Florida to describe a discrete inshore community within the larger Florida population (see also Duffield and Wells 1991, Sellas et al. 2005), suggesting social analyses can be used to define biologically meaningful population units. Similarly, association patterns and genetic analysis revealed two demographically isolated populations of false killer whales (Pseudorca crassidens) around the main Hawaiian Islands, resulting in the division of the Hawai'i stock into a pelagic stock and an insular stock, each with specific management considerations (Chivers et al. 2007, Baird et al. 2008b, Carretta et al. 2011).

Pilot whales (Globicephala spp.) are thought to exhibit natal group philopatry, a type of social structure documented in killer whales in the coastal eastern North Pacific (Bigg et al. 1990) and characterized by a lack of dispersal of male and female offspring from the natal group (Heimlich-Boran 1993). The extreme cohesiveness characteristic of this type of social structure has been suggested as a partial explanation for the frequency of pilot whale mass stranding events, which commonly involve groups of largely healthy 
individuals (Olson 2009). Indeed, these characteristic social bonds have been exploited by drive fisheries in the Faroe Islands as an efficient means of herding large groups or "grinds" of long-finned pilot whales (G. melas) to shore where they are killed (Bloch $e t$ al. 1993). As with killer whales in the coastal eastern North Pacific, genetic analysis of relatedness within grinds has suggested a multigenerational matrilineal group structure composed of both sexes, with little evidence of breeding occurring within the group (Amos et al. 1993a, Fullard et al. 2000); however, without knowledge of association patterns, limited inferences about long-term stability can be drawn.

No long-term photo-identification studies exist for short-finned pilot whales $(G$. macrorhynchus); however a 22-month study off the island of Tenerife identified a yearround resident population demonstrating persistent preferential associations (HeimlichBoran 1993). Similarly, studies of long-finned pilot whales in the Strait of Gibraltar (de Stephanis et al. 2008b) and off Cape Breton Island, Nova Scotia (Ottensmeyer \& Whitehead 2003) found subsets of the study population organized into stable, long-term groups demonstrating preferential associations, although dyads disassociating over a period of a few days were also identified in the Nova Scotia population. Differing ecology of the two study populations might account for slight differences in observed social structure; long-finned pilot whales in the Strait of Gibraltar represent a year-round resident population (de Stephanis et al. 2008a, b) while those studied off Nova Scotia are thought to be part of an offshore population with little residency (although some seasonal fidelity) to the area (Ottensmeyer \& Whitehead 2003).

The short-finned pilot whale has a ubiquitous presence around the main Hawaiian Islands; a 2002 ship line-transect survey listed pilot whales as one of the most 
abundant and frequently encountered cetaceans within the Exclusive Economic Zone (EEZ) (Barlow 2006), and this species is consistently the most commonly encountered cetacean during small boat surveys (Baird et al. 2006). However, despite year-round presence and relative accessibility from shore, little research has been published on this species in Hawai 'i. Preliminary studies suggest short-finned pilot whales in Hawai ‘i may be a genetically isolated island-associated population (Chivers et al. 2003) demonstrating a high degree of site fidelity and group cohesiveness (Shane \& McSweeney 1990, Baird et al. 2006); however, there is no knowledge of whether social or genetic isolation exists among islands or island regions within the archipelago. Research off the island of Hawai' $i$ has demonstrated the existence of small resident populations of several other typically deep-water odontocetes, including pygmy killer whales (Feresa attenuata), rough-toothed dolphins (Steno bredanensis), and two species of beaked whales (McSweeney et al. 2007, Baird et al. 2008a, McSweeney et al. 2009), suggesting that there may be features off the island of Hawai' $i$ that are ecologically important to deepwater odontocetes and potentially favorable for the development of resident populations.

In this study, I used repeated observations of photographically-identified individual short-finned pilot whales in Hawai' $i$ to describe association patterns among individuals, following the framework developed by Hinde (1976), in which individual interactions are used to describe the "nature, quality and patterning of relationships" among individuals within a population. Short-finned pilot whales were photographically documented from 2003 through 2007 in Hawai' $i$ as part of a long-term multi-species study on odontocete stock structure (e.g., Baird et al. 2008a, b). This study uses longterm photographic datasets from both directed research surveys and opportunistic 
encounters to assess levels of site fidelity, residency and association patterns of shortfinned pilot whales, focusing particularly off the island of Hawai'i. Only a single stock of this species is currently recognized in Hawai'i (Carretta et al. 2011); however, the demonstration of population substructure could greatly influence future management decisions. 


\section{Methods}

\section{Field methods}

\section{Study area}

Research was conducted in the main Hawaiian Islands from 2003 through 2007 as part of a long-term multi-species study of odontocete stock structure. The study area consisted of the main Hawaiian Islands, ranging from the island of Hawai' $i$ in the southeast to the islands of Kaua' $\mathrm{i}$ and $\mathrm{Ni}^{\text {' }}$ ihau in the northeast. The majority of the study was conducted in an area of approximately $2,500 \mathrm{~km}^{2}$ off the west side of the island of Hawai‘i from May 2003 to August 2007, with additional effort off Lana`i, O`ahu, Ni‘ihau and Kaua'i in 2003 and effort off Kaua'i in 2005 (Figure 2.1).

Effort

Research vessels used over the course of the study ranged in length from 5.8 to $18 \mathrm{~m}$; the majority of surveys were conducted using outboard-powered vessels from 6 to $8.2 \mathrm{~m}$ in length. Survey protocol remained consistent throughout the duration of the study and consisted mainly of surveys launched from port each morning; on select occasions larger vessels designed for offshore surveys extending to multiple days were used. Regardless of vessel used, survey effort was nonsystematic and nonrandom, and tracklines followed were intended to maximize the probability of encountering odontocetes without duplication of previous tracklines. Effort was made to cover as great an area and depth range as possible given constraints by sea conditions (effort primarily attempted to remain in conditions below Beaufort 4) and in the case of small vessel surveys, distance to shore. During surveys the vessel transited at speeds from 15 to 30 $\mathrm{km} / \mathrm{h}$ while two to six observers scanned 360 degrees around the survey vessel to look for 
cetaceans. Vessel location was recorded automatically every five minutes to a global positioning system (GPS) on board the vessel and waypoints were used to record any important events (such as sightings) during the survey period.

\section{Wild Whale Research Foundation: opportunistic effort and encounters}

Prior to and concurrent with the multi-species odontocete study mentioned above, the Wild Whale Research Foundation (WWRF) based in Holualoa, Hawai'i has been opportunistically collecting photo-identification data on odontocetes off the west coast of Hawai'i Island since 1986. Photographic data was collected in conjunction with whale watching trips on board the Lady Ann that generally operated in deeper water $(>500 \mathrm{~m})$ in the spring, summer and fall (end of March to end of December), and in shallower water $(<500 \mathrm{~m})$ in the winter months (January to the middle of March). Winter excursions focused on humpback whale groups while excursions from April to November focused on short-finned pilot whale groups. Photographic data taken from September 2004 to December 2007 was included in this study. Sighting data was recorded on a cassette recorder in the field and transcribed to hard copy once on land, and more recently to an Excel file. Once a group was sighted, the date and time of the encounter was recorded; location was recorded using a GPS when available, and details of the encounter including group size, and approximate age classes were also noted.

Additional opportunistic photographs contributed by independent researchers off the islands of Kaua' $\mathrm{i}$ and $\mathrm{O}^{`}$ ahu also were used in this study.

\section{Directed research encounters}

Once a short-finned pilot whale group was sighted, the research vessel would reduce speed in order to minimize disturbance. Encounters (used synonymously with 
"sightings" here) could be terminated due to inclement weather conditions, time of day, sighting of a higher-priority species or if all of the individuals within the group had been photographed.

This study employed the "gambit of the group" methodology, a spatio-temporal designation stating that individuals within the same group are assumed to be associated (Whitehead \& Dufault 1999); thus, the definition of "group" was of particular importance. Based on initial visual observations off the island of Hawai'i of widelydispersed individuals believed to belong to the same group, an encounter definition using an operational 1,000 m chain-rule (where individuals separated by 1,000 $\mathrm{m}$ or less were considered to be members of the same group) was employed. While likely a conservative measure of group membership that may contain additional outside individuals, the 1,000 m chain-rule was designed to capture sparse groups as accurately as possible and avoid artificially sub-dividing large groups. A chain-rule is frequently used in situations in which groups are not discrete or when group boundaries are somewhat ambiguous (e.g., Smolker et al. 1992). Although it was not known whether all individuals within sparse groups defined using the 1,000 $\mathrm{m}$ chain-rule were behaviorally interacting, behaviors appeared coordinated among members of groups and acoustic communication at that distance was likely possible (Weilgart \& Whitehead 1990).

\section{Photographic effort}

Attempts were made to equally photograph the right and left sides of all individuals present within an encounter, with the exception of tagged individuals, for which additional photos were taken for tag analysis purposes. All photographs were 
taken using SLR digital cameras with 200-400 mm lens; the number of photographers ranged from 1-4 for directed research, and there was one photographer for WWRF effort.

\section{Photo-identification}

Photo-identification protocol

Following the protocol of Baird et al. (2008a), all photographically-documented encounters were analyzed for incorporation into an existing short-finned pilot whale photo-identification catalog for the main Hawaiian Islands. Encounters were sorted visually by individual into folders using the unique pattern of nicks, notches and scars on the leading and the trailing edge of the dorsal fin. Sorted individuals were assigned a temporary identification number (ID) and compared against the existing photoidentification catalog to determine if the individuals had previously been documented. New individuals were assigned a new permanent sequential alphanumeric ID (e.g., HIGm\#\#\#\#) in the catalog and those that were re-sightings were incorporated under their existing permanent ID. All photographic sorting/matching was done visually using ACDSee 8.0 and 10 Photo Manager Software.

Photographic encounters were processed using previously established protocols by Baird et al. (2008a, b) and McSweeney et al. (2009). Photographic quality (PQ) of each individual in a given encounter was rated on a scale of 1-4 (1=poor, 2=fair, 3=good, 4=excellent) using several criteria such as the focal clarity, size of animal in the frame, image contrast, and angle of dorsal fin in frame. These qualitative criteria were equally weighted such that in order for a photograph to be considered "good" or "excellent" the image needed to be of good to excellent focal clarity, positioned squarely with respect to 
the photographer, etc. Similarly, the distinctiveness (Dist) of an individual from each encounter was also rated on a scale of 1-4 (1=not distinctive, $2=$ slightly distinctive, $3=$ distinctive, $4=$ very distinctive) using criteria based on the number, size and shape of nicks, notches and scars on the leading and the trailing edge of the dorsal fin. Individuals were evaluated on each of these criteria to determine an overall distinctiveness rating; however, in general, the number, size and pattern of notches increased with distinctiveness. It should be noted that photo quality and individual distinctiveness ratings were determined independently, and effort was made to minimize bias from images of highly distinctive animals artificially increasing photo quality ratings, and for images of individuals of lower distinctiveness artificially lowering photo quality.

Changes to the leading and trailing edge of the dorsal (such as the addition of new nicks or notches) were recorded for an individual each time they were observed and these mark changes were verified by another experienced matcher.

\section{Clean fins}

Individuals without identifying marks on their dorsal fins were not necessarily unidentifiable. Ephemeral scarring such as cookie cutter shark (Isistius spp.) bites and tooth-rake marks, as well as overall dorsal fin shape, were occasionally used to re-sight individuals between encounters on a short temporal scale. Juveniles, calves and neonates were also matched between encounters based on this secondary scarring and by close, constant association with a conspecific, usually thought to be the mother based on repeated observed associations. However, although not previously documented in pilot whales, alloparental care has been observed in sperm whales (Whitehead 1996) and killer whales (Haenel 1986) (two species with social structures believed to be similar to that of 
pilot whales), and thus cannot be discounted here. Clean individuals were eliminated from the majority of analyses but were necessary to determine the proportion of marked animals in a given encounter.

Age/Sex classification

Without the aid of genetic analysis, it was not possible to confirm the sexes of any of the individuals observed; however, inferences about the age and sex of certain individuals were made based on several factors. Pilot whales are sexually dimorphic, with adult males obtaining an asymptotic or maximum length of up to one meter greater than adult females. Although the ratio of dorsal fin height to width (at the base of the dorsal) is not considered to be diagnostic of an adult male for long-finned pilot whales (Seargent 1962), it is thought that the thickening of the leading edge is characteristic of adult males and can be distinguished in the field (Heimlich-Boran 1993). Thus, individuals exhibiting a substantial thickening of the dorsal fin were considered adult males. Neonates, considered less than two months of age, were characterized by clearly visible fetal folds and an uneven "lumpy" appearance to the skin; a dorsal fin that was not yet erect but folded as it would have been in the womb was indicative of neonates less than a day or two old. Young of the year were considered individuals that were less than half the length of an adult and that were in constant close association with the same larger individual, presumed to be the mother. Similarly, calves and juveniles were considered individuals that were less than $2 / 3$ and 3/4 the length of an adult, respectively; both were in consistent association with the same larger individual, again presumed to be the mother. Adult females were determined from individuals that were in close, consistent association with the same individual thought to be a calf because of small size. 
Individuals matching the length description for adult females but without younger individuals in close association were considered adults, and sub-adults were individuals slightly smaller than adults.

All analyses presented here are restricted to distinctive or very distinctive individuals with good or excellent-quality photos unless otherwise specified.

\section{Data analysis}

\section{Encounters}

In an effort to reduce the probability that an individual present during an encounter was not photographed, a coverage rating was assigned to each encounter. Using the protocol developed by Ottensmeyer \& Whitehead (2003), encounters were assigned a coverage index based on the ratio of the number of photos taken during an encounter to group size (see Table 2.1 for encounter coverage ratings). Restricting association analyses to encounters with a coverage index of two provides a more representative view of the individuals present within a group, and also allows for comparison between this study and other studies utilizing the same parameters (see Ottensmeyer \& Whitehead 2003, de Stephanis et al. 2008b). Encounters for which group size information was not available (e.g., certain WWRF and opportunistic encounters), the number of individuals identified was used as a proxy for group size in the calculation of coverage. In order to determine the appropriateness of using the number of individuals as a proxy for group size, the coverage values for each method were compared for encounters for which both values existed. Of 173 encounters, three encounters were given a coverage index of two using the proxy method when the actual coverage index 
was zero, and in 13 encounters the proxy coverage index was increased by one higher than the actual coverage index, suggesting the proxy was not sufficiently conservative. Based on this discrepancy, the coverage index of the encounters using the proxy value was scaled from $0-3$, with only those encounters with a coverage $=3$ included in the analysis. However, in order to minimize confusion surrounding two separate coverage indices, an overall coverage index $\geq 2$ was used in all analyses to encompass encounters for both directed research with coverage $\geq 2$ and opportunistic encounters with coverage $=3$.

Table 2.1. Coverage ratings for directed research and opportunistic encounters off the island of Hawai' $i$ from 2003 through 2007. Coverage ratings were assigned to provide a metric of how completely groups were sampled (Ottensmeyer \& Whitehead 2003).

\begin{tabular}{|c|l|l|}
\hline Coverage Index (0-3) & \multicolumn{1}{|c|}{ Description (directed research) } & \multicolumn{1}{|c|}{ Description (opportunistic) } \\
\hline 0 & \# Photos $<$ grp size & \# Photos $<$ \# indiv \\
\hline 1 & \# Photos $>$ 1x grp size $<2$ x grp size & \# Photos $>1 x$ \# indiv $<2 x$ \# indiv \\
\hline 2 & \# Photos $>2 x$ grp size & \# Photos $>2 x$ \# indiv $<3$ x \# indiv \\
\hline 3 & - & \# Photos $>3 x$ \# indiv \\
\hline
\end{tabular}

\section{Sampling period}

A sampling period is a temporal unit used to show how relationships change over time. How a sampling period is defined has a direct impact on association patterns between individuals and thus, the perceived social structure of the population. Unless otherwise specified, a sampling period of a day was used; all individuals documented during an encounter at least once during that day were assumed to be associated for the day. A sampling period of a day has been used in studies of association patterns in several odontocete species, including long-finned pilot whales (Ottensmeyer \& Whitehead 2003, de Stephanis et al. 2008b), killer whales (Ivkovich et al. 2009), spinner dolphins (Karczmarski et al. 2004) and common bottlenose dolphins (Lusseau et al. 
2003), and was chosen following Whitehead (2008b), who noted that a sampling period should be long enough to allow individuals sufficient opportunity to interact but not long enough to allow the majority of the study population to interact. Each encounter was assigned a "group code" for which group membership was defined as all individuals documented during an encounter. This approach, termed the "gambit of the group," assumes that individuals observed together are associating on some level rather than merely being concentrated in the same area, and is thus dependent on the definition of "group" to eliminate random co-occurrences (Whitehead \& Dufault 1999). Associations were defined using a symmetric 1:0 similarity matrix that simply states that if $\mathrm{A}$ is associated with B then B is associated with A (symmetric) and indicates whether the individuals are associated (1) or not (0).

Distinctiveness and rate of mark change

The proportion of the population that could be reliably identified between years using good or excellent-quality photographs was estimated within each encounter and averaged over all encounters as the ratio of distinct and very distinct individuals to all individuals regardless of distinctiveness (Equation 1). This method follows previous studies of several cetacean species off Hawai'i (see Baird et al. 2008a, b, McSweeney et al. 2009, Aschettino et al. 2011).

$$
\text { (\# Dist } \geq 3, \mathrm{PQ} \geq 3 \text { )/(\# Dist } \geq 1, \mathrm{PQ} \geq 3 \text { ) }
$$

Equation 1

This number is likely a conservative estimate of the true proportion of identifiable individuals since those classified as slightly distinctive (and even non-distinct) could often be identified between encounters, given good-quality photographs (see section on Clean fins). As only distinctive and very distinctive individuals with good or excellent- 
quality photos were used in all analyses (unless otherwise specified), Equation 1 also provides an estimate of the proportion of the population NOT included in the analysis, allowing results to be scaled accordingly (e.g., group size increased by the percentage considered non-distinctive).

The proportion of individuals that were re-sighted over the course of the study was calculated within each distinctiveness category (see section on Photo-identification protocol) by dividing the total number of individuals seen on more than one occasion by the total number of re-sightings. Similarly, the mean number of re-sightings per individual within each distinctiveness category was calculated by dividing the total number of re-sightings by the total number of individuals.

To determine the likelihood of misidentifying an individual due to a mark change, the rate at which mark changes occurred in the study population was calculated following previous studies of cetaceans off Hawai'i (Baird et al. 2008a, b, McSweeney et al. 2009, Aschettino et al. 2011). As several mark-change events could have occurred between sightings, the rate of mark change was calculated using both the minimum number of mark changes (i.e., the total number of occasions on which mark changes were documented) and maximum number of mark changes (i.e., the total number of individual mark changes documented). The rate of mark change was calculated by first summing the length of time between the first and last sighting of each individual across all individuals, and then dividing by the minimum and maximum number of mark changes. Rate of discovery of new individuals

A discovery curve is a visual representation of the proportion of the population that has been documented and provides a reference for the completeness of a data set. 
Discovery curves have been used in cetacean studies to inform residency (e.g., Karczmarski et al. 2004) and whether populations are open or closed to factors such as immigration, emigration, birth or mortality (Merriman et al. 2009). A discovery curve was plotted for the cumulative number of individuals versus the cumulative number of identifications made (maximum of one per day to prevent pseudoreplication); the discovery curve was constructed using all available encounters, regardless of coverage index; however, only sightings of distinctive individuals with good-quality photos were used.

\section{Residency to the study area}

Potential residency to the study area was examined using individual sighting histories and social network analysis. For the purposes of this study, individuals demonstrating a high degree of site fidelity to the study area were termed core residents and defined as those documented on at least five occasions in three or more years, while individuals that fell below this threshold (but that were seen more than once) were termed residents, and individuals seen on a single occasion were termed visitors. While the criteria used to designate residency is somewhat arbitrary, it is meant to separate individuals that exhibited multi-year site fidelity to the area (core residents) from individuals with multiple sightings over a short temporal scale (residents). Due to the conservative nature of the residency criteria, it is acknowledged that individuals assigned visitor status may also demonstrate some degree of site fidelity to the area; however, the size of the study area limited the inferences for residency that could be drawn because the potential for individuals to be present in a portion of the study area not being surveyed 
could alter the perception of habitat usage. Thus, the ability to detect fine-scale patterns of occurrence was beyond the scope of this study.

Social network analysis was used to visually examine association patterns among individuals; individuals that did not link to the main social network were potentially indicative of multiple populations. For an explanation of social network analysis, see section on Social network analysis.

\section{Lagged identification rate}

Given that the identification of the study population is dependent in part on presence in the study area, it is important to assess the potential for movement of individuals in relation to the area being surveyed. The lagged identification rate (LIR) is the probability that an individual documented in the study area at a given time will still be present $(\tau)$ time lags in the future (Whitehead 2001) and is given by Equation 2:

$$
\mathrm{R}(\tau)=\frac{\sum_{j, k \backslash\left(t_{k}-t_{j}\right)=\tau} m_{j k}}{\sum_{\mathrm{j}, \mathrm{k} \backslash\left(\mathrm{t}_{\mathrm{k}}-\mathrm{t}_{\mathrm{j}}\right)=\tau} n_{j} \cdot n_{k}}
$$

Following Whitehead (2001), “ $n_{i}$ is the number of individuals identified in sampling period $j$ and $m_{j k}$ is the number of individuals identified in both periods $j$ and $k$ ". Although both the Lagged Association Rate (see sections on Temporal aspects of social structure) and LIR are temporal analyses, the lagged identification rate is not a dyadic association measure and is simply the probability of an individual remaining in the study area divided by the size of the study population within the same area. LIR analysis affords the option to define the area(s) being considered in the analysis which can then be used to calculate rates within and/or among certain areas. Given the paucity of 
identifications from other islands, only identifications from the island of Hawai' $i$ were used in this analysis; all encounters were included regardless of coverage. The lagged identification rate was displayed graphically with time lag $(\tau)$ along the $\mathrm{x}$-axis.

To aid in the interpretation of lagged identification rates, models generated using SOCPROG 2.4 (Whitehead 2009) in MATLAB Student version 7.1 (MATLAB 2005) were fit to the data using maximum likelihood and binomial loss (Table 2.2); selection of the most appropriate model was determined as that with the lowest quasi Akaike Information Criterion (QAIC) value. Relative support for the different models was determined using the difference in QAIC values ( $\triangle$ QAIC) among that of the best-fit model and other models. Differences of 0-2 indicated strong support; 4-7 indicated some support; and differences greater than 10 indicated no support (Whitehead 2009).

Although the nature of the data violates the assumption of independence, selection of the QAIC over the Akaike Information Criterion (AIC) provides acceptable compensation (Whitehead 2007). Standard error was estimated using 1,000 bootstrap replications. 
Table 2.2. Exponential models available in SOCPROG 2.4 that can be fitted to the LIRs using maximum likelihood and binomial loss. Models describe movements of individuals in and out of one study area; model equations and possible interpretations were taken from the SOCPROG 2.4 manual (Whitehead 2009).

\begin{tabular}{|c|c|c|}
\hline Model & Model Equation & $\begin{array}{l}\text { Possible Model Interpretation } \\
\text { ( } N=\text { population in the study area) }\end{array}$ \\
\hline A & $\mathrm{R}=\mathrm{a}$ & $\begin{array}{l}\text { Closed population } \\
1 / a=N\end{array}$ \\
\hline B & $\mathrm{R}=1 / \mathrm{a}$ & $\begin{array}{l}\text { Closed population } \\
\mathrm{a}=\mathrm{N}\end{array}$ \\
\hline C & $R=b * e^{-a \tau}$ & $\begin{array}{l}\text { Emigration/mortality } \\
a=e m i g r a t i o n ~ r a t e \\
1 / b=N\end{array}$ \\
\hline $\mathrm{D}$ & $R=(1 / a)^{*} e^{(-\tau / b)}$ & $\begin{array}{l}\text { Emigration/mortality } \\
a=N \\
b=M e a n \text { residence time }\end{array}$ \\
\hline $\mathrm{E}$ & $R=b+c^{*} e^{(-a \tau)}$ & $\begin{array}{l}\text { Emigration + remigration } \\
a=\text { emigration rate } \\
b /(b+c)=\text { proportion of population } \\
\text { in the study area at a given time }\end{array}$ \\
\hline $\mathrm{F}$ & $\mathrm{R}=(1 / \mathrm{a})^{*}\left((1 / \mathrm{c})+(1 / \mathrm{b}) * \mathrm{e}^{(-(1 / \mathrm{c}+1 / \mathrm{b}) \tau)}\right) /(1 / \mathrm{c}+1 / \mathrm{b})$ & $\begin{array}{l}\text { Emigration + remigration } \\
a=N \\
b=\text { Mean time in the study area } \\
c=\text { Mean time out of study area }\end{array}$ \\
\hline G & $R=c^{*} e^{(-a \tau)}+d^{*} e^{(-b \tau)}$ & $\begin{array}{l}\text { Emigration + remigration }+ \\
\text { mortality }\end{array}$ \\
\hline $\mathrm{H}$ & $\mathrm{R}=\left(\mathrm{e}^{(-\mathrm{d} t / \mathrm{a})}\right) *\left((1 / \mathrm{c})+(1 / \mathrm{b}) * \mathrm{e}^{(-(1 / \mathrm{c}+1 / \mathrm{b}) \tau)}\right) /(1 / \mathrm{c}+1 / \mathrm{b})$ & $\begin{array}{l}\text { Emigration + remigration }+ \\
\text { mortality } \\
\mathrm{a}=\mathrm{N} \\
\mathrm{b}=\text { Mean time in the study area } \\
\mathrm{c}=\text { Mean time out of study area } \\
\mathrm{d}=\text { Mortality rate }\end{array}$ \\
\hline
\end{tabular}

\section{Dyadic associations}

As the name suggests, an association index is an estimation of the proportion of time (range 0.0-1.0) two individuals spend associated. Rather than simply measuring the number of co-occurrences among dyads, association indices provide a quantitative measure of the frequency of co-occurrence by also controlling for effort (Whitehead 2008b). Several association indices have been proposed to compensate for potential 
biases in the data collected; the most appropriate association index is one that equals or most closely matches the true association index (Cairns \& Schwager 1987, Whitehead 2008b). Assuming biases in the dataset do not exist, the most appropriate and least biased association index is the simple ratio index (SRI) of association (Cairns \& Schwager 1987), given by Equation 3.

$$
\mathrm{SRI}=\frac{\mathrm{x}}{\mathrm{x}+\mathrm{y}_{\mathrm{AB}}+\mathrm{y}_{\mathrm{A}}+\mathrm{y}_{\mathrm{B}}}
$$

Here, $\mathrm{x}$ is the number of sampling periods individuals in which A and B are observed in association; $\mathrm{y}_{\mathrm{AB}}$ is the number of sampling periods where $\mathrm{A}$ and $\mathrm{B}$ were identified but were not observed in association; $\mathrm{y}_{\mathrm{A}}$ is the number of sampling periods in which only A was identified; $\mathrm{y}_{\mathrm{B}}$ is the number of sampling periods in which only $\mathrm{B}$ was identified.

The simple ratio index of association (and therefore the ideal data set) assumes that all individuals within a sampling period are identified, are equally identifiable, and that individuals are identified irrespective of dyadic association (Ginsberg \& Young 1992, Whitehead 2008b). For situations in which not all assumptions are met (as with many field studies), the SRI will become biased and alternate association indices are preferable. The half-weight index (HWI) of association is suggested in situations in which not all individuals within a sampling period are identified or when individuals are more likely to be identified when they are not in association (Cairns \& Schwager 1987, Whitehead 2008b) and is given by Equation 4 .

$$
H W I=\frac{x}{x+y_{A B}+1 / 2\left(y_{A}+y_{B}\right)}
$$


Although Ginsberg \& Young (1992) recommend using the simple ratio index of association with the intention of discussing any potential biases, the nature of the current data set is inherently biased such that not all individuals were identified during many of the sampling periods. Thus, the HWI was selected as the most appropriate association index as it was less biased in this situation. Unless otherwise stated, only individuals seen off the island of Hawai' $i$ on more than 4 occasions were included in the analysis and the half-weight index of association was used. For ease of readership, association indices will be reported in the format $\mathrm{AI} \pm \mathrm{SD}$.

\section{Social differentiation and precision analysis}

As addressed by Whitehead (2008b), association indices are estimates of the proportion of time a pair of individuals spends associating and may not necessarily reflect true relationship patterns. A correlation coefficient $(r)$ between true association indices (amount of time actually spent associating) and estimated association indices was therefore used to determine how accurately matrices of association indices modeled social structure. A correlation coefficient of $r=0.8$ is considered strongly representative of social structure, while $r=0.4$ is considered somewhat representative (Whitehead 2008b). The correlation coefficient was estimated from Equation 5,

$$
r=\frac{\mathrm{S}}{\mathrm{CV}\left(\alpha_{\mathrm{AB}}\right)} \quad \text { Equation 5 }
$$

where (S) is the social differentiation of the system (Whitehead 2008a, b), representing the coefficient of variation $(\mathrm{CV})$ of the true association indices, and $\mathrm{CV}\left(\alpha_{\mathrm{AB}}\right)$ is the $\mathrm{CV}$ of the estimated association indices. Social differentiation is a measure used to indicate the relative homogeneity of association indices, with a value between 0-0.3 indicative of a 
somewhat homogenous society, greater than 0.5 indicative of a differentiated society and greater than 2.0 indicative of a strongly differentiated society (Whitehead 2008a, b). Both the correlation coefficient and social differentiation estimates were calculated using the half-weight index of association, the likelihood method with 100 bootstrap replicates and a resolution of integration $=0.001$.

Once the social differentiation of the system was calculated, the value was compared to Table 3.15 in Whitehead (2008b) in order to estimate the number of observations per dyad needed to form a somewhat accurate view of social structure (at $r=0.4$ ) and a highly accurate view (at $r=0.8$ ). While the nature of the study population violates the assumption that "effort is equally concentrated on all dyads," the equation may still provide a useful approximation of the amount of data required (Whitehead, pers. comm.).

\section{Preferential associations}

While an association index is an appropriate measure of the strength of a dyadic relationship, it does not indicate whether the observed relationship resulted from random associations or if the dyad actively discriminated among members of the study population. This is most appropriately addressed with a modification of Bejder et al.'s (1998) permutation test by Whitehead (1999, 2008a) and carried out using SOCPROG 2.4. Here, the null hypothesis states that members of the study population associate randomly among other available members and do not preferentially associate with or avoid other members of the same population. The permutation tests used here are a series of random, non-independent data sets created by permuting the data through a number of flips sufficient to stabilize the $p$-value. There are several options available for permuting 
data. 'Permuting groups within samples' uses a group by individual matrix to test the null that there are no preferred/avoided companions within a sampling period by taking into account the number of groups in which each individual was seen during the sampling period. This method tests for both short-term (within a sampling period) and long-term (between sampling periods) preferred/avoided companions by examining the SD and mean of association indices; a significantly high SD of the real association indices is indicative of preferred companions extending between sampling periods, and a significantly low mean of the real association indices is indicative of preferred companions within a sampling period (Whitehead 2008b, 2009). 'Permuting associations within samples' uses a symmetric association matrix to test the null of no preferred/avoided companions between sampling periods by taking into account the number of associations for a given individual within the sampling period. This method tests for long-term preferred/avoided associations by examining the SD of the association indices; a significantly high SD of the real association indices is indicative of preferred/avoided companionships extending between sampling periods (Whitehead 2009). Whitehead (2008b, 2009) has suggested that "permuting associations within samples' is the most useful of the different permutation methods due to fewer assumptions and the fact that, unlike 'permuting groups within samples,' it controls for gregariousness as well as factors affecting the presence of group members (birth, mortality, migration). However, it does not describe short-term companionships; therefore, both tests are included here. Differences in gregariousness were also tested; a significantly high SD of typical group sizes $(p>0.95)$ taken from 'permuting groups 
within samples' indicates that individuals consistently differ in the size of the groups in which they are encountered.

Preferred associations among dyads were determined by examining dyadic association indices relative to the mean association index of the study population; following Durrell et al. (2004) and Gero et al. (2005) "preferred associations" were those with an association index $\geq$ twice the mean association index of the study population and "acquaintances" were those that fell below this threshold.

\section{Detecting community structure}

In order to determine whether realistic divisions exist within the study population, the modularity (Newman 2004) of the population was measured using association indices. Modularity $(\mathrm{Q})$, defined as the difference between the proportion of the total association within clusters and the expected proportion, has a range from 0.0 (randomly formed clusters) to 1.0 (clusters with no shared associations). SOCPROG 2.4 implements two modified versions of Newman's (2004) test to calculate expected proportions, the first controlling for gregariousness by focusing on association preference (termed Modularity-G), and the second controlling for gregariousness and data structure by focusing solely on preferred/avoided associates (termed Modularity-P). Whitehead (2008b) noted that maximum modularity would likely be higher for Modularity-G since it has the advantage of incorporating past sighting history. Newman (2004) indicates that acceptable cluster division occurs at $\mathrm{Q} \geq 0.3$.

Several methods available for delineating clusters (including cluster analysis and social network analysis detailed below) were used in order to ensure the most accurate representation of the population structure (i.e., the method yielding the highest 
modularity). Temporal methods were also employed to determine whether clusters defined using the methods mentioned above were indeed representative of social units or were possible artifacts of individuals associating frequently over a short temporal scale (for temporal analysis see section on Delineating stable groups (units)). Analysis was restricted to individuals sighted on more than four occasions.

\section{Cluster analysis}

Despite being considered marginally useful when dealing with large, sparse populations (Whitehead 2008b), cluster analysis can be a useful way to classify and visually display relationships between individuals using association indices. A variety of methods exist that can be used to determine how individuals within the study population are clustered; results are often visually displayed using a tree-like shape characteristic of dendrograms. Here, clusters of individuals are formed that correspond to association strengths along an axis; the branchlets are representative of tightly-clustered individuals (with a corresponding high index of association) while larger branches are representative of clusters with a lower association index. Dendrograms are thus hierarchicallystructured where individuals that are clustered at low indices of association are less strongly associated than those at higher indices. As cautioned by Whitehead (2008b), a dendrogram can prove visually deceptive, purporting complex social structures when none in fact exist. The use of a cophenetic correlation coefficient (CCC) is therefore necessary to separate suspect dendrograms from those that are truly representative of complex social structure. A CCC indicates whether cluster analysis can be appropriately used to model social structure by measuring the correlation strength between the dyadic association values in the similarity matrix and their position within the dendrogram. 
Values for the CCC range from 0.0 (no correlation) to 1.0 (complete correlation) with CCC $\geq 0.8$ indicative of a well-represented population (Whitehead 2008b, 2009).

For the purposes of this study, an agglomerative hierarchical cluster analysis using average-weight linkage was chosen and implemented using SOCPROG 2.4. Hierarchical cluster analysis is most appropriate when working with a similarity matrix (e.g., association indices) as non-hierarchical cluster analyses rely on rectangular matrices to construct the dendrogram, and are thus not applicable. The formation of clusters can be either a divisive or agglomerative process; here the agglomerative method, which begins with each individual existing in its own cluster and establishes links with other individual(s) based on degree of association, was selected based on accuracy and relative computation time (Whitehead 2008b). Once clusters were constructed, associations were calculated using the average-linkage method which works directly on similarity matrices and is favored over other methods such as single-linkage or complete-linkage methods as it is less affected by sampling error and extreme values (Whitehead \& Dufault 1999). As suggested by the name, the average-linkage method averages all similarities between individuals and neighboring clusters rather than relying solely on the most similar (single-linkage) or least similar (complete linkage) individual.

Dendrograms can provide a useful visual display of how individuals within a study population are clustered; however, cluster analysis alone provides no further information about the relative social significance of a given cluster. It is thus important to define points along the dendrogram (sometimes referred to as "stopping points") that can be used to delineate sociologically meaningful clusters. Several different criteria have been used in previous studies of cetacean social structure to delineate groups. For 
studies of the fish-eating killer whale ecotype from coastal Pacific waters of northern Washington and southern British Columbia, a "50\% rule" was used in which individuals that spent at least $50 \%$ of their time associated were considered a "pod" (Bigg et al. 1990), whereas a study of sperm whales considered any individual with an association index more than twice that of the average across the study population to be grouped (Gero et al. 2005). Following the advice of Whitehead (2008b) and Lusseau (2007), modularity was used to determine where (if at all) meaningful clusters exist along the dendrogram. Using a modification to Newman's (2006) test for modularity, Lusseau (2007) designed a method to maximize modularity through a series of tests along the dendrogram, with maximum modularity providing a corresponding association index (i.e., stopping point). Clusters formed above this stopping point represented meaningful social divisions within the study population. To examine whether substructure existed within clusters, the presence of meaningful sub-clusters was investigated for each cluster using community division.

\section{Social network analysis}

In contrast to dendrograms which are visually hindered by large study populations, social networks have the ability to visually present the same population in a more clear and accessible manner. In simple terms, social networks graphically depict a social system using nodes (or vertices) to represent individuals within the study population and edges (or ties) to link associated individuals. Social network analysis thus adopts a comprehensive approach to the study of social structure by combining graphical network displays with quantitative analysis. 
Originally developed from mathematical graph theory and used to model human relationships, social network analysis has recently been applied to the study of nonhuman vertebrate societies (Croft et al. 2004). As such, analyses applicable to similarity matrices are still being developed; the introduction of weighted networks, which indicate association strengths between dyads as opposed to a 1:0 binary network designation of present: absent, are particularly useful.

As opposed to the agglomerative method utilized in hierarchical cluster analysis to assign individuals to clusters, social network analysis creates clusters using a divisive method. Here, all individuals within the study population are initially contained within one large cluster which is further divided until a desired stopping point (such as maximum modularity), is reached. Following a method for maximizing modularity in weighted networks developed by Newman (2006) and implemented in SOCPROG 2.4, the study population was divided based on the dominant eigenvector of the modularity matrix such that cluster division was stopped when modularity was maximized. Whitehead (2008b) has suggested that of the two methods used to divide the study population into clusters, the eigenvector-based method utilized in social network analysis is preferable, yielding the highest modularity for both modularity-G and modularity-P in tested data sets.

In order to determine if associations within clusters were significantly different than associations among clusters a Mantel test was carried out for clusters formed using both hierarchical cluster analysis and social network analysis. As the data are not independent, a Mantel test with 1,000 permutations was also conducted; a resulting large 
$p$-value, positive t-value and positive matrix correlation indicate associations are significantly higher within clusters than among them.

\section{Temporal aspects of social structure}

Referring back to Hinde's (1976) framework, an important aspect of social structure is the temporal patterning of relationships. As this might suggest, the identification of dyadic associations in the absence of a temporal context offers little insight into the longitudinal nature of these relationships. In order to examine dyadic associations against a temporal scale, Whitehead (1995) introduced a series of analyses to describe how relationships change with time. Centered on dyadic relationships and generalized to the societal level, the lagged association rate (LAR) is the probability that two individuals associated at a given time will still be associated $(\tau)$ time lags in the future, and is given by Equation 6:

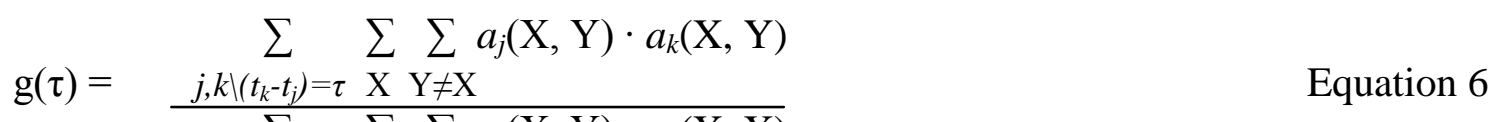

For sampling period $j, a_{j}(\mathrm{X}, \mathrm{Y})=1$ if $\mathrm{X}$ and $\mathrm{Y}$ were observed in association and $a_{j}(\mathrm{X}, \mathrm{Y})=0$ if $\mathrm{X}$ and $\mathrm{Y}$ were not observed in association (or if either individual was not recorded). Similarly, for sampling period $k, a_{k}(\mathrm{X}, \mathrm{X})=1$ if $\mathrm{X}$ was observed and $a_{k}(\mathrm{X}, \mathrm{X})$ $=0$ if $\mathrm{X}$ was not observed. The lagged association rate is an estimate that uses individual identification histories to calculate the ratio of the number of observed dyadic associations occurring at different time lags to all potential associations. In situations in which it is unclear whether all individuals within each sampling period were accurately identified, Whitehead (1995) suggests using the standardized lagged association rate 
(SLAR) in place of the LAR; the SLAR estimates the probability that if two individuals $(\mathrm{X}, \mathrm{Y})$ are associated, then following some chosen time lag $(\tau)$, a randomly chosen associate of $\mathrm{X}$ will be $\mathrm{Y}$. The standardized lagged association rate is given by Equation 7

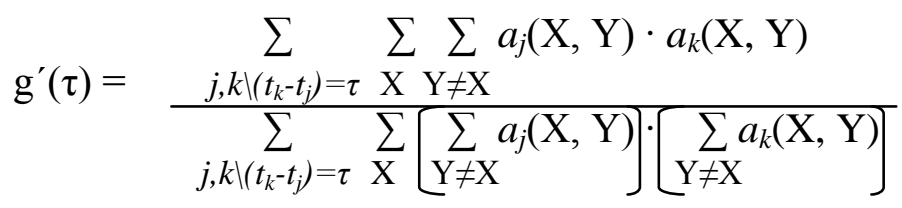

Lagged association rates are displayed graphically with time lag $(\tau)$ along the $\mathrm{x}-$ axis and are plotted using a moving average that can be adjusted by changing the range of time over which $\mathrm{g}(\tau)$ is calculated (and thus the number of potential associations considered) to eliminate random noise and create a smoother graph. However, care must be taken to find an appropriate moving average that does not compromise the data, as $\tau$ will become less precise as the lagged association rate curve becomes smoother.

As with other methods outlined thus far to describe the social structure of the study population, inclusion of a null model provides an important basis for comparison. Here, the null association rate represents the lagged association rate in the absence of association preference and is calculated for each sampling period using the ratio of the average number of associates of an individual to the number individuals documented (minus that individual). The standardized null association rate is not calculated for each sampling period and is simply the inverse of the number of individuals documented (i.e., population size) minus that individual.

SOCPROG 2.4 provides four models that can be used to describe SLARs; models accompanied by brief explanations offered in the program are shown in Table 2.3. All 
SLAR models were fit to the curve using maximum likelihood and binomial loss; the model with the best-fit was determined as that with the lowest QAIC value.

Table 2.3. Exponential models available in SOCPROG 2.4 that can be fitted to the LARs and SLARs using maximum likelihood and binomial loss. Models allow for quantitative analysis of the lagged association rate(s); possible interpretations are also given.

\begin{tabular}{|l|l|l|}
\hline Model Description & Model Equation & Possible Model Interpretation \\
\hline $\begin{array}{l}\text { Constant Companions } \\
(C C)\end{array}$ & $\mathrm{g}^{\prime}=\mathrm{a}$ & $\begin{array}{l}\text { Permanent associations, possibly indicative } \\
\text { of closed, non-interacting units }\end{array}$ \\
\hline $\begin{array}{l}\text { Casual Acquaintances } \\
(C A)\end{array}$ & $\mathrm{g}^{\prime}=\mathrm{a}^{*} \mathrm{e}^{-\mathrm{b} \tau}$ & $\begin{array}{l}\text { Association followed by disassociation and } \\
\text { possible later re-association }\end{array}$ \\
\hline CA $+\mathrm{CC}$ & $\mathrm{g}^{\prime}=\mathrm{a}+\mathrm{c}^{*} \mathrm{e}^{-\mathrm{b} \tau}$ & $\begin{array}{l}\text { Association followed by disassociation at } \\
\text { some time lag to a lower level of association } \\
\text { where associations stabilize }\end{array}$ \\
\hline Two Levels of CA's & $\mathrm{g}^{\prime}=\mathrm{a}^{*} \mathrm{e}^{-\mathrm{b} \tau}+\mathrm{c}^{*} \mathrm{e}^{-\mathrm{d \tau}}$ & $\begin{array}{l}\text { Association and disassociation occurring on } \\
\text { two different time scales }\end{array}$ \\
\hline
\end{tabular}

As neither confidence intervals nor nonparametric bootstraps are practical measures of precision for LARs or SLARs, Whitehead (2007) recommends temporal jackknifing, an approximate measure of precision in which one or more sampling periods are eliminated during repeated runs of the analysis (Efron \& Stein 1981). Jackknifing is considered an acceptable measure of precision by Whitehead $(1995,2007)$ in spite of the fact that estimates are conservative and the assumption of independence might not be met. Jackknife estimates are indicated by error bars on the graph.

Only individuals documented off the island of Hawai' $i$ were included in this analysis; however, sighting histories were not restricted as the lagged association rate is meant to describe the entire population, not just those most frequently encountered. Given the possibility of missed associations within the study population, the standardized lagged association rate was used in all analyses. 


\section{Delineating stable groups (units)}

In order to begin to detect the presence of long-term social bonds between individuals, a robust sighting history is needed; therefore, individuals most commonly observed in the study area (i.e., core residents) were used in the analysis of group structure. Following the original framework of Christal et al. (1998) and modifications of Ottensmeyer \& Whitehead (2003) and de Stephanis et al. (2008), "units” of pilot whales were defined as key individuals and their constant companions. Criteria for the selection of key individuals were designed to capture those with longitudinal sighting histories in the study area and was defined as individuals sighted in at least four different years and on eight different occasions (with sightings between years separated by a minimum of 180 days). Specifying a span of 180 days for sightings between years ensured that calendar years did not artificially inflate sighting records (e.g., an individual seen in December of one year and January of the next is technically seen in two different years though it provides little temporal information) and allowed for comparison with the study of long-finned pilot whale social structure in the Strait of Gibraltar (de Stephanis et al. 2008b). Although specifying a span of 180 days between sightings was somewhat arbitrary, when applied it did not remove any potential key individuals from the analysis. Using the above criteria, it was possible for key individuals with overlapping sighting histories to belong to the same unit; in such instances, association indices were also examined to determine whether allocation to the same unit was truly representative of longitudinal association preferences or if it was simply an artifact of extensive sighting histories. Thus, a minimum dyadic association index of 0.50 was required in order for key individuals to be placed in the same unit; in situations in which the association index 
was below 0.50 for one or more dyads, a key individual was only allowed to remain in the unit if the majority $(>50 \%)$ of dyadic associations were above the 0.50 criterion. Similarly, key individuals that did not meet the minimum criteria for inclusion in a given unit but that did have multiple dyadic associations above 0.50 with other key individuals were also considered on an individual basis. Selection of a minimum association index of 0.50 , while somewhat arbitrary, mirrors an established criterion for designating "pods" of killer whales in coastal North Pacific waters (Bigg et al. 1990) and allows for limited comparison between killer whale populations and the study population.

Constant companions were defined as individuals sighted with key individuals in at least three different years and five different occasions (with sightings between years separated by a minimum of 180 days). As with key individuals, multiple constant companions could be assigned the same unit providing that the majority $(>50 \%)$ of dyadic associations were above the 0.50 criterion for both key individuals and other constant companions. Given the sighting criteria mentioned above, it was also possible to assign constant companions to more than one unit; in such situations association indices were examined to determine the most appropriate unit for allocation.

Once units were established using the outlined criteria, each was examined quantitatively and qualitatively to ensure unit membership was an accurate depiction of social structure; any discrepancies and subsequent changes are addressed in the results section. 


\section{Results}

\section{Effort and sightings}

A total of $30,470 \mathrm{~km}$ of trackline (265 days on the water, 1,899 $\mathrm{h}$ of survey effort) were covered during the study period, over which time short-finned pilot whales were encountered an average of once every $105 \mathrm{~km}$ or every 6.5 hours of effort (Figure 2.1). Short-finned pilot whales were the most frequently encountered species of odontocete during the study period, representing $23 \%$ of all directed research sightings. A total of 298 short-finned pilot whale encounters were photographed off the main Hawaiian Islands between 2003 and 2007, and a total of 50,480 photographs were analyzed for the current study. Effort varied significantly among islands with the majority of both effort and sightings from which photos were available occurring off the leeward side of the island of Hawai'i $(267,90 \%) ; 123$ from directed research efforts and 144 from WWRF efforts. Twelve directed research encounters were available from a 2003 survey off Lana' $\mathrm{i}, \mathrm{O}^{`}$ ahu, Kaua' $\mathrm{i}$ and $\mathrm{Ni}^{\text {‘ }}$ ihau and an additional five encounters were available from a 2005 survey off Kaua'i. Ten opportunistic encounters from O`ahu (spanning 2004$2007)$ and four opportunistic encounters from Kaua'i $(2005,2007)$ were also analyzed.

Over the course of the study, short-finned pilot whales were encountered off the main Hawaiian Islands in every month of the year, and off the island of Hawai' $i$ in every month of the year expect June, when there was no research effort off the island. Effort from 2008 has since confirmed the presence of short-finned pilot whales off Hawai' $i$ during the month of June. Although research effort varied seasonally and between years, short-finned pilot whales were encountered during every month of directed research, with the exception of October of 2004 when the only sighting during that time period was by 


\section{WWRF.}

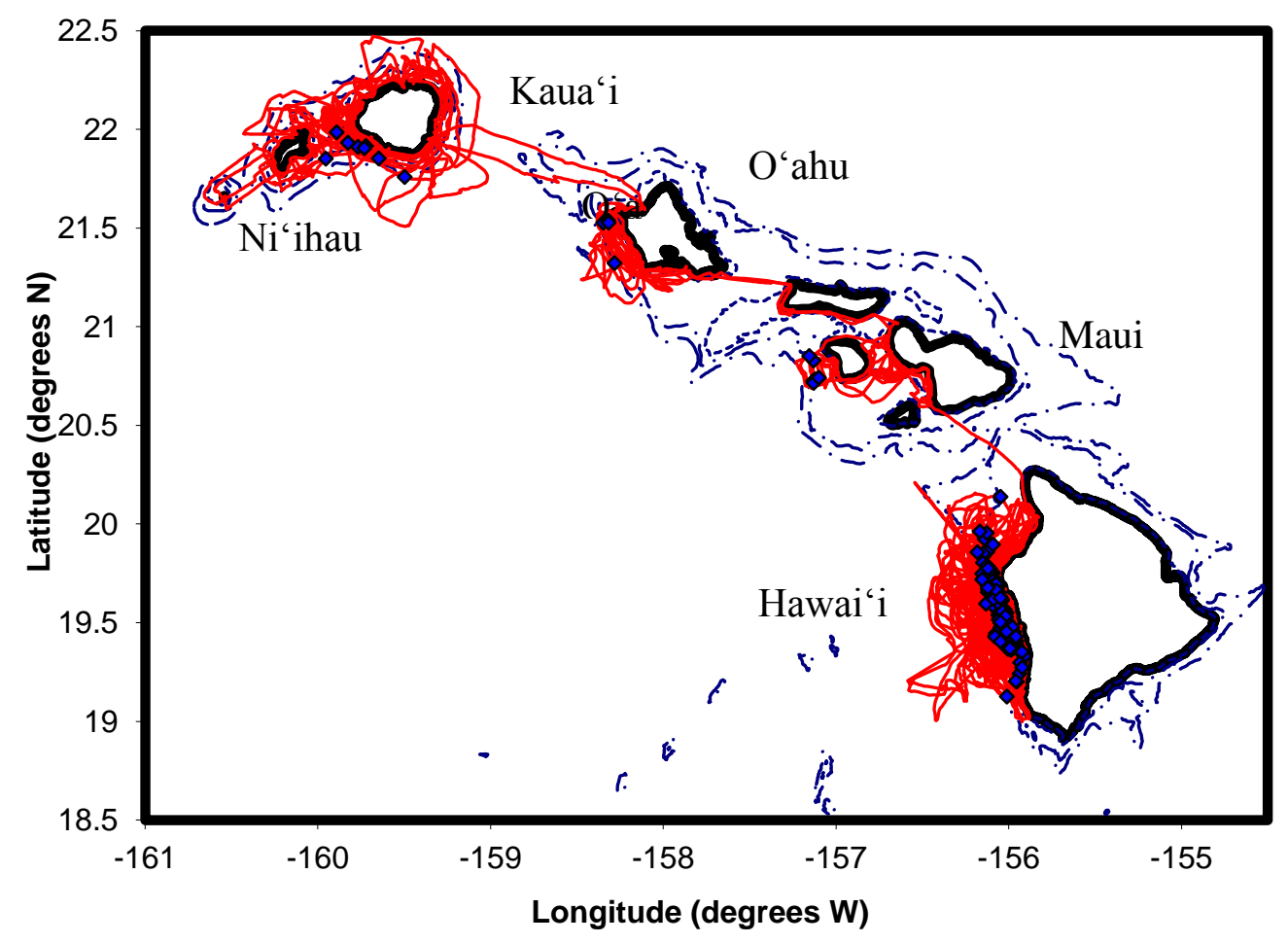

Figure 2.1. Map showing directed research effort around the main Hawaiian Islands from 2003 through 2007. Short-finned pilot whale sightings are represented by blue diamonds and survey tracklines are shown in red; the 1,000 $\mathrm{m}$ and 2,000 $\mathrm{m}$ depth contours are represented as broken lines.

Surveys were conducted as far as $70.08 \mathrm{~km}$ from shore; however, the majority of survey effort occurred within $15 \mathrm{~km}$ of shore and effort decreased with increasing distance from shore. Short-finned pilot whales were sighted 2-24 km from shore with the highest sighting rates (corrected for effort) occurring 6-10 km from shore (Figure 2.2). Sightings off the island of Hawai'i occurred 5-25 km from shore, with 76 sightings (55.1\%) 5-10 km from shore. 


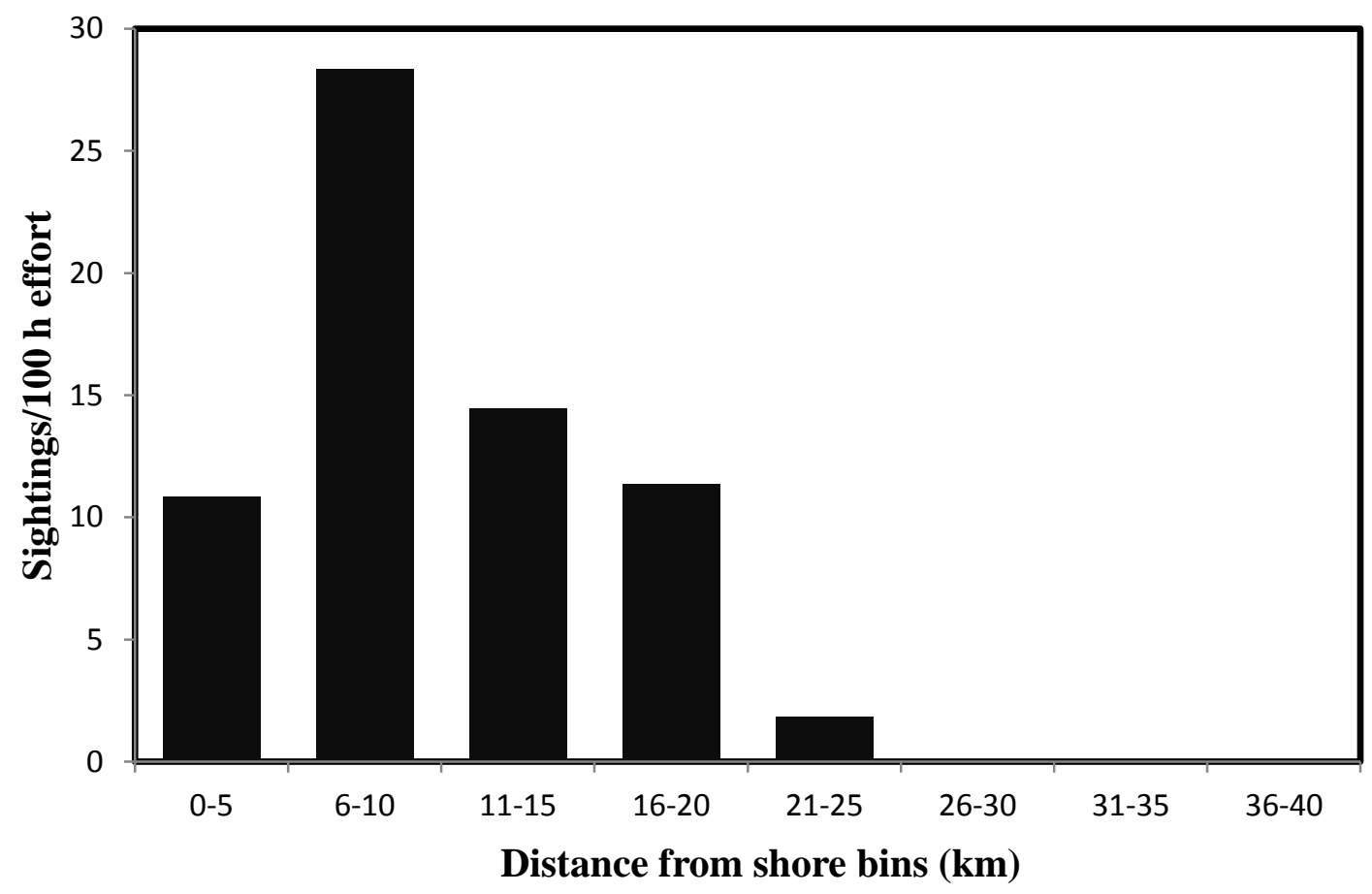

Figure 2.2. Distance from shore of short-finned pilot whale sightings (per $100 \mathrm{~h}$ effort) around the main Hawaiian Islands from 2003 through 2007.

Short-finned pilot whales were sighted in depths ranging from 371 to $2,616 \mathrm{~m}$, with the highest sighting rates (corrected for effort) between 1000-2000 m depth (Figure 2.3). Sighting rates were lowest in water depths less than $500 \mathrm{~m}$ and greater than $2,500 \mathrm{~m}$ (Figure 2.3). 


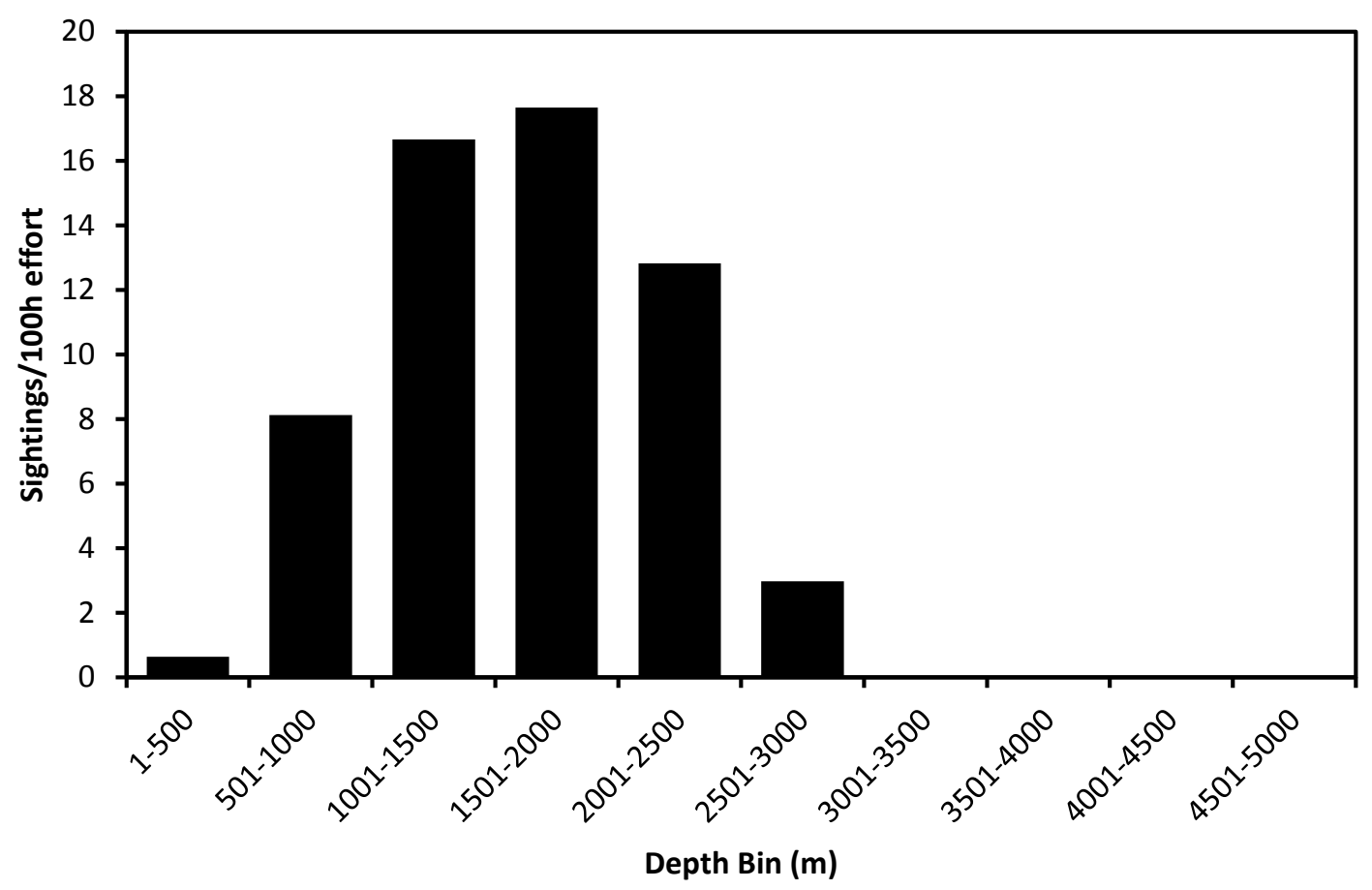

Figure 2.3. Depth distribution of short-finned pilot whale sightings (per $100 \mathrm{~h}$ effort) around the main Hawaiian Islands from 2003 through 2007.

Assessing encounter coverage

Field estimates of the percent of the group that was observed during an encounter (\% coverage) were available for 86 of the 141 directed research encounters around the main Hawaiian Islands; of these, 42 (48.8\%) had 100\% coverage while $11(12.8 \%)$ had coverage of $50 \%$ or less. Such incomplete sampling indicates that not all individuals present were documented and that some dyadic associations were missed. Removing encounters with a coverage index $<2$ (see Methods) resulted in 262 encounters, 241 of which were off the island of Hawai'i. Although the coverage index largely complimented the $\%$ coverage estimate by removing many encounters with low $\%$ coverage, the two coverage measures at times conflicted. Eight encounters with a coverage index $\geq 2$ had $\%$ coverage estimates $\leq 50 \%$ (range $10 \%-50 \%$ ); for each of these 
encounters, the number of individuals photo-identified in the field was less than the estimated group size.

Groups could be incompletely sampled for several reasons; presence of a higher priority species, losing sight of the group, adverse weather conditions and/or fuel constraints were collectively responsible for 27 terminated encounters $(19.1 \%$ of all encounters). The most common reason for leaving a group (96 encounters; $68.1 \%$ ), to continue searching after some of the individuals had been identified, was a conservative measure used either when it was known that the group was incompletely sampled or if there was any uncertainty. Although only 18 encounters listed "complete identification of the group" as a reason for leaving, the 42 encounters that estimated $100 \%$ coverage had no difference between the estimated group size and number of individuals photographically identified, suggesting that some of the groups that listed only "some identified" were likely completely sampled. Reasons for leaving the group did not necessarily correspond to \% of group sampled, however; $100 \%$ coverage was also recorded for some encounters terminated due to weather conditions, the group not being a priority and when the search was continued after some of the individuals were sampled.

\section{Groups}

For encounters with photographic coverage and group size estimates available, the mean group size was 20.4 individuals (range: $1-53, \mathrm{SD} \pm 9.6, n=175$ ) for the main Hawaiian Islands and 20.7 (range 1-53, SD $\pm 9.6, n=157$ ) for the island of Hawai' $i$. In contrast, the average number of individuals photographically identified for those same encounters was 16.3 individuals $(\mathrm{SD} \pm 8.9)$ for the main Hawaiian Islands and 16.6 ( $\mathrm{SD} \pm 9.0)$ for the island of Hawai' $i$, indicating that in some cases the percent of the group 
that was photographically documented was less than the number of individuals present or that group size estimates were positively biased. However, when only considering encounters with $100 \%$ coverage, the difference between the average group size estimate and number of individuals identified was negligible (mean $=0.49, \mathrm{SD} \pm 3.0$, median $=0$, $n=41)$.

\section{Group composition}

Group composition was visually estimated in the field using previously established parameters for age and sex determination. Of 141 directed research encounters around the main Hawaiian Islands with photographic coverage, neonates were observed on 11 occasions in four different years (in $7.8 \%$ of sightings) with all sightings occurring between July and November, and five of the 11 sightings occurring in July. Young of the year were observed on 54 occasions (37.5\% of sightings), with sightings occurring in all months of the year except March and June. The presence/absence of adult males was noted in the field for 97 of the directed research encounters; of these, one or more (range 1-8) adult males were present in 87 (89.7\%) encounters in all months with effort. Neonates were observed in the same group as adult males on six occasions (54.5\% of sightings that included neonates), suggesting short-finned pilot whales commonly travel in groups of mixed sex and age, although with some segregation between adult males and neonates.

\section{Distinctiveness and rate of mark change}

Restricting encounters to those with coverage $\geq 2,80.5 \%$ (SD $\pm 16.5 \%$; median $=82.1 \%$ ) of the entire study population was estimated to be distinctive and $81.2 \%$ $(\mathrm{SD} \pm 16.2 \%$; median=82.4\%) was estimated to be distinctive off the island of Hawai' $\mathrm{i}$. 
The proportion of individuals within the study population that were re-sighted increased with increasing distinctiveness; $55.9 \%$ of non-distinctive individuals, $70.0 \%$ of slightly distinctive individuals, $79.4 \%$ of distinctive individuals and $87.0 \%$ of very distinctive individuals were re-sighted over the course of the study. Similarly, the mean number of times an individual was re-sighted generally increased with increasing distinctiveness, (although there was no difference between distinctive and very distinctive individuals): non-distinctive individuals $($ mean= 2.3$)$, slightly distinctive individuals (mean=3.2), distinctive individuals (mean= 5.1) and very distinctive individuals (mean=5.1).

A total of 155 mark-change or acquisition events (183 individual mark changes) were documented on 105 individuals, 78 of which were considered distinct or very distinct. Mark changes resulted in a change in distinctiveness rating on 15 occasions, and on nine occasions mark changes elevated the distinctiveness of an individual from slightly distinct to distinct; in such cases, an individual's entire sighting history was reclassified as distinctive and included in subsequent analyses. Restricting analyses to only those individuals documented off the island of Hawai' $i$ that were distinctive or very distinctive, the mark-change rate was estimated to be once every 2.9 to 3.5 years, depending on whether multiple mark changes were considered to have occurred independently or not, respectively. Assuming this rate applies across all age/sex classes, this translates to between $28.6 \%$ and $34.5 \%$ of the population undergoing mark changes each year.

\section{Individual sightings}

Using only good and excellent-quality photos, a total of 448 distinctive individuals were identified off the island of Hawai' $i$ during the study period; of these, 
$305(68.1 \%)$ were seen more than once and $250(55.8 \%)$ were seen in more than one year. Individual sighting histories varied substantially, ranging from individuals seen once over the entire course of the study to individuals seen a total of 27 times and in all five years of the study (range 1-29, median=3). Despite 4,611 total identifications $(2,877$ when restricted to $\operatorname{Dist} \geq 3, \mathrm{PQ} \geq 3$, coverage $\geq 2$ ), only 14 individuals were documented moving between islands (representing $0.30 \%$ of all identifications and $0.49 \%$ of distinctive identifications), and these represented only two groups moving between islands. In February 2005, 13 individuals documented off Kaua'i were re-sighted in September of that same year off the island of Hawai' $i$; however, six of the Kaua' $i$ individuals were removed from the analysis due to distinctiveness and photo quality restrictions. Similarly, one individual documented off Kaua'i in 2003 and 2005 was sighted off O‘ahu in 2006; however the 2006 encounter also was removed due to coverage and photo quality restrictions. It should be noted that the 13 individuals sighted off Kaua' $i$ and later re-sighted off the island of Hawai' $i$ had extensive sighting histories off Hawai'i Island between 2005 and 2007; each of the seven distinctive individuals was documented on 13-18 occasions $($ mean $=16.3)$ in three separate years, and those individuals were not documented with any other individuals off Kaua'i (see section on Delineating stable groups, associations of Unit B1).

Although effort off other islands within the archipelago is limited, multi-year within-island re-sightings were documented for every island with effort. Detailed analysis of re-sighting rates off Kaua' $\mathrm{i}$ and $\mathrm{Ni}^{\text {‘ihau between }} 2003$ and 2005 are available from Baird et al. (2006) and re-sighting rates off Kaua'i and $\mathrm{O}^{`}$ ahu (which incorporate 
encounters from 2003-2011) are available from Baird et al. (2011); therefore, these results are not presented here.

\section{Rate of discovery of new individuals}

An assessment of the rate of discovery of new individuals (Figure 2.4) showed a steady increase in the number of new individuals identified during the first two years of the study (2003-2004) and for the majority of the encounters in 2005. Beginning late in 2005 and continuing into 2006, the curve began to level off as more of the individuals encountered were re-sightings of previously identified individuals rather than new individuals entering the study. Visually, the curve appeared to reach an asymptotic limit around 480 individuals in late 2006; however, the curve continued to climb as new individuals were identified in 2007. The shape of the discovery curve illustrates the high level of re-sighted individuals seen off the island of Hawai'i relative to the total number of individuals identified.

Of the individuals seen only once, 17 (representing seven encounters) were first documented in the first two years of the study, 34 (representing eight encounters) were first documented in 2005, 49 (representing 11 encounters) were first documented in 2006 and 43 (representing six encounters) were first identified in 2007. Individuals were documented in all seasons of the study. 

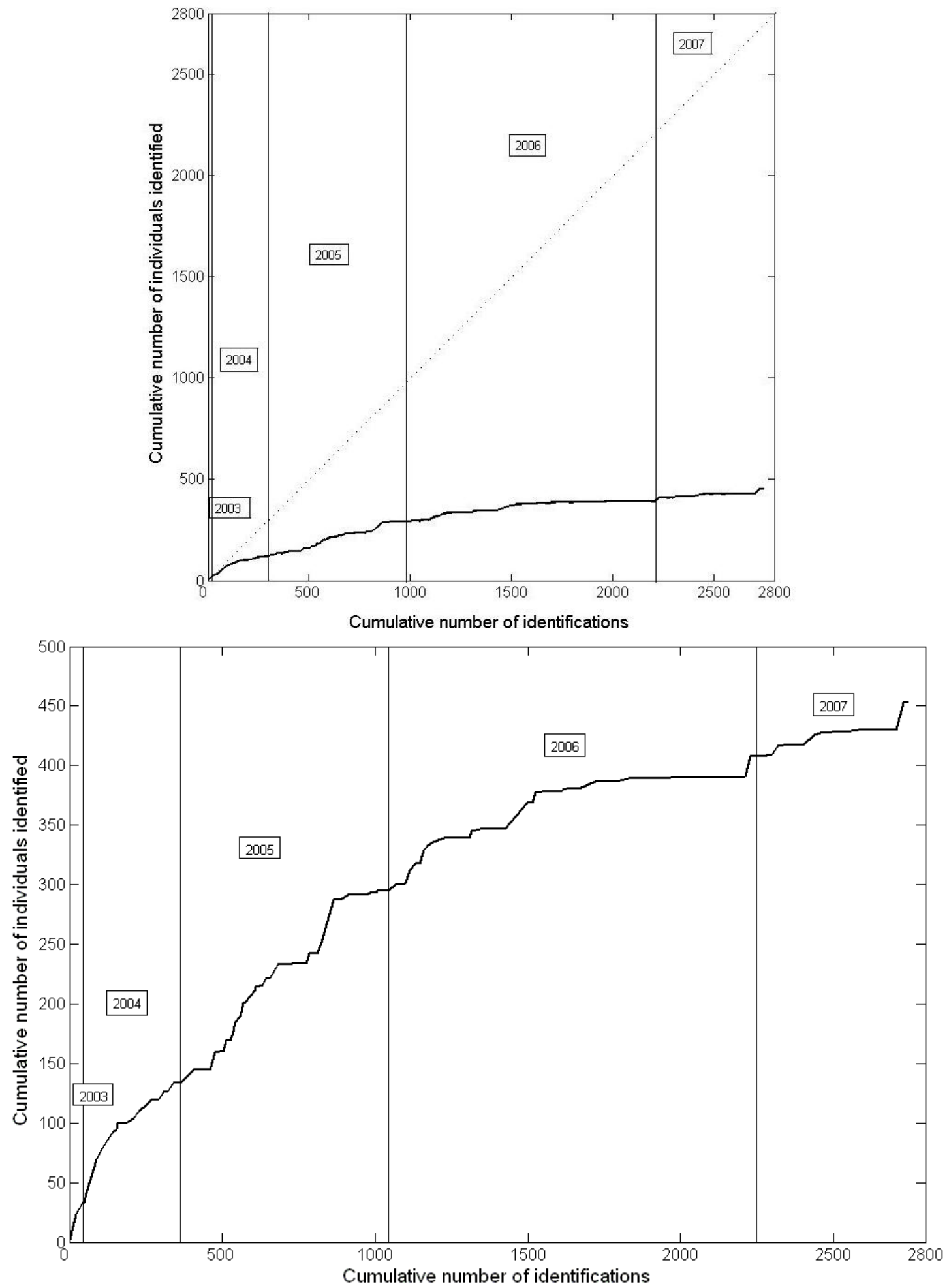

Figure 2.4. Rate of discovery of new individuals showing the cumulative number of individuals documented versus the cumulative number of identifications made (maximum of one identification per day) off the island of Hawai' $i$. Top: including a 1:1 line for comparison. Bottom: detailed view of the curve. 


\section{Residency to the study area}

Based on established residency criteria, a total of 156 core residents, 150 residents and 142 visitors were identified. A social network diagram identified a core social network of 322 individuals ( $71.9 \%$ of the Hawai' $i$ study population) and ten satellite clusters containing 126 individuals (membership range 2-32; mean=13.4) that did not link back to the main component (Figure 2.5). A solitary node was also present; closer inspection shows that this individual was originally sighted with one other individual but was the only member in the group with sufficient distinctiveness and photo quality to be included in the analysis.

With the exception of two individuals, all individuals present in the satellite clusters were determined to be residents or visitors based on sighting history; 85 (67.5\%) of the individuals were seen on one occasion, $36(28.6 \%)$ were seen twice, and three were seen four times. The two core resident individuals that did not link back to the main social network were present in the largest of the satellite clusters, a cluster of 32 individuals sighted 1-5 times. All core residents (with the exception of one), $52.7 \%$ of residents and $36.6 \%$ of visitors were first identified in 2005 or earlier. Over the course of the study, $87.7 \%$ of core residents and $13.3 \%$ of residents were seen in $\geq$ three seasons. Following the definitions of resident and visitor, individuals that were seen infrequently could still link to the main social network and could also link to core residents if documented in the same encounter; thus the main social network was composed of 57 visitors, 98 residents and 154 core residents (Figure 2.6). Inspection of the main social network showed two distinct cut-points, areas of the network where individuals were linked to main component by a single individual; removal of either individual would 
sever the link, creating two isolated components. One of the cut-points identified was of a resident linking 32 visitors to the main social network, and the other was of a core resident linking 14 residents and 18 visitors to the main social network, suggesting a weak association between these individuals and the main component.

$\Delta$

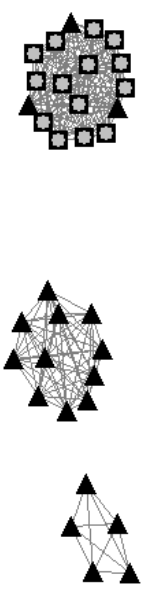

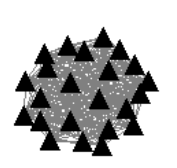
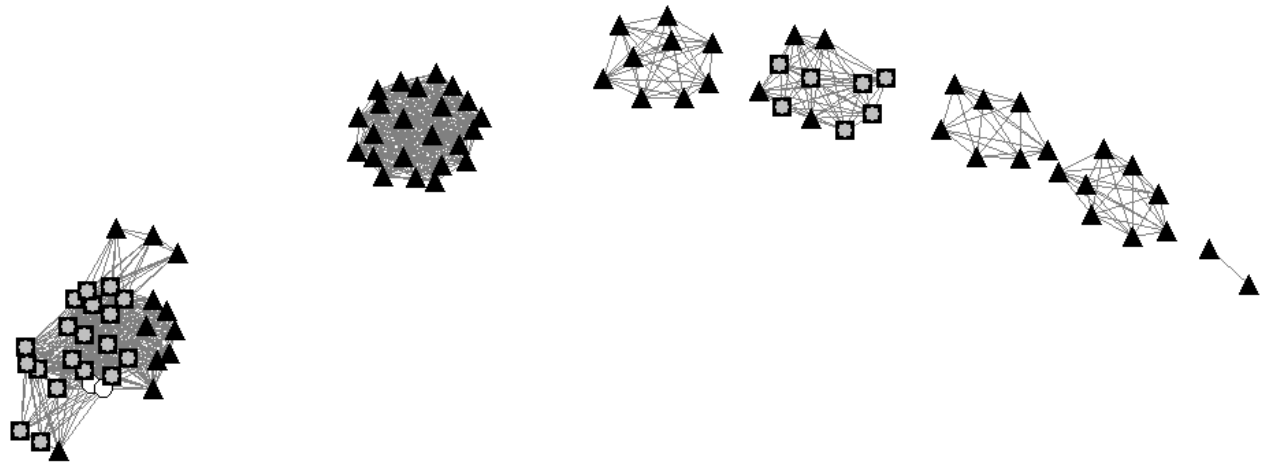

Figure 2.5. Social network diagram of all distinctive short-finned pilot whales documented off the island of Hawai' $i$ from 2003 through 2007. Distances between nodes were determined using a spring-embedding algorithm to depict closeness between individuals. Core residents are shown as white circles, residents are shown as gray boxes and visitors are shown as black triangles. Note the two core residents that do not link by association to the main social network. 


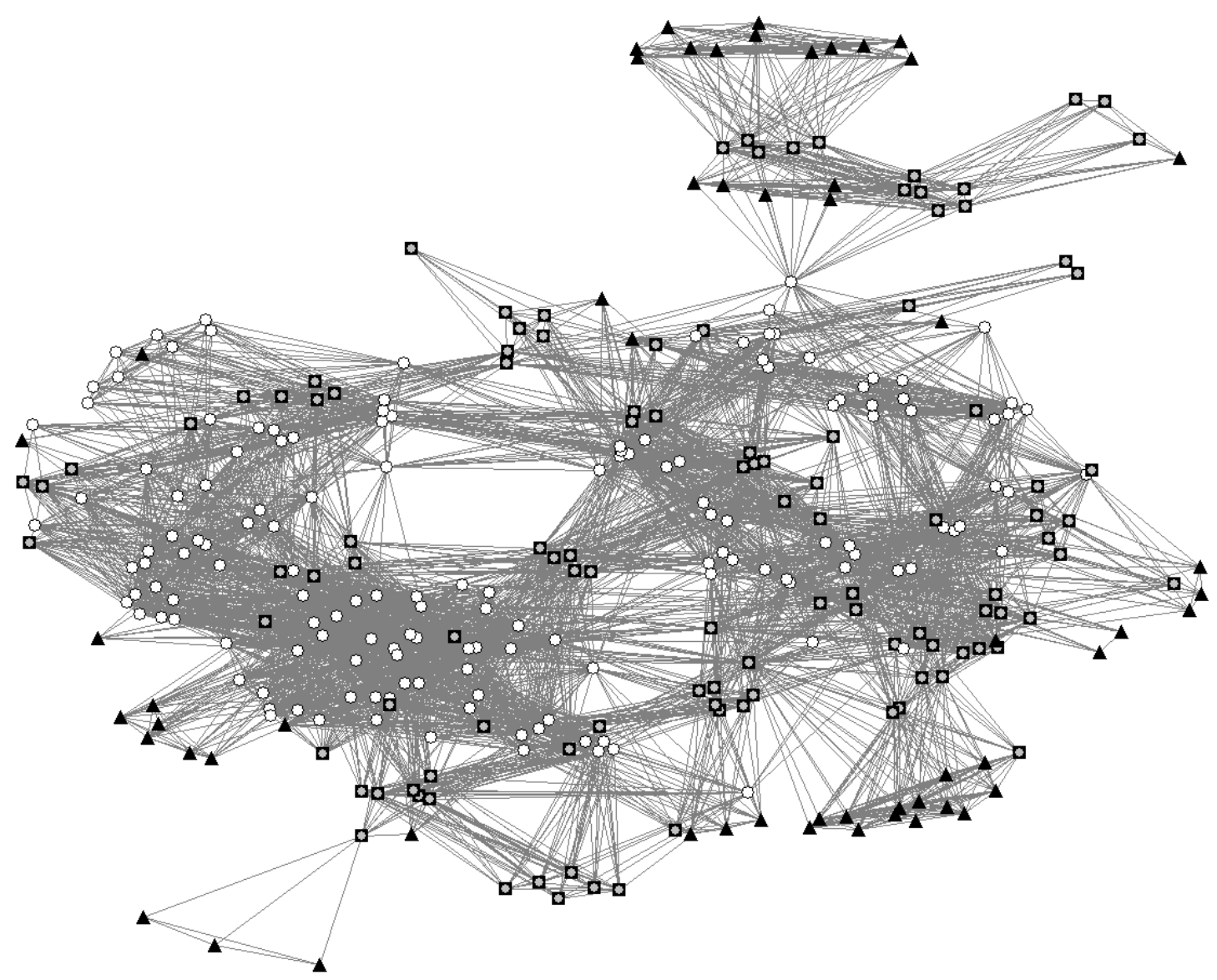

Figure 2.6. Enlargement of main social network cluster taken from Figure 2.5. Note the presence of two cut-points (clusters linked to the main component by a single individual). Removal of either individual would cause the main cluster to fragment slightly.

\section{Lagged identification rate}

Using a sampling period of a day, the model that best described the movements of the study population off the island of Hawai' $i$ was of "emigration and remigration" (Models E and F, Table 2.4, Figure 2.7). The models indicate that on average, 136 $(\mathrm{SE}=7.43)$ individuals were in the study area at any one time, and that an individual remained in the study area an average of 74.3 ( $\mathrm{SE}=9.2)$ days. Individuals were estimated to spend an average of $56.6(\mathrm{SE}=4.70)$ days outside of the study area with an emigration rate per individual per day of 0.031 ( $\mathrm{SE}=0.018)$. For further discussion of lagged identification rates, see section on Temporal aspects of social structure. 
Table 2.4. Exponential models fitted to the entire dataset using maximum likelihood and binomial loss, and used to describe movements of individuals in and out of study area off the island of Hawai' $i$. The best-fit model was that with lowest $\triangle$ QAIC value; standard errors were obtained using 1,000 bootstrap replications.

\begin{tabular}{|c|c|c|c|c|c|}
\hline Model & Best Fit & Parameters & QAIC & $\begin{array}{c}\Delta \\
\text { QAIC }\end{array}$ & $\begin{array}{c}\text { Model } \\
\text { Support }\end{array}$ \\
\hline $\mathrm{E}$ & $\begin{array}{l}\mathrm{R}=0.0041742+0.0031783 * \mathrm{e}^{(-} \\
0.0311142 \tau)\end{array}$ & $\begin{array}{l}\text { Emigration }+ \\
\text { remigration } \\
0.0311142=\text { emigratio } \\
\mathrm{n} \text { rate } \\
0.567725=\text { proportion } \\
\text { of population in the } \\
\text { study area at a given } \\
\text { time }\end{array}$ & 27967.2 & 0 & $\begin{array}{l}\text { Strong } \\
\text { support }\end{array}$ \\
\hline $\mathrm{F}$ & 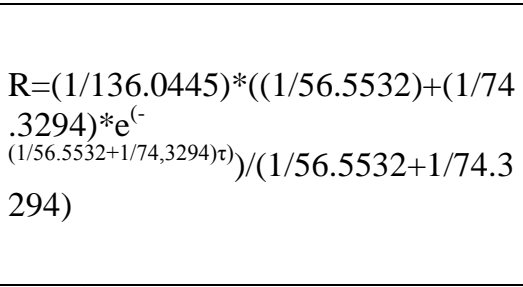 & $\begin{array}{l}\text { Emigration }+ \\
\text { remigration } \\
136.0445=\mathrm{N} \\
74.3294=\text { Mean time } \\
\text { in the study area } \\
56.5532=\text { Mean time } \\
\text { out of study area }\end{array}$ & 27967.2 & 0 & $\begin{array}{l}\text { Strong } \\
\text { support }\end{array}$ \\
\hline $\mathrm{H}$ & 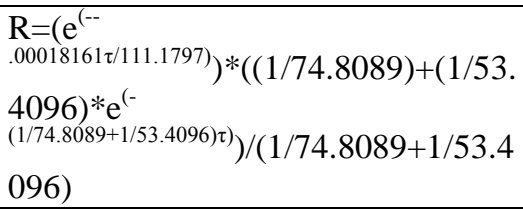 & $\begin{array}{l}\text { Emigration + } \\
\text { remigration }+ \\
\text { mortality }\end{array}$ & 27975.1 & 7.9 & $\begin{array}{l}\text { Some } \\
\text { support }\end{array}$ \\
\hline $\mathrm{C}$ & $\mathrm{R}=0.0046801 * \mathrm{e}^{-0.00015199 \tau}$ & Emigration/mortality & 28003.7 & 36.4 & $\begin{array}{l}\text { No } \\
\text { support }\end{array}$ \\
\hline $\mathrm{D}$ & $\mathrm{R}=(1 / 213.6739) * \mathrm{e}^{(-\tau / 6589.3261)}$ & Emigration/mortality & 28003.7 & 36.4 & $\begin{array}{c}\text { No } \\
\text { support }\end{array}$ \\
\hline A & $\mathrm{R}=0.0044128$ & Closed population & 28005.9 & 38.7 & $\begin{array}{l}\text { No } \\
\text { support }\end{array}$ \\
\hline B & $R=1 / 223.9974$ & Closed population & 28005.9 & 38.7 & $\begin{array}{l}\text { No } \\
\text { support }\end{array}$ \\
\hline G & $\begin{array}{l}\mathrm{R}=-1.6947 * \mathrm{e}(- \\
.00015207 \tau)+1.6994 * \mathrm{e}(- \\
0.00015207 \tau)\end{array}$ & $\begin{array}{l}\text { Emigration + } \\
\text { remigration + } \\
\text { mortality }\end{array}$ & 28007.7 & 40.4 & $\begin{array}{l}\text { No } \\
\text { support }\end{array}$ \\
\hline
\end{tabular}




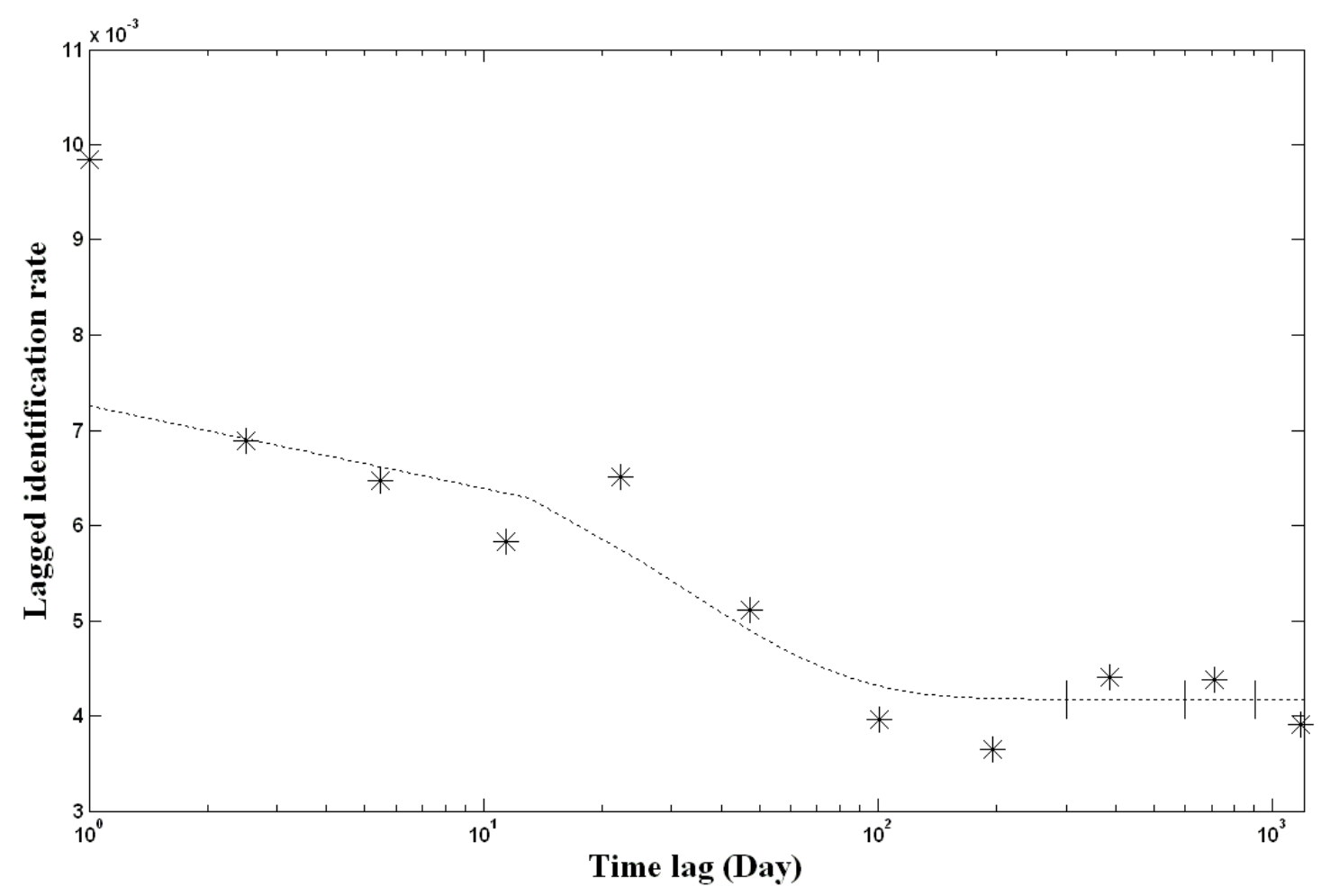

Figure 2.7. Lagged identification rate $*$ ) for short-finned pilot whales documented off the island of Hawai' $i$. The two models that best described the study population were both of emigration and remigration and are shown as completely overlapping dashed lines (Models E and F, Table 2.4). Standard error bars were produced using 1,000 bootstrap replications.

\section{Social differentiation and precision analysis}

The social differentiation of the study population was estimated at $S=1.311$ ( $\mathrm{SE}=0.014)$ for individuals documented on more than four occasions, indicating a well differentiated society. The estimated correlation coefficient of $r=0.428$ ( $\mathrm{SE}=0.013)$ indicated a "somewhat" accurate depiction of the social system (Whitehead 2008b, 2009). Social differentiation calculated using the same parameters but without the bootstrap replicates produced similar estimates $(S=1.305, r=0.420)$. Given the computational time needed to run such a large data set with bootstraps, values of $\mathrm{S}$ and $r$ were calculated without replicates (but with a resolution of integration=0.001) for 
individuals documented on more than two occasions and again for those documented on more than three occasions. Results showed that both the social differentiation and correlation coefficient increased with increasing restrictions (data not presented), strengthening the argument that limiting the analyses to those individuals seen multiple times provides a more accurate view of social structure.

\section{Dyadic associations}

Distinctive individuals seen on more than four occasions off the island of Hawai ${ }^{i} \mathrm{i}$ had an average association index of 0.06 (range $=0.01-0.09, \mathrm{SD} \pm 0.01$ ), indicating overall associations within the study population were low. In contrast, an average maximum association index for each individual of 0.91 (range $=0.50-1.00, \mathrm{SD} \pm 0.08$ ) indicated the presence of some strong dyadic associations; all individuals were seen in association with the same individual at least 50\% of the time (Figure 2.8a). Individuals within the study population also differed in the number of individuals with whom they were associated (mean=12.15, $\mathrm{SD} \pm 2.61$ ); membership ranged from 2 to 18.07 , suggesting differences in individual gregariousness (Figure 2.8b).
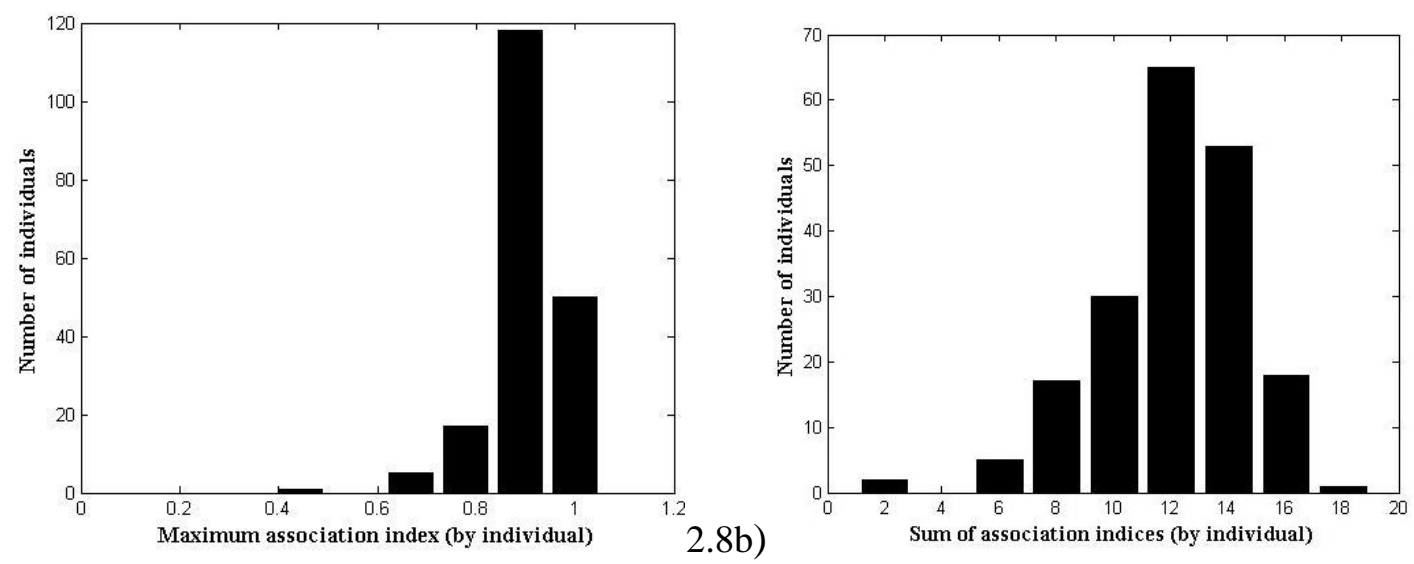

Figure 2.8. Distribution of association indices for distinctive individuals seen off the island of Hawai' $i \geq 5$ times: a) maximum association index, and $b$ ) sum of associates for each individual. 


\section{Preferential associations}

Associations were found to be non-random for both short-term and long-term companionship. Significantly higher SD and CV of the real data set over the permuted data set for both permutation tests indicated long-term preferential associations between individuals, while a lower proportion of non-zero association indices in the real data for both tests indicated the presence of long-term avoidance of some individuals (Table 2.5). Further, for groups permuted within samples, a significantly lower mean of the real association indices indicated short-term preferential associations. Individuals were found to have significant differences in gregariousness ( $p=0.999) . P$-values stabilized at 50,000 random permutations for associations that were permuted within samples, and at 50,000 for groups permuted within samples (both at 1,000 trial flips per permutation). Each test was repeated four times once the $p$-value had stabilized.

A total of 35,958 dyadic associations were possible among distinctive individuals in the study population; of these 4,042 (11.2\%) were considered "preferred associations" (i.e., had an association index $\geq 0.12)$. The majority of dyads $(29,956 ; 83.3 \%)$ were never documented in association; dyads that did associate but that fell below the 0.12 association index threshold for preferential associations accounted for 1,960 (5.45\%) of all possible dyadic associations, indicating few casual "acquaintance" associations occurred within the study population. 
Table 2.5. Tests for non-random associations among distinctive short-finned pilot whales seen $\geq 5$ times off the island of Hawai' $i$; permutation tests performed in SOCPROG 2.4 were used to test for short-term and long-term preferred or avoided associations and for differences in individual gregariousness. $P$-values $>0.95$ are considered significant.

\begin{tabular}{|c|c|c|}
\hline & $\begin{array}{l}\text { Permute groups within samples } \\
\text { (short-term* and long-term test) }\end{array}$ & $\begin{array}{c}\text { Permute associations within } \\
\text { samples (long-term test) }\end{array}$ \\
\hline Standard deviation & $\begin{array}{l}\text { Observed: } 0.18249 \\
\text { Permuted: } 0.14379 \\
p=1.00000\end{array}$ & $\begin{array}{l}\text { Observed: } 0.18249 \\
\text { Permuted: } 0.14453 \\
p=0.99998\end{array}$ \\
\hline Coefficient of variation & $\begin{array}{l}\text { Observed: } 3.10469 \\
\text { Permuted: } 2.42543 \\
p=0.99998\end{array}$ & $\begin{array}{l}\text { Observed: } 3.10469 \\
\text { Permuted: } 2.50255 \\
p=1.00000\end{array}$ \\
\hline $\begin{array}{l}\text { Proportion of non-zero } \\
\text { AIs; proportion of non- } \\
\text { zero AIs from permuted } \\
\text { data }\end{array}$ & $\begin{array}{l}\text { Observed: } 0.16185 \\
\text { Permuted: } 0.27765 \\
p=0.00002\end{array}$ & $\begin{array}{l}\text { Observed: } 0.16185 \\
\text { Permuted: } 0.26133 \\
p<0.000001\end{array}$ \\
\hline Mean association index & $\begin{array}{l}\text { Observed: } 0.05878^{*} \\
\text { Permuted: } 0.059298 * \\
p=0.00012 *\end{array}$ & \\
\hline $\begin{array}{l}\text { Standard deviation of } \\
\text { typical group size }\end{array}$ & $\begin{array}{l}\text { Observed: } 2.46529 \\
\text { Permuted: } 2.20822 \\
p=0.99998\end{array}$ & \\
\hline
\end{tabular}

* indicate results reported are from short-term test.

\section{Detecting community structure}

Division of the study population into clusters was supported using both hierarchical cluster analysis and social network analysis when examining association preferences in conjunction with sighting history (maximum modularity-G using cluster analysis: $\mathrm{Q}=0.798$; association index $=0.048$ ), while examining association preferences in the absence of sighting history did not support such a division (modularity-P using cluster analysis: $\mathrm{Q}=0.172$; association index $=0.172$ ), suggesting sighting history plays an important role in social analyses. Maximum modularity values obtained from social network analysis were not appreciably different from those obtained using cluster analysis (modularity-G: $\mathrm{Q}=0.798$; modularity-P: $\mathrm{Q}=0.173$ ). Only results obtained using the modularity-G approach are discussed further as modularity-P did not support community division. 


\section{Hierarchical cluster analysis and network analysis}

The dendrogram produced (Figure 2.9) was highly representative of the structure within the study population $(\mathrm{CCC}=0.983)$. Maximum modularity- $\mathrm{G}$ occurred at an association index of 0.048 resulting in the division of the study population into nine clusters of variable size and association strength (Figure 2.9). Community division using Newman's (2006) eigenvector-based method similarly resulted in nine clusters; cluster membership ranged from 2-34 individuals, and mean association indices within clusters ranged from $0.27 \pm 0.05$ to $1.00 \pm 0.00$ (all values: Mean \pm SD). However, it should be noted that one of the nine clusters (Cluster 9) differed substantially in both the number of individuals (two) and the mean association index (1.00); membership for the remaining eight clusters ranged from 16-34 (mean=23.25 \pm 7.80$)$ individuals and mean association indices ranged from $0.27 \pm 0.05$ to $0.78 \pm 0.06$. Cluster 9 also appeared to be socially isolated on the dendrogram, having no links to any of the other clusters (each of the other eight clusters were linked to at least one other cluster at some low level of association).

Individuals within clusters had significantly higher levels of association than those among clusters (Mantel permutation test, $p=1.00$ ); the mean association index within clusters was $0.48 \pm 0.20$ while the mean association index among clusters was $0.00 \pm 0.00$. Maximum association indices were also substantially greater within clusters than among clusters $(0.91 \pm 0.08$ vs. $0.08 \pm 0.05)$, supporting the divisions within the study population created by maximizing modularity. A large, positive matrix correlation coefficient of 0.768 further supported rejection of the null hypothesis that no significant difference in association strength within or among clusters existed. Removing Cluster 9 
from the analysis had a negligible effect, reducing the average association index within clusters to $0.47 \pm 0.20$ and the maximum to $0.90 \pm 0.08$; all other values remained the same. Examination of individual clusters using community division indicated the presence of meaningful sub-clusters in four of the nine clusters $(\mathrm{Q}=0.069-0.441)$; Clusters 1 and 3 were each divided into two sub-clusters, and Clusters 2 and 5 were each divided into three sub-clusters. However, although cluster subdivision within the study population was supported, maximum modularity values obtained were lower than for the overall study population, indicating that within-cluster divisions were not as strong. Further, clusters that were successfully subdivided were substantially larger than those in which sub-clusters were not supported (membership ranges: 26-34 and 2-17, respectively), indicating that cluster subdivision could partially be an artifact of size rather than (or as well as) social partitioning. Considering only sub-clusters, and clusters 1-8 where sub-division was not supported, membership ranged from 8 to 18 individuals (mean $=12.53 \pm 3.65$ ), substantially less than the mean group size encountered in the field. Although not highlighted in the dendrogram, sub-clusters are evident when viewing the configuration of relevant clusters in Figure 2.9. 


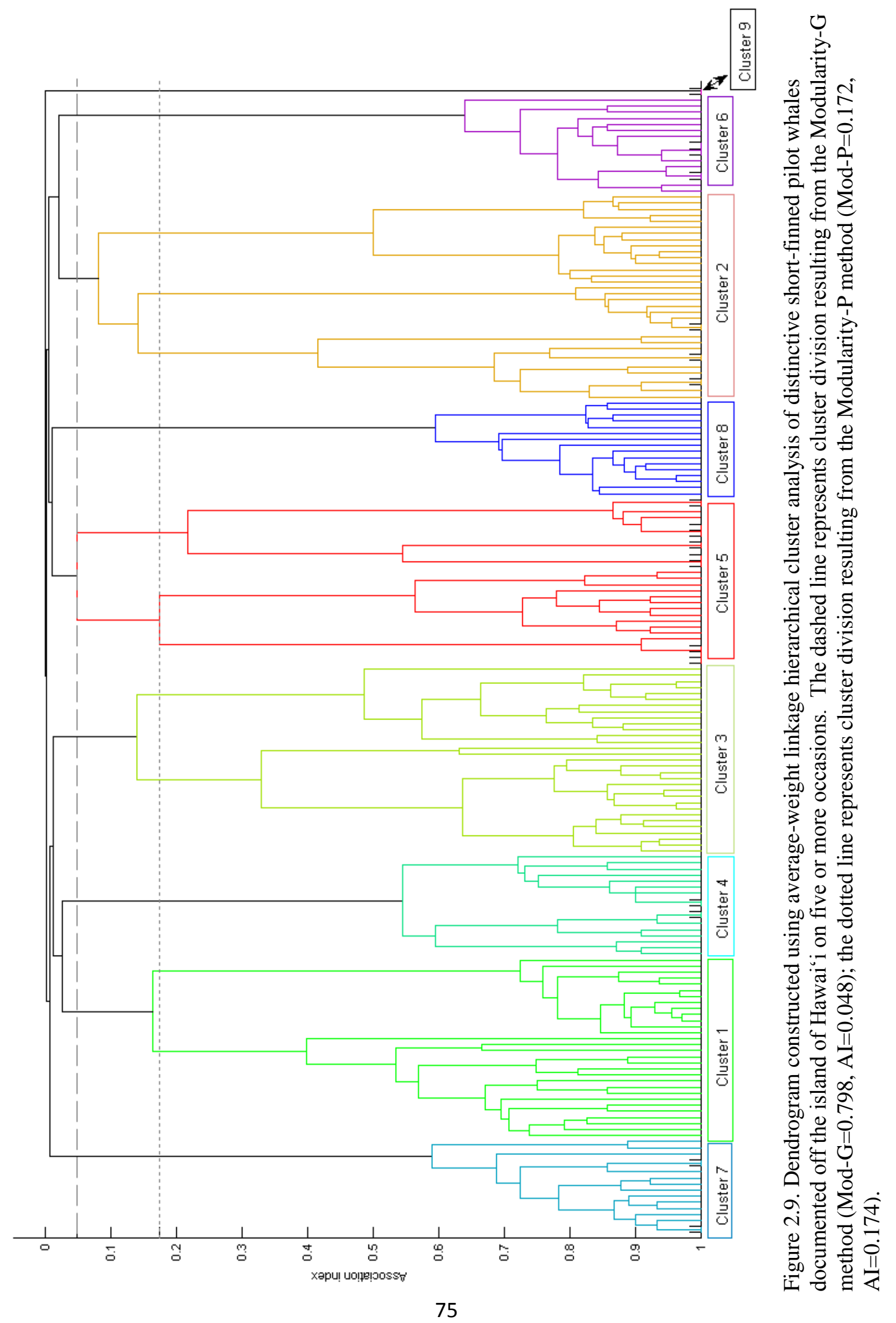




\section{Temporal aspects of social structure}

Using previously established parameters for sampling period and association, the model fit to the standardized lagged association rate that best described the study population was of "casual acquaintances", as defined by Whitehead (1995) (Figure 2.10, Table 2.6).

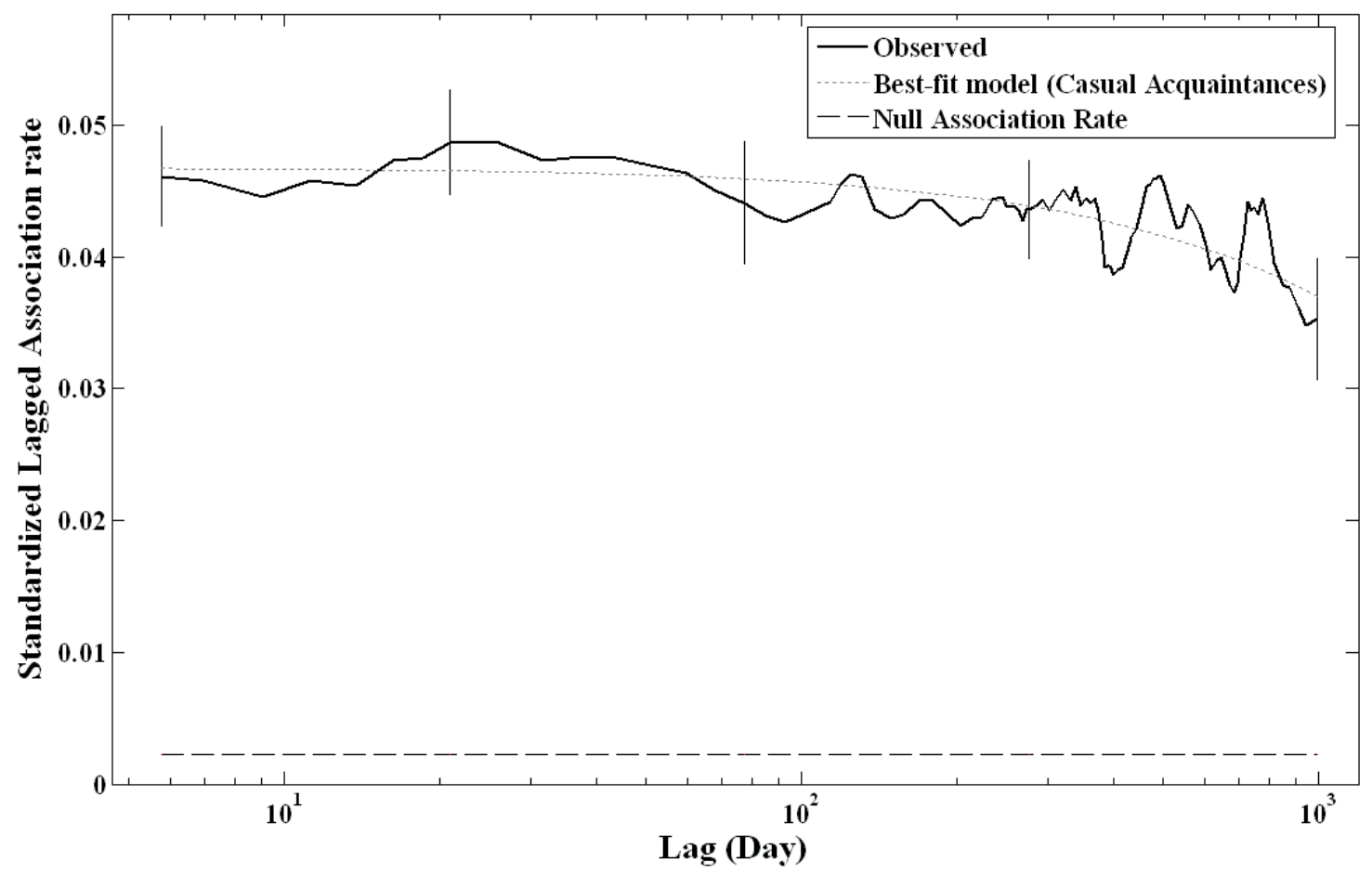

Figure 2.10. SLAR for short-finned pilot whales documented off Hawai'i Island using a moving average of 200,000 associations. Associations are defined as individuals grouped within an encounter. Approximate standard error bars (+/- one standard error) were produced by jackknifing on each sampling period. The best-fit model (casual acquaintances, $\mathrm{g}^{\prime}=0.046^{*} \mathrm{e}^{-0.0002 \tau}$ ) was obtained using maximum likelihood methods; the null association rate is included for reference. 
Table 2.6. Exponential models fitted to the entire dataset using maximum likelihood and binomial loss and used to describe long-term associations (SLAR, g') of distinctive individuals off the island of Hawai' $i$. Associations were defined as individuals grouped within an encounter; the best-fit model was that with lowest $\triangle$ QAIC value.

\begin{tabular}{|c|c|c|c|c|c|}
\hline Model & Best Fit & Parameters & QAIC & AQAIC & $\begin{array}{c}\text { Model } \\
\text { Support }\end{array}$ \\
\hline $\begin{array}{c}\text { Casual } \\
\text { Acquaintances }\end{array}$ & $\mathrm{g}^{\prime}=0.046 * \mathrm{e}^{-0.0002 \tau}$ & 2 & $\mathbf{6 6 0 0 4 . 1 0}$ & 0 & Best \\
\hline $\begin{array}{c}\text { Two Levels of } \\
\text { Casual } \\
\text { Acquaintances }\end{array}$ & $\mathrm{g}^{\prime}=-0.001 * \mathrm{e}^{-0.807 \tau}+0.0468 * \mathrm{e}^{-0.0002 \tau}$ & 4 & 66008.08 & 3.98 & $\begin{array}{c}\text { Some } \\
\text { Support }\end{array}$ \\
\hline $\begin{array}{c}\text { Constant } \\
\text { Companions }\end{array}$ & $\mathrm{g}^{\prime}=0.043$ & 1 & 66039.44 & 35.34 & $\begin{array}{c}\text { No } \\
\text { Support }\end{array}$ \\
\hline $\begin{array}{c}\text { Constant } \\
\text { Companions } \\
\& \text { Casual } \\
\text { Acquaintances }\end{array}$ & $\mathrm{g}^{\prime}=0.0423+0.016^{*} \mathrm{e}^{-1.32 \tau}$ & 3 & 66042.56 & 38.46 & $\begin{array}{c}\text { No } \\
\text { Support }\end{array}$ \\
\hline
\end{tabular}

Visual inspection of the SLAR curve shows fairly consistent associations over an approximate temporal period of 100 days, after which gradual disassociation of the study population is evident. The fact that the SLAR curve continues to fall (and does not appear to stabilize over any time lag) supports the description of casual acquaintances. However, although the standardized lagged association rate is falling, over a period almost of three years the rate has only declined by $\sim 1 / 4$ and not come close to reaching the null association rate, indicating the presence of non-random associations. Following the model for casual acquaintances, the typical group size (gregariousness) of the study population was estimated at 21.7 individuals (1/a) and associations were estimated to persist for 4,264 days (11.68 years)(1/b), which is beyond the scope of the study.

When using lagged association rates to address the temporal nature of relationships it is important to make sure the results are consistent with those obtained through other methods such as cluster analyses and basic data analysis (Whitehead 2008b). Whitehead (2008b) also stresses the importance of choosing an appropriate 
sampling period and definition of association that will produce the most accurate depiction of the study population. Basic inspection of the data used to generate the SLAR above indicates that some individuals were not casual acquaintances but, in fact, maintained strong dyadic associations throughout the duration of the study. For example, over a three year period HIGm0309 was sighted on 16 occasions and HIGm0311 was sighted on 17 occasions; both individuals were documented together in 15 of these encounters (spanning all three years) and had a dyadic association index of 0.94. Individuals HIGm0309 and HIGm0311 were both assigned to Cluster 1 using network analysis and hierarchical cluster analysis (see Figure 2.9); further examination of this cluster shows a maximum association index range of $0.50-0.97$, suggesting heterogeneity of associations within the cluster itself but also showing preferential associations spanning the duration of the study. As such, reexamination of the parameters used to calculate the lagged association rates is warranted.

Restricting analysis of temporal relationships to encounters with an estimated \% group coverage $\geq 80 \%$ removes a fair amount of data (such as all opportunistic encounters and directed research encounters prior to 2006 where \% group coverage was not recorded in the field) but also ensures a more accurate representation of group composition. Calculating standardized lagged association rates using the same parameters (sampling period of a day and associations defined as individuals grouped within an encounter) but restricting encounters to those with coverage $\geq 80 \%$ produced a SLAR curve that appeared fairly constant with a best-fit model of constant companions, although there was also strong support for casual acquaintances and some support for the other two models (Figure 2.11, Table 2.7). As mentioned, restricting encounters to those with coverage 
$\geq 80 \%$ reduces the number of encounters included in the analysis from 239 encounters spanning 2003-2007 to 63 encounters spanning 2006-2007, and is thus much less powerful. However, this restricted data set is also less biased and, therefore, more accurately represents the temporal associations within the study population.

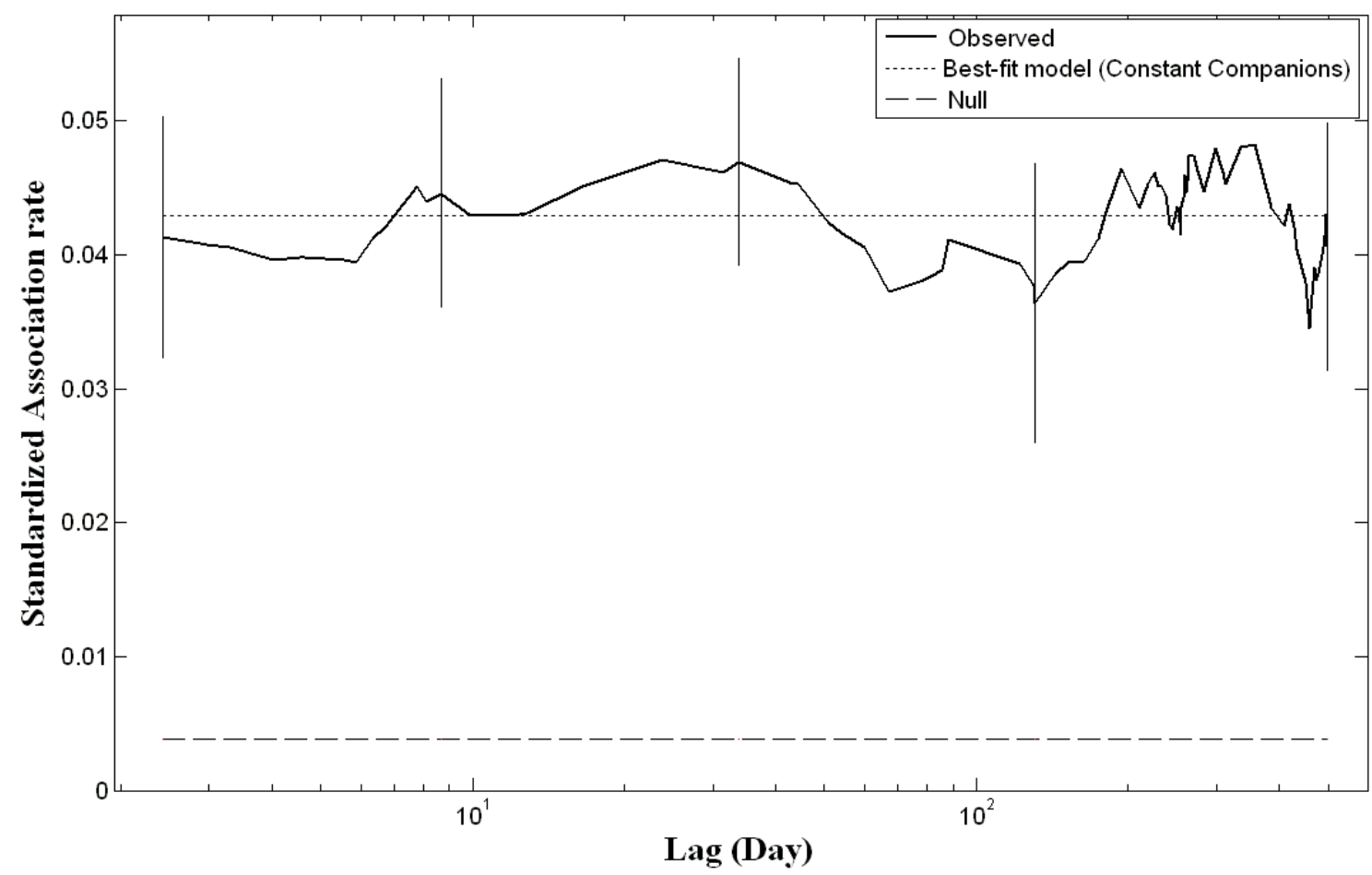

Figure 2.11. SLAR for short-finned pilot whales documented off the island of Hawai' $i$ (restricted to coverage $\geq 80 \%$ ), using a moving average of 30,000 associations. The bestfit model was constant companions, $\mathrm{g}^{\prime}=0.0429$; the null association rate is included for reference. 
Table 2.7. Exponential models fitted to the entire dataset using maximum likelihood and binomial loss, and used to describe long-term associations of distinctive individuals off the island of Hawai' $i$ restricted to coverage $\geq 80 \%$; the best-fit model was that with lowest $\triangle \mathrm{QAIC}$ value.

\begin{tabular}{|c|c|c|c|c|c|}
\hline Model & Best Fit & Parameters & QAIC & $\Delta$ QAIC & $\begin{array}{c}\text { Model } \\
\text { Support }\end{array}$ \\
\hline $\begin{array}{c}\text { Constant } \\
\text { Companions }\end{array}$ & $\mathrm{g}^{\prime}=0.0429$ & 1 & $\begin{array}{c}\mathbf{4 2 2 8 . 0} \\
\mathbf{1}\end{array}$ & 0 & Best \\
\hline $\begin{array}{c}\text { Casual } \\
\text { Acquaintances }\end{array}$ & $\mathrm{g}^{\prime}=0.0428 * \mathrm{e}^{-.00001 \tau}$ & 2 & $\begin{array}{c}4230.0 \\
0\end{array}$ & 1.99 & $\begin{array}{c}\text { Strong } \\
\text { Support }\end{array}$ \\
\hline $\begin{array}{c}\text { Constant } \\
\text { Companions } \\
\& \text { Casual } \\
\text { Acquaintances }\end{array}$ & $\mathrm{g}^{\prime}=0.0429+0.001 * \mathrm{e}^{-1.26 \tau}$ & 3 & $\begin{array}{c}4232.0 \\
0\end{array}$ & 3.99 & $\begin{array}{c}\text { Some } \\
\text { Support }\end{array}$ \\
\hline $\begin{array}{c}\text { Two Levels of } \\
\text { Casual } \\
\text { Acquaintances }\end{array}$ & $\mathrm{g}^{\prime}=-0.0012 * \mathrm{e}^{-0.705 \tau}+0.0429 * \mathrm{e}^{-0.000005 \tau}$ & 4 & $\begin{array}{c}4234.0 \\
0\end{array}$ & 5.99 & $\begin{array}{c}\text { Some } \\
\text { Support }\end{array}$ \\
\hline
\end{tabular}

Given that temporal analysis of encounters restricted to those with $\geq 80 \%$ coverage produced a different model of social structure than encounters restricted to a coverage index $\geq 2$, it is reasonable to assume that encounters which did not meet the $80 \%$ criterion may have been incompletely sampled and that some individuals were in fact present even though they were not photographically documented. To test the hypothesis that individuals not documented during an encounter were present in the study area the definition of groups was altered from individuals documented within the same encounter to individuals documented on the same day; a coverage index $\geq 2$ was chosen to increase the power of the analysis along with a sampling period of a day. Altering only the definition of association resulted in a best-fit model of constant companions (although, as with restricting the data to coverage $\geq 80 \%$ there was strong support for casual acquaintances and some support for the other two models, as seen in Table 2.8) and a SLAR curve with a somewhat cyclical appearance (Figure 2.12). 


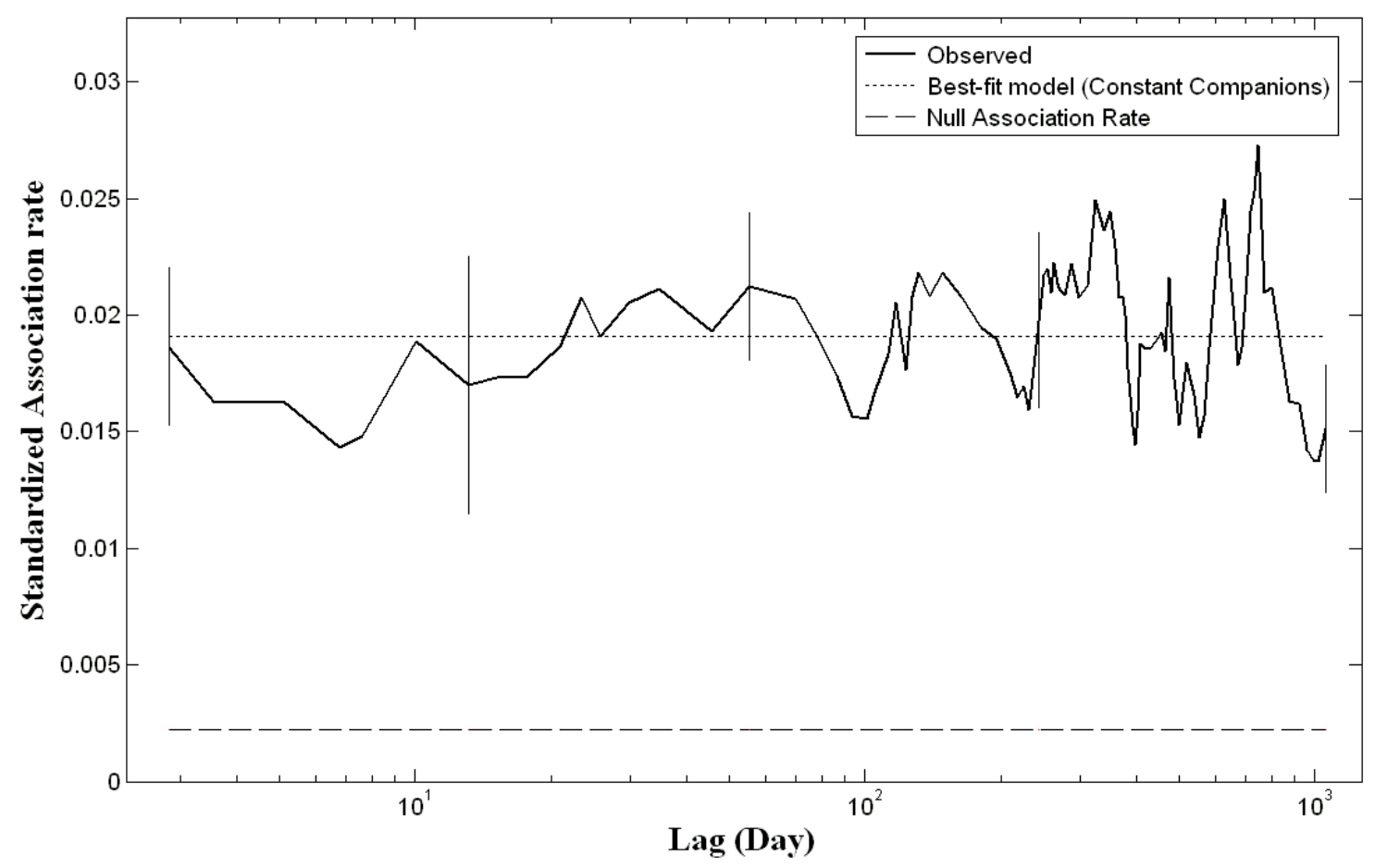

Figure 2.12. SLAR for short-finned pilot whales documented off the island of Hawai' $i$ using a moving average of 250,000 associations. Associations were defined as individuals seen on the same day. The best-fit model (constant companions, $\mathrm{g}^{\prime}=0.0191$ ) was obtained using maximum likelihood methods; the null association rate is included for reference.

Table 2.8. Exponential models fitted to the entire dataset using maximum likelihood and binomial loss, and used to describe long-term associations of distinctive individuals off the island of Hawai' $i$ using a sampling period of a day and associations defined as individuals seen on the same day; the best-fit model was that with lowest $\triangle$ QAIC value.

\begin{tabular}{|c|c|c|c|c|c|}
\hline Model & Best Fit & Parameters & QAIC & $\Delta$ QAIC & $\begin{array}{c}\text { Model } \\
\text { Support }\end{array}$ \\
\hline $\begin{array}{c}\text { Constant } \\
\text { Companions }\end{array}$ & $\mathrm{g}^{\prime}=0.0191$ & 1 & $\mathbf{2 8 0 2 1 . 1 9}$ & 0 & Best \\
\hline $\begin{array}{c}\text { Casual } \\
\text { Acquaintances }\end{array}$ & $\mathrm{g}^{\prime}=0.0193 * \mathrm{e}^{-.00004 \tau}$ & 2 & 28022.87 & 1.68 & $\begin{array}{c}\text { Strong } \\
\text { Support }\end{array}$ \\
\hline $\begin{array}{c}\text { Constant } \\
\text { Companions } \\
\& \text { Casual } \\
\text { Acquaintances }\end{array}$ & $\mathrm{g}^{\prime}=0.0191+0.002 * \mathrm{e}^{-1.30 \tau}$ & 3 & 28025.16 & 3.97 & $\begin{array}{c}\text { Some } \\
\text { Support }\end{array}$ \\
\hline $\begin{array}{c}\text { Two Levels of } \\
\text { Casual } \\
\text { Acquaintances }\end{array}$ & $\mathrm{g}^{\prime}=-0.0019^{-1.778 \tau}+0.0193 * \mathrm{e}^{-}$ & 4 & 28026.87 & 5.68 & $\begin{array}{c}\text { Some } \\
\text { Support }\end{array}$ \\
\hline
\end{tabular}

The LIR model indicated that, on average, 136 individuals were in the study area at any one time and that an individual remained in the study area an average of 74.3 days, 
which corresponds to the fairly uniform portion of the SLAR curve for casual acquaintances, visually estimated to persist for around 100 days (Figure 2.10). When the SLAR curve used to generate the best-fit model of casual acquaintances is restricted to a maximum time lag of 78 days and the models are fit to the new curve, the description of the study population changes to that of constant companions (data not presented). The correlation between the estimated length of time individuals remain in the study area and the societal description of constant companions suggests that the disassociation indicated by the fall in the standardized lagged association rate might be due in part to the emigration of certain companions from the study area, rather than the dissolution of associations from dyads that remained in spatio-temporal proximity.

\section{Delineating stable groups}

Initial analysis of the study population using criteria outlined by Ottensmeyer \& Whitehead (2003) and de Stephanis et al. (2008b) produced eight longitudinally stable social units (membership range 2-28, mean=9.75) from 154 core residents. However, when pair-wise association indices were applied to members within each unit, many dyadic associations fell below the 0.50 criterion, suggesting that further inspection of unit membership was necessary. Membership remained unaltered by the addition of association indices in five of the eight units; two units only contained dyadic associations above the 0.50 criterion and three units contained dyadic associations where less than half fell below the 0.50 criterion. The largest social unit identified, Unit B, contained 28 individuals; 15 key individuals (seen $\geq 8$ times in $\geq 4$ years) and 13 constant companions (seen $\geq 5$ times in $\geq 3$ years). When Unit B was examined using association indices, two distinct levels of association were apparent; the majority of associations between key 
individuals (0.44-0.87) and all associations between constant companions (0.64-0.97) remained above 0.50 , while none of the associations between key individuals and constant companions reached the 0.50 criterion. In fact, with the exception of one constant companion who failed to meet the 0.50 criterion for either key individuals or constant companions, associations between the two ranged from 0.05-0.29. Therefore, despite the fact that all individuals within the unit met the initial criteria for membership, following analysis using association indices, Unit B was divided into 2 separate units: Unit B1 which contained all key individuals, and Unit B2 which contained all constant companions. Additionally, HIGm0383 was also the only constant companion assigned to another unit that contained only one key individual (HIGm0166); further inspection of this unit showed a dyadic association of 0.43 , below the minimum criteria. However, examination of the sighting history of HIGm0166 suggested that even though it was itself a key individual, it met the criteria as a constant companion for Unit B1. Given that HIGm0166 would have been counted as a key individual of Unit B1 if it had met the four year criteria (HIGm0166 only met three of the four years, though it should be noted that for the fourth year it had been sighted the same day, though in a different encounter, than many of the members of Unit B1), this unit was merged with Unit B1 and HIGm0383 was removed. It should also be noted that all of the members of B1 were documented in a single encounter off Kaua'i in 2005 (see section on Individual Sightings) and were not observed in association with any other individuals at that time, suggesting that although movement between islands occurs, visitors do not necessarily interact with individuals outside of their social network. 
Although two constant companions initially were assigned to Unit C, all of their dyadic association values fell below the 0.50 criterion $(0.11-0.31)$ and so were removed; however, the same two constant companions were successfully assigned to Unit H. Unit $\mathrm{C}$ contained only one additional individual (HIGm0211) in which $>50 \%$ of the dyadic associations fell below 0.50. Rather than removing HIGm0211 from the analysis, Unit C was divided such that all individuals that had dyadic associations with HIGm0211 $\geq 0.50$ were placed in sub-unit $\mathrm{C} 1$ and all individuals with dyadic associations $\leq 0.50$ were placed in sub-unit $C 2$. Unlike Unit B, all dyadic associations within Unit $C$, with the exception of HIGm0211, were above the 0.50 criterion; therefore, although subdivision of this unit resulted in subunits with higher average dyadic associations than the unit as a whole, the subdivision remains somewhat tenuous. Final unit delineation (see Table 2.9) resulted in nine social units (membership range 5-16, mean=10.44, $\mathrm{SD} \pm 3.75$ ).

Table 2.9. Longitudinally stable social units of short-finned pilot whales off the island of Hawai' $i$ constructed from shared sighting histories and composed of key individuals and constant companions.

\begin{tabular}{|c|c|c|c|c|c|}
\hline Unit & $\begin{array}{c}\text { \# Key } \\
\text { individuals }\end{array}$ & $\begin{array}{c}\text { \# Constant } \\
\text { companions }\end{array}$ & $\begin{array}{c}\text { Total \# unit } \\
\text { members }\end{array}$ & $\begin{array}{c}\text { Association } \\
\text { Index range }\end{array}$ & $\begin{array}{c}\text { Mean Association } \\
\text { Index }\end{array}$ \\
\hline A & 2 & 3 & 5 & $0.83-0.93$ & 0.897 \\
\hline B1 & 16 & 0 & 16 & $0.44-0.87$ & 0.618 \\
\hline B2 & 0 & 12 & 12 & $0.64-0.97$ & 0.827 \\
\hline C1 & 8 & 0 & 8 & $0.50-0.91$ & 0.766 \\
\hline C2 & 9 & 0 & 9 & $0.65-0.95$ & 0.807 \\
\hline E & 2 & 5 & 7 & $0.76-0.96$ & 0.878 \\
\hline F & 2 & 7 & 9 & $0.43-0.83$ & 0.676 \\
\hline H & 13 & 2 & 15 & $0.43-0.97$ & 0.687 \\
\hline
\end{tabular}

Age/sex classes were visually estimated for individuals within each unit (Table 2.10) using terms and criteria outlined in the section on Age/Sex Classification. Although qualitatively assigning age and sex descriptors to individuals is somewhat subjective, 
broad inferences may still be drawn about the overall structure of the social unit. Adult males were identified in eight of the nine social units; notably, the social unit without any adult males (Unit B1) contained almost twice as many calves and juveniles as the other social units (Table 2.10). More than half of the social units did not have individuals observed in association with younger individuals such as calves or juveniles. Adult females were only present in four of the nine social units; however, the criteria used to define adult females was more restrictive than for adult males, suggesting that some of the individuals simply listed as "adults" were likely adult females without younger individuals in close association.

Table 2.10. Visually estimated age/sex classes of individuals within social units; see section on Age/Sex Classification for a review of terms and criteria.

\begin{tabular}{|c|c|c|c|c|c|c|c|c|}
\hline Unit & $\begin{array}{c}\text { Total \# } \\
\text { unit } \\
\text { members }\end{array}$ & $\begin{array}{c}\text { Adult } \\
\text { Male }\end{array}$ & $\begin{array}{c}\text { Adult } \\
\text { Female }\end{array}$ & Adult & $\begin{array}{c}\text { Sub- } \\
\text { Adult }\end{array}$ & Juvenile & $\begin{array}{c}\text { Calf (C), } \\
\text { Juvenile (J), } \\
\text { *not included in } \\
\text { Units }\end{array}$ & $\begin{array}{c}\text { Est. total } \\
\text { Unit size }\end{array}$ \\
\hline A & 5 & 1 & - & 3 & 1 & - & - & 5 \\
\hline B1 & 16 & - & 5 & 9 & 2 & - & $4(\mathrm{~J}), 1(\mathrm{C})$ & $\mathbf{2 1}$ \\
\hline B2 & 12 & 3 & - & 8 & 1 & - & - & 12 \\
\hline C1 & 8 & 3 & - & 4 & 1 & - & - & 8 \\
\hline C2 & 9 & 1 & - & 5 & 3 & - & - & 9 \\
\hline E & 7 & 2 & -- & 5 & - & - & - & 7 \\
\hline F & 9 & 1 & 2 & 4 & 2 & - & $2(\mathrm{~J})$ & $\mathbf{1 1}$ \\
\hline G & 15 & 1 & 3 & 11 & - & - & $3(\mathrm{C})$ & $\mathbf{1 8}$ \\
\hline H & 13 & 2 & 2 & 6 & 1 & 2 & $1(\mathrm{~J})$ & $\mathbf{1 4}$ \\
\hline
\end{tabular}

*The number of calves and juveniles was estimated for each unit based on close, consistent association with a member of the unit thought to be an adult female.

It should be noted that 59 core residents were not allocated to social units since they did not share sufficient sighting histories with any key individuals, although it is possible that these individuals may in fact form stable social units with each other and might emerge as key individuals as more data are collected. A social network diagram using a spring-embedding algorithm to depict closeness between core residents, residents and visitors showed visitors mainly confined to the outer fringes of the main component 
and residents clustered in interior portions of the graph between dense clusters of core residents (Figure 2.13). Removal of residents and visitors from the main component of the social network diagram provided a more direct comparison of core residents allocated to various social units with those left unallocated; the majority of unallocated core residents remained clustered together, further suggesting that they might constitute new social units (Figure 2.14).

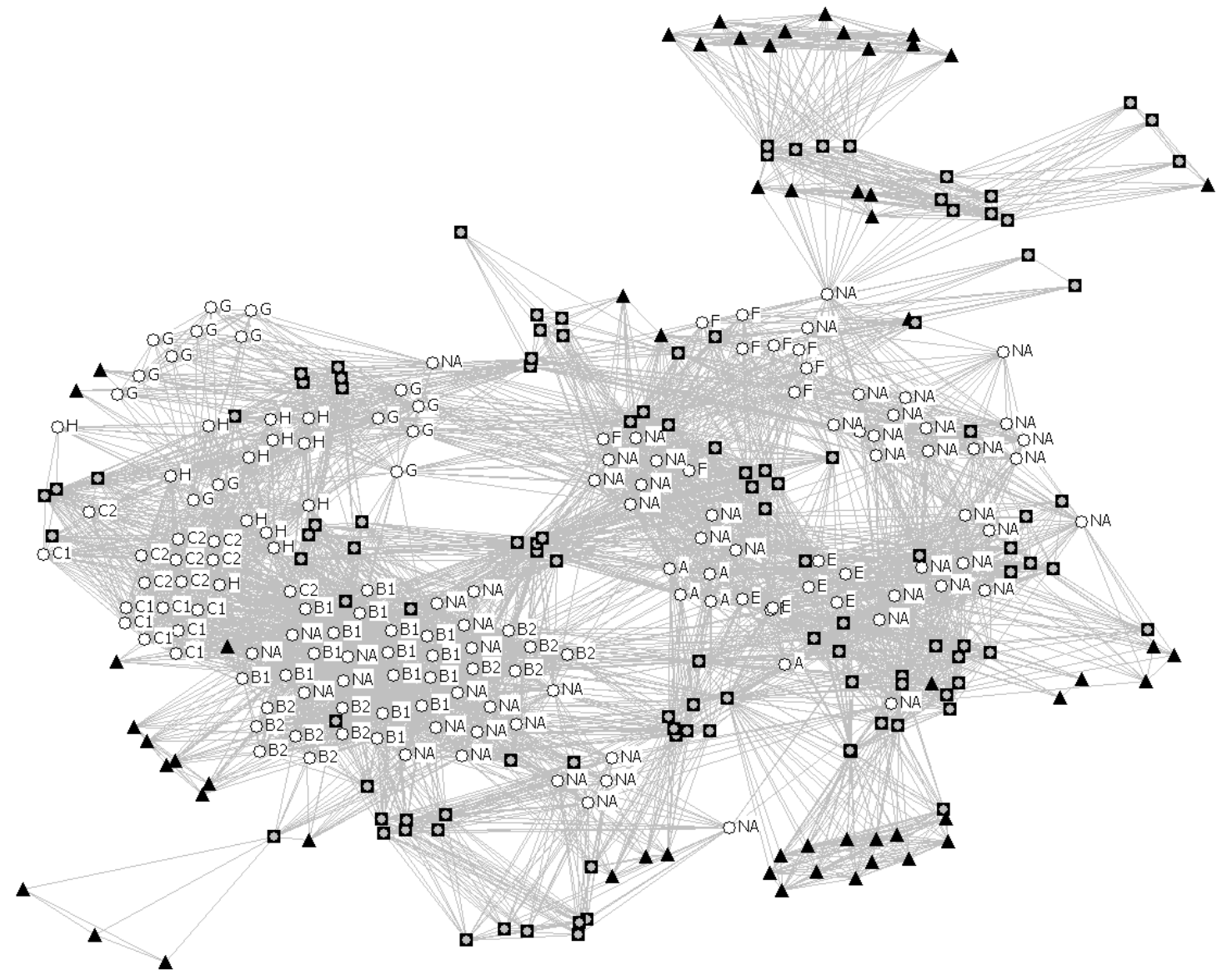

Figure 2.13. Social network diagram depicting all distinctive individuals documented off Hawai' $i$ Island that link back to the main social network. Visitors are depicted as black triangles, residents are depicted as gray squares and core residents are depicted as white circles; individuals assigned to units are labeled with their unit designation and core residents not allocated to a social unit are labeled "NA". 


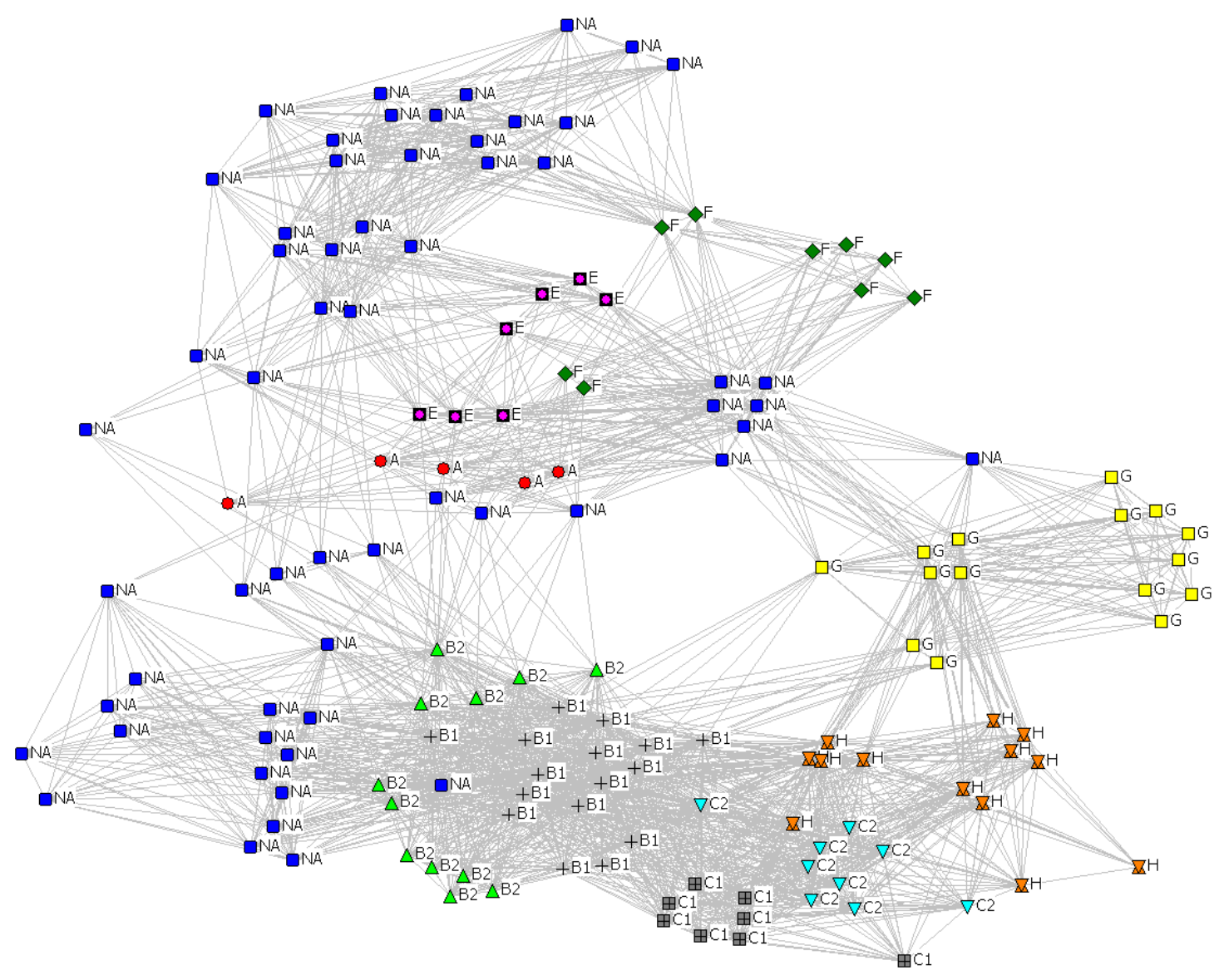

Figure 2.14. Social network diagram depicting core residents documented off Hawai' $i$ Island that link back to the main social network: Unit A (red circle), Unit B1 (black plus sign), Unit B2 (light green up triangle), Unit C1 (gray hatched box), Unit C2 (light blue down triangle), Unit E (pink boxed-circle), Unit F (dark green diamond), Unit G (yellow square) and Unit $\mathrm{H}$ (orange inverted triangles). Core residents not allocated to a social unit are shown as dark blue squares.

Socials units versus cluster analysis

In order to compare membership profiles between social units delineated using the key individual/constant companion criteria and clusters generated by maximizing modularity using the eigenvector-based method from network analysis, the original dendrogram generated from all distinctive individuals seen on more than four occasions (see Figure 2.9) was modified such that individuals that did not meet the minimum 
criteria for key individuals/constant companions were grayed-out (see Figure 2.15).

Removing the individuals that did not fit the key individual/constant companion criteria resulted in the complete elimination of four of the nine clusters and partial elimination of two additional clusters; one cluster remained completely intact and two clusters only lost one individual. It should be noted that one of the remaining clusters (Cluster 1) corresponded exactly to Unit B before it was subdivided in Units B1 and B2. 

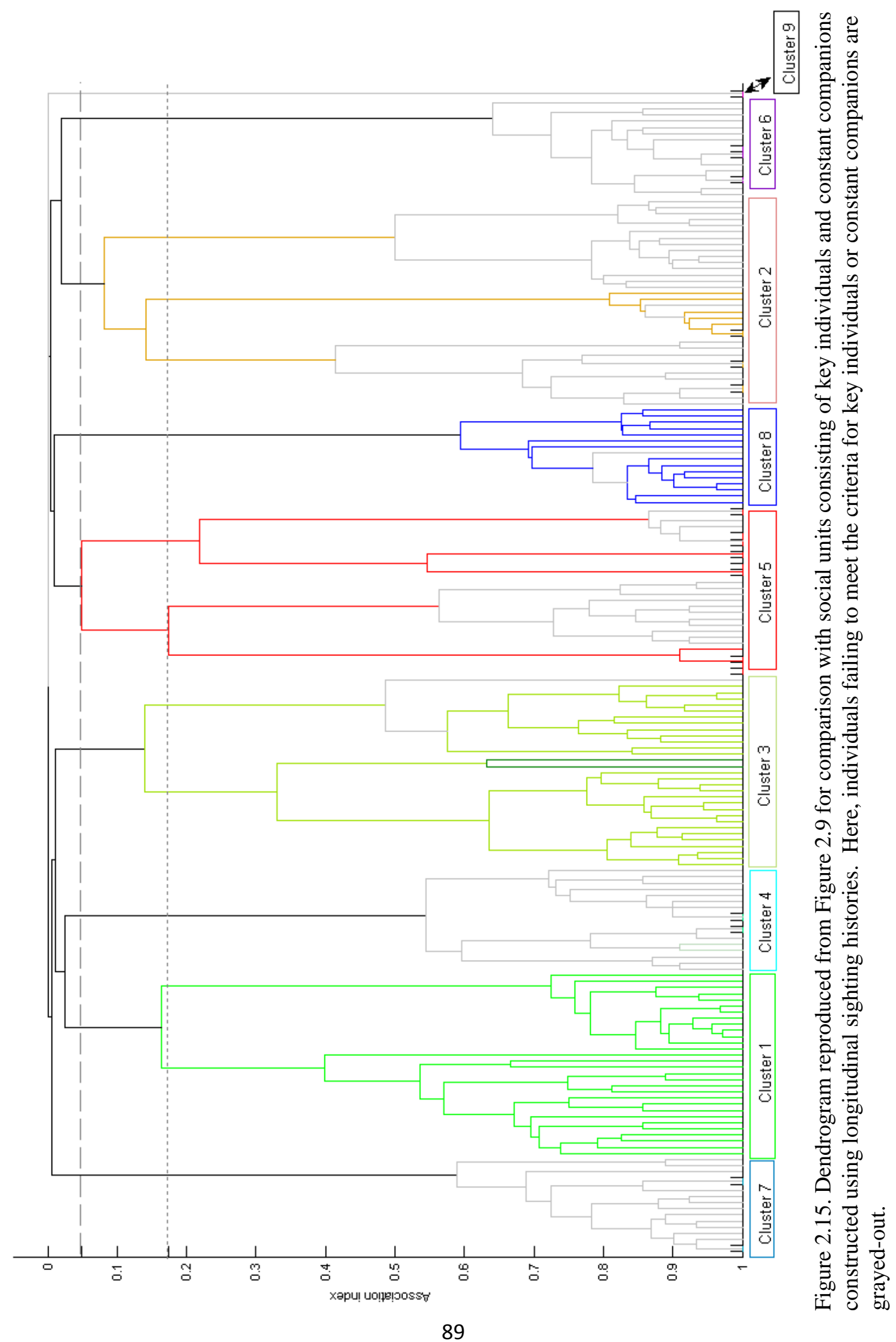
To further illustrate the difference between social units established using sighting histories and clusters established using eigenvector methods, a dendrogram was constructed using only key individuals and constant companions; individuals were then assigned to both social units and clusters (Figure 2.16). As mentioned above, key individuals and constant companions were divided into a total of nine social units using longitudinal sighting histories; application of the eigenvector-based method for community division resulted in six clusters, three that corresponded exactly to previously established social units and three that were each formed from merging two social units. When sub-cluster membership was compared to unit membership, results were very similar: sub-clustering successfully predicted unit membership with the exception of Units $\mathrm{C} 1$ and $\mathrm{C} 2$, which were combined into a single cluster.

Several features of sub-clusters were similar to those of units; sub-cluster size ranged from eight to 18 individuals (mean=12.1, $\mathrm{SD} \pm 3.7$ ) and nine of the 10 sub-clusters had an overall average association index $\geq 0.50$ (range: $0.48 \pm 0.14-0.84 \pm 0.02$ ). However, unlike unit membership which required that the majority of dyadic associations for each member be $\geq 0.50$, four of the 10 sub-clusters contained individuals (range 1-4) that failed to meet the $\geq 0.50$ criterion used to determine unit membership. Dyadic associations within sub-clusters were also more heterogeneous than those within units; minimum dyadic association indices within sub-clusters ranged from 0.06 to 0.76 with five of the 10 sub-clusters having a minimum dyadic association index $\leq 0.50$. It should be noted for the clusters in which within-cluster division was not supported, that, although all minimum association indices were below 0.50 (range $0.29-0.46$ ), the average association index for each cluster was $\geq 0.50$ (range $0.64-0.78$ ) and there were no dyadic associations 
that failed the criteria for unit membership, suggesting the clusters would meet unit membership criteria if they had sufficient sighting histories. 


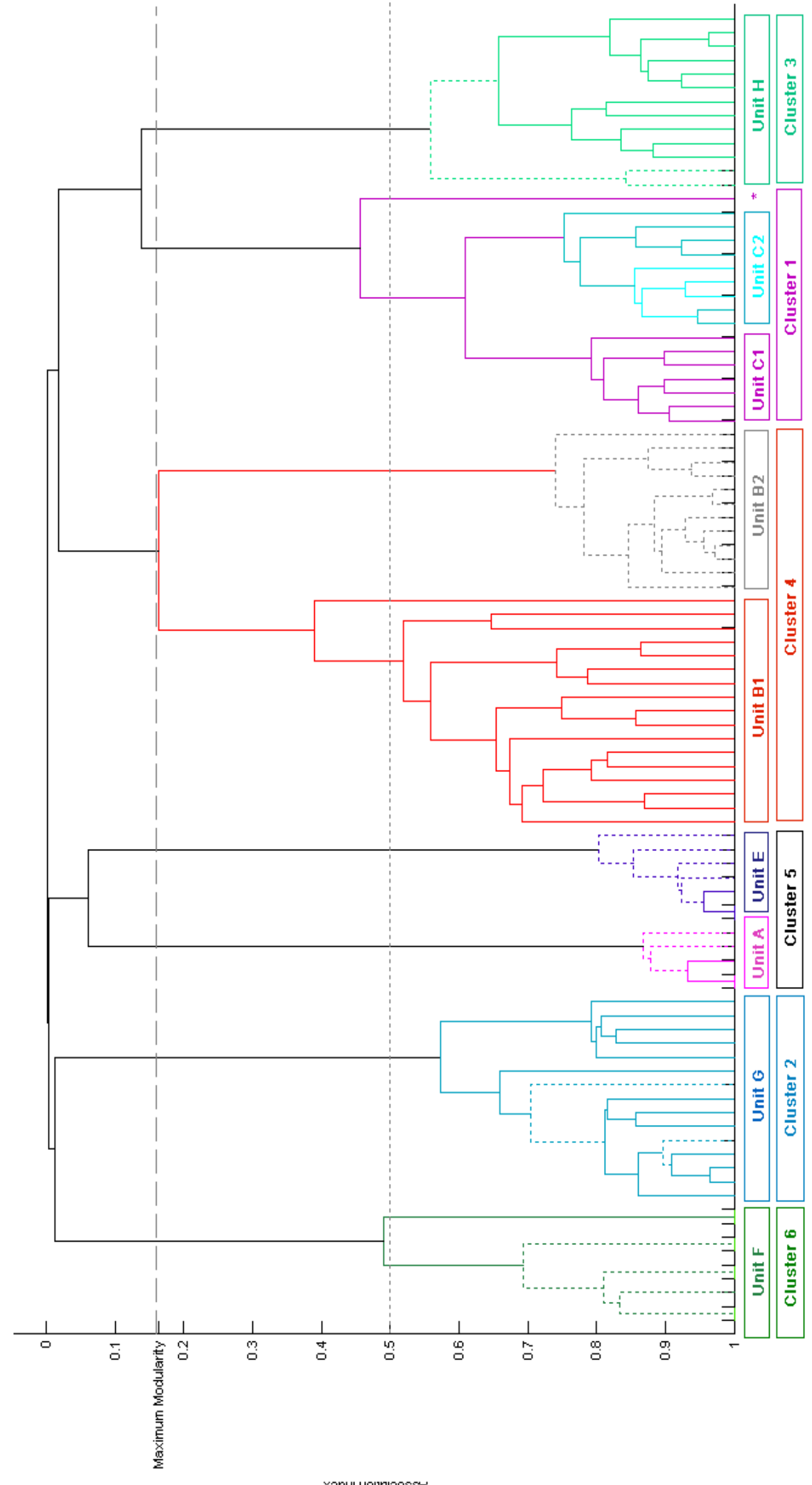

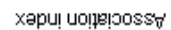

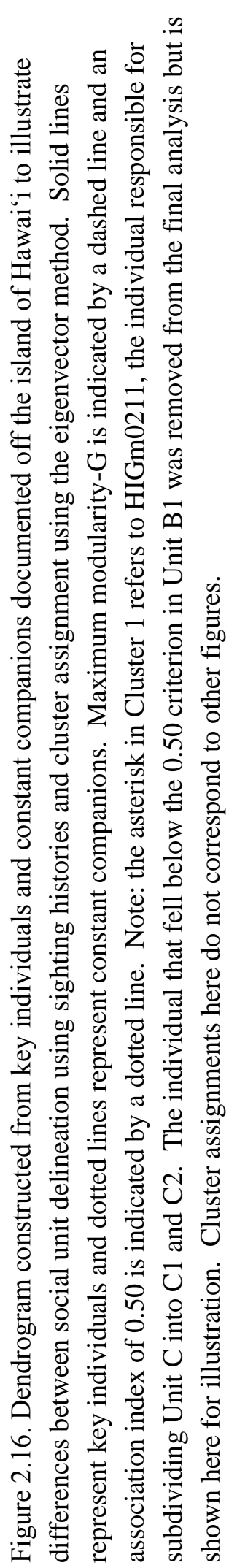




\section{Discussion}

Residency, site fidelity and differential patterns of habitat usage off the island of Hawai ' $i$ Individual short-finned pilot whales documented off the island of Hawai' $i$ exhibited dramatically different levels of site fidelity over the course of the study, suggesting heterogeneous usage of the study area. Individuals demonstrating strong, long-term fidelity to the area (such as one individual documented on 27 occasions in all five years of the study) indicated the presence of a core resident population off the leeward side of Hawai'i Island. However, individuals infrequently re-sighted also demonstrated some degree of site fidelity to the island and thus were considered residents, although unlike core residents their core range likely did not overlap substantially with that of the study area. As would be expected given the definitions of residency, the majority of core residents $(87.7 \%)$ were seen in $\geq$ three seasons over the course of the study, suggesting year-round presence in the study area, while only $13.3 \%$ of residents were documented in three or more seasons. Although measuring the length of time all individuals surveyed spent in the study area was not practical given the nature of the field research conducted, repeated identification of the same individuals over the course of a field project was indicative of the fact that some individuals remained associated with the leeward side of the island for an extended period of time (rather than just passing through), further supporting residency to the area.

Labeling individuals as core residents or residents did not imply that they never left the study area, however, and instead suggested that the majority of their time was 
spent off the island of Hawai' $i$. The lagged identification rate estimated that, on average, individuals spent 74.3 days in the study area and 56.6 days outside of the area, suggesting that individuals regularly traveled over a larger range than that covered during vessel surveys (Table 2.1). Indeed, individuals which were satellite tagged off the leeward side of the island of Hawai'i have been documented moving north of the study area into the Alenuihaha Channel separating the northern tip of the island of Hawai'i from Maui (Schorr et al. 2007), and individuals tagged in 2008 generally remained associated with the island (Baird et al. 2008c). Additionally, inter-island movements of short-finned pilot whales have been occasionally documented between the islands of Hawai'i and Kaua' $i$ using photo-identification, though such instances are infrequent. Given the paucity of inter-island re-sightings, it is more likely that short-finned pilot whales frequent all sides of the island of Hawai' $i$ (and are thus not present for many surveys).

Individuals seen only once were encountered in all seasons and in all years; however, $64.3 \%$ of the individuals that were only seen on a single occasion were first documented during the last two years of the study, indicating that there was a steady influx of new (i.e., previously undocumented) individuals into the area over the period of the study. Although the probability of these individuals being re-sighted differed depending on the point in the study when they were first identified (with those identified earlier being more demonstrative of individuals having no fidelity to the area), the fact that some individuals were not encountered until the latter portion of the study, despite significant survey effort, is also informative. However, it is important to note that individuals labeled visitors that appear within social clusters containing residents or core 
residents are likely ones that have only recently entered the marked population, or are members who died before the end of the study, thus limiting the number of times they could be documented.

With the exception of a single individual, all core residents were first identified in 2005 or earlier; the initial year sighted as presented here is conservative as many early sightings of core residents, residents and visitors were removed from the analysis due to photo quality restrictions. In contrast, the initial year sighted for visitors spanned the length of the study period with $36.6 \%$ of visitors first documented in or before 2005 ; the fact that more than a third of initial sightings of visitors were contemporary to those of core residents further emphasizes the differing levels of site fidelity and patterns of habitat usage exhibited by members of the study population. Despite unequal survey coverage, individuals were encountered and re-sighted in all months with effort.

Although not referred to as site fidelity, Heimlich-Boran (1993) reported a similar range of re-sighting rates for short-finned pilot whales off the island of Tenerife, with the number of sightings per individual ranging between one and 28 (mean=5.27, SE \pm 0.27$)$ over a 22-month study. Individuals in the Tenerife study population were considered resident if sighted more than once or in the company of other residents, ignoring any temporal components to an individual's sighting history. As such, direct comparisons regarding resident and visitor status cannot be made between the Heimlich-Boran (1993) study and the current study; however, it is apparent that new individuals were being identified throughout the study period and that some individuals off Tenerife exhibited a strong degree of residency. The residency documented in a portion of the study 
population off the island of Hawai' $i$ is in sharp contrast to habitat usage of long-finned pilot whales off the coast of Nova Scotia, which were estimated to remain in the study area for less than a day (Ottensmeyer 2001).

\section{Preliminary evidence of population structure}

Following Whitehead (2008b), a population is defined as a group of individuals in which the majority of interactions occur with other members within, rather than outside of, the group. The behaviorally-based definition of population introduced here is admittedly different from the geopolitical boundaries typically used to describe stocks for management purposes, and also does not take into account genetic or reproductive isolation commonly used to delineate population boundaries; however, in the absence of genetic information, association patterns may inform management decisions (e.g., Bigg 1982). Although additional research is needed to fully characterize the population structure of short-finned pilot whales in the Hawaiian archipelago, analysis of association patterns presented here in concert with current knowledge of movement patterns and habitat usage suggest the presence of both a demographically-independent islandassociated population and an offshore or pelagic population off the island of Hawai' $i$. The high degree of residency and site fidelity used to define core resident individuals off the island of Hawai' $\mathrm{i}$, combined with a lack of inter-island re-sightings, suggest core residents represent a separate, insular population. Preliminary evidence of multi-year within-island re-sightings of short-finned pilot whales off other islands within the main Hawaiian Islands (Baird et al. 2006, Baird et al. 2011), combined with a lack of interisland re-sightings, provide evidence of site fidelity to each island and support the 
existence of additional demographically-independent island-associated populations or sub-populations within the archipelago. The existence of multiple populations is evident for several species of odontocetes in the main Hawaiian Islands; insular and offshore populations have been described for false killer whales (Baird et al. 2009), and demographically independent island-associated populations have been described for common bottlenose dolphins (Baird et al. 2009, Martien et al. 2011), melon-headed whales (Aschettino et al. 2011), pantropical spotted dolphins (Courbis 2011) and spinner dolphins (Andrews et al. 2010).

Although community is a term commonly used in studies of social structure to describe social groupings of individuals, the lack of a consistent definition in the literature makes delineating communities in the core resident population more difficult and of questionable utility. For example, Whitehead (2008b) considers a community to be a group of behaviorally-isolated individuals where the majority of individuals associate with each other. In reference to fish-eating "resident" killer whales, Bigg et al. (1990) defines a community as a group of individuals in occasional association that occupy the same area. Under Bigg's definition, the island of Hawai'i core resident population would also be considered a community; however, given the small proportion of dyadic associations that have been documented, the core resident population would not be considered a community under Whitehead (2008b). Communities have commonly been described for species with a fission-fusion type of social structure, such as bottlenose dolphins (e.g., Wells 1991), that lack strong social differentiation. Even bottlenose dolphin communities differing from the typical fission-fusion model (Lusseau 
et al. 2003, Augusto et al. 2011) maintain associations with the majority of community members without clear community division. Long-finned pilot whales in the Strait of Gibraltar have been labeled a community by de Stephanis et al. (2008b) and their social structure likened to that of fish-eating "resident" killer whales in the temperate coastal eastern North Pacific; however, as the proportion of the study population documented in association has not been reported, it must be assumed that the majority of individuals were in occasional association based on the report of large temporary aggregations of several "pods." Therefore, while the core resident population could arguably be considered a community following Bigg et al.'s (1990) definition, the ambiguity surrounding the definition cautions against its usage here.

\section{Depth distribution and movements: potential influences of prey abundance}

Although detailed knowledge of preferred prey of short-finned pilot whales in the main Hawaiian Island is lacking due to the paucity of strandings in the area, and subsequent absence of stomach content analysis (Mazzuca et al. 1999), tattered squid remains occasionally observed during encounters with short-finned pilot whales off the island of Hawai'i suggest cephalopods represent a portion of their diet (Baird, pers. comm.). Additionally, cephalopods have been found in the diet of sperm whales and melon-headed whales (representing ten families and four families, respectively) in Hawai'i (Clarke \& Young 1996). While bathymetric challenges around the main Hawaiian Islands limit the sampling of benthic adult cephalopods necessary to measure distribution and diversity, knowledge of paralarvae can inform adult spawning characteristics (Bower et al. 1999). The most diverse paralarval assemblages of squid 
documented to date occur off the main Hawaiian Islands (Bower et al. 1999); enhanced feeding conditions are thought to influence increased spawning near the islands by bottom, nearshore and even oceanic species.

Short-finned pilot whales were observed throughout the study area; however, sighting densities were greatest between 1,500 and 2,500 m (Figure 2.3), corresponding to areas of steep bathymetric relief generally associated with high concentrations of cephalopods (Boyle \& Rodhouse 2005). Short-finned pilot whales off the island of Tenerife showed a significant preference for areas of steep slope and high relief, corresponding to areas of upwelling along the 1,000 m depth contour (Heimlich-Boran 1993); as with the current study, short-finned pilot whales were encountered in all months of the study, indicating that prey concentrations were likely sufficient to sustain individuals in that area year-round, although directed studies of prey distribution and abundance are lacking.

Despite effort extending up to $70.8 \mathrm{~km}$ from shore (12.9\% in water deeper than 3,000 m), short-finned pilot whales were never observed more than $25 \mathrm{~km}$ (Figure 2.2) from shore, or in water depths greater than 3,000 m (Figure 2.3), suggesting a strong association with the island. In contrast, short-finned pilot whales tagged off the island of O`ahu in October 2010 demonstrated dramatically different movement patterns and degrees of site fidelity; individuals tagged with a group that had been previously been

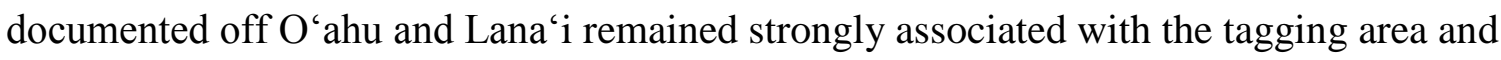
the slope for the duration of tag transmission (maximum=228 days), while individuals tagged with a group that had not previously been documented did not remain associated 
with the tagging area or slope, instead ranging beyond the Hawaiian EEZ (Baird et al. 2011). Such disparate movement patterns and depth preferences observed for individuals tagged off the islands of $\mathrm{O}^{`}$ ahu and Kaua' $\mathrm{i}$ further indicate differential patterns of habitat usage and suggest that island-specific resident and visitor communities may exist off other islands within the Hawaiian archipelago.

\section{Distinctiveness}

A population-wide distinctiveness estimate for the current study of $80.5 \%$ is substantially higher than all of the other pilot whale studies reviewed here, with the possible exception of the Heimlich-Boran (1993) study (see Appendix C). While it is possible that the Hawaiian population of short-finned pilot whales are more distinctive in general, differing calculation methods and the advantage of digital high-resolution photography are likely partially responsible, especially when considering the Shane \& McSweeney (1990) study. Although higher than the other pilot whale studies reviewed here, the proportion of the study population estimated to be distinctive is likely conservative as slightly distinctive individuals have been repeatedly (and in some cases consistently) re-sighted between years using good and excellent-quality photos, as have individuals with clean fins. In some cases, match confirmation required additional markings beyond the leading or the trailing edge of the dorsal fin, such as saddle pigmentation patterns or persistent scars; however, scarring was only used to aid in confirmation of a match, and never to deny a match since it was not known which scars were ephemeral. 
Following similar methodologies, the proportion of the study population considered distinctive was greater than many other species in Hawai'i such as melonheaded whales (median=61.8\%, CV=0.06, $n=6)$ (Aschettino et al. 2011) and pygmy killer whales (mean=73.7\%, SD $\pm 22.8 \%, n=79)$ (McSweeney et al. 2009), and may indicate more frequent or aggressive interactions with predators or conspecifics.

\section{Mark changes}

The rate of mark change (once every 2.9 to 3.5 years) for re-sighted short-finned pilot whales in the current study was higher than that of many other Hawaiian species (Baird et al. 2008b, McSweeney et al. 2009, Aschettino et al. 2011) (see also Appendix B). This could either indicate a real difference in the rate of injury between species, or reflect the ability to detect mark changes due to high re-sighting rates of short-finned pilot whales. Given a high rate of mark change within the study population, failure to recognize mark-change events could have a significant impact by altering observed association patterns and artificially inflating the catalog. In particular, mark changes in non-distinctive individuals such as calves have a greater probability of not being recognized (or reconciled), and will artificially truncate the sighting record and association history of a mother/calf pair. While the majority of mark changes should be recognized by an experienced photo-identification matcher, dramatic mark-change events significantly alter the appearance of the dorsal fin and carry a greater potential for missed matches; such mark changes may be impossible to reconcile with previous sightings and should always be acknowledged as a limitation of photo-identification catalogs. Dramatic mark-change events were documented on several individuals in the study 
population and, in such cases, secondary characteristics such as pigmentation patterns were used to confirm matches. However, although it is acknowledged that missed matches might still exist in the study population, the ability to use association patterns to predict the presence of certain individuals increases the probability of identifying an individual that has undergone a dramatic mark-change event.

Although not quantitatively analyzed here, the presence of a saddle patch and post-orbital eye blaze were noted for several individuals within the study population. Providing opportune lighting conditions, the saddle patch was used in certain instances to offer additional confirmation of a match; however, the post-orbital eye blaze was never used as a diagnostic aid. Similar to the short-finned pilot whales documented in the current study, and unlike those off Japan (Yonekura et al. 1980), the population off Tenerife was reported to have non-distinctive saddle patches (Heimlich-Boran 1993), though they did have distinct post-orbital eye blazes. Shane \& McSweeney (1990) noted that the saddle patterns of the Hawaiian population are only truly visible underwater; while an obvious contrast between pigmentation patterns was evident in underwater photos from the current study, saddle patterns were also clearly defined above the surface with excellent lighting conditions. Although Auger-Méthé \& Whitehead (2007) suggest that adding saddle patch identification in the photo-identification protocol would double the proportion of individuals identified in the Nova Scotia population, the faint appearance of the saddle patch in the Hawaiian population, requiring excellent lighting conditions to be seen, cautions against its use as anything other than a secondary matching aid. 
The diversity of mark types documented in the study population imply a number of different sources. Possible causes of disfigurement include: tooth-rake marks caused by interactions with conspecifics, circular or oval scars from cookie cutter sharks, large scarring patterns suggesting bite impressions from predators such as sharks and possibly killer whales, deep depressions in the back and peduncle from anthropogenic sources such as boat propellers, and all or part of the dorsal shaved off indicating fishing line injuries. The frequencies with which fresh and healed wounds from cookie cutter sharks and tooth-rake marks from conspecifics are seen on individuals off Hawai' $i$ indicate that injurious interactions with predators and other members of the population are fairly commonplace. For further discussion of mark changes, see Appendix B.

Characteristics of the individual: examining differences in association patterns and gregariousness

Analysis of short-finned pilot whale association patterns off the island of Hawai ${ }^{\circ} i$ using both quantitative techniques and social network analysis indicated a welldifferentiated society demonstrating strong long-term and short-term preferential associations. The strength of association indices found among members of the study population, as indicated by an average maximum dyadic association index of 0.91 , suggests the importance of strong inter-individual bonds within the population. Indeed, strong dyadic associations were not prescriptive homogeneous associations; despite the fact that all individuals within the study population were documented in the same area (with $71.9 \%$ linking to the main social cluster, see Figure 2.5), individuals were only documented in association with a small fraction of possible associates. Further analysis 
indicated that few casual associations existed and that the majority of associations were preferential in nature (Table 2.5). Similarly, preferential associations were found among long-finned pilot whales off the coast of Nova Scotia (Ottensmeyer \& Whitehead 2003) and in the Strait of Gibraltar (de Stephanis et al. 2008b), although information on differing levels of individual gregariousness was not available from either study. Ottensmeyer (2001) also noted that the majority of possible associations between individuals were never documented (as is the case with the current study); however, unlike the current study, the maximum association index for some members of her study population was low, suggesting no consistent associates. Ottensmeyer (2001) reasoned that strong associations may still exist for those individuals with low maximum association index values, and it seems reasonable given photographic limitations that not all potential associates were documented (see Appendix C).

Individuals within the study population also demonstrated differences in gregariousness, with some individuals consistently found in large or small groups. Reasons for the differences in individual sociality are unknown and could be associated with specific age/sex classes (as found in wild chimpanzees; Pepper 1999), or indicative of relative social standing within the population. Individuals included in the analysis were largely thought to belong to the adult or sub-adult age class; however, age class estimation was based on qualitative rather than quantitative methods. From a logistical perspective, individual differences in gregariousness can negatively impact an individual's sighting history, as larger groups probably have a somewhat higher 
probability of being spotted in the field. Thus, it is possible hyper-social individuals have a higher probability of being documented in the field than less social individuals. Detecting community structure: hierarchical cluster analysis and temporal methods

Social network analysis supported the division of the study population into nine socially meaningful clusters of varying size and association strength. The mean association index within clusters $(\mathrm{AI}=0.48 \pm 0.20$ ) was similar to the $50 \%$ criterion used to designate pod membership in killer whales in the coastal eastern North Pacific (Bigg et al. 1990), and thus could be indicative of persistent social groups. However, although the mean number of individuals assigned to each social cluster was similar to the mean group size estimated in the field, within-cluster mean association indices ranged from 0.27 to 0.78 , suggesting that social clusters (and thus groups encountered in the field) were broadly representative of preferential associations among specific individuals, but were not necessarily indicative of strongly cohesive groups within the study population. Given the wide range in membership and association strengths among clusters, it is likely that some social clusters were aggregations of one or more smaller more cohesive groupings. Indeed, sub-clustering was only supported for the social clusters that had a mean association index $<0.50$; resulting sub-cluster membership (range 8-18) was smaller than the mean group size estimated in the field, and mean association indices ranged from 0.48 to 0.84 , indicating that clusters with a mean association index $<0.50$ likely contained multiple, smaller cohesive social groups.

When compared to social units constructed using shared sighting histories rather than social network analysis, mean membership and association index ranges were 
similar for both sub-clusters and for clusters where sub-clustering was not supported. However, although sub-clusters were similar in size and membership to units, they also contained peripheral individuals that only strongly associated with some members of the sub-cluster and maintained weak associations with other members, suggesting subclusters are slightly less conservative than units. Whether peripheral individuals represent new additions to the social cluster or long-term associates with newly-acquired markings that have just entered the marked population (such as calves or juveniles) is not known, and will require future research effort. The results suggest that considering the temporal aspects of social structure is important in predicting longitudinally-stable social units; however, in the absence of unit information, sub-clusters may serve as a reasonable proxy for determining cohesive social groups.

One of the limitations of the current analysis is that by restricting analyses only to distinctive individuals, potential associations between unmarked individuals (such as most calves, juveniles and some sub-adults) and the rest of the study population are not taken into account. Short-finned pilot whales were frequently encountered off the island of Hawai' $i$ in groups of mixed sex and age (but see Table 2.10), suggesting that social cluster and social unit sizes presented here are likely conservative and membership is biased toward older individuals. Considering the overall distinctiveness of the study population, it is possible that true mean social unit membership is closer to 12.5 individuals. Given the discrepancy between the mean group size encountered in the field and the mean cluster, sub-cluster and unit sizes, groups encountered likely represent multiple social units in temporary association. This assumption has also been suggested 
by Ottensmeyer \& Whitehead (2003) for units of long-finned pilot whales, but is contrary to one made by de Stephanis et al. (2008b), which is that groups encountered in the field are most likely representative of pods akin to those documented in killer whales in the coastal eastern North Pacific. As such, de Stephanis et al. (2008b) cited similar mean group sizes between long-finned pilot whales in the Strait of Gibraltar (mean=14, SD \pm 18 ) and pods of fish-eating killer whales in the coastal eastern North Pacific (mean=12, range: 3-50; Bigg et al. 1990); however, although units satisfied the criterion for pods, it was unclear whether groups encountered in the Strait were also behaviorally consistent with killer whale pods (i.e., spent $\geq 50 \%$ of their time in association). Mean group sizes were roughly $25 \%$ higher in the current study and off Nova Scotia (mean=20.7, SD \pm 9.6 ; mean $=20, S D \pm 18$, respectively) than the Strait of Gibraltar study, and could indicate differences in social structure or ecology between populations.

Although the spatial distribution of individual short-finned pilot whales within an encounter was not documented in the field, preliminary evidence from the timestamp, nearest neighbor, and sequence of photos taken suggests that within-encounter clustering of social groups occurs, and should be considered in future analyses.

Detecting community structure: comparisons to other studies

Despite more than a three-fold difference in mean unit size between the current study and Ottensmeyer \& Whitehead's (2003) study (mean=10.44, SD \pm 3.74 ; mean=3, $\mathrm{SD} \pm 1.3$, respectively), when scaled by the proportion of non-distinctive individuals within each study population this difference decreases substantially (mean=12.5; mean $=8.0(95 \%$ confidence intervals of the mean $(8.0-8.9),(7.7-8.6)$, respectively). 
Ottensmeyer \& Whitehead (2003) further used the point at which the SLAR curve stabilized to determine the proportion of individuals present in a group that are actually long-term companions; when scaled again by the proportion of distinctive individuals in the study population, the unit size was estimated to be 11-12 individuals, similar to the mean unit size estimate from the current study. However, while multiple SLAR curves were generated for the current study, none demonstrated a period of decline followed by stabilization, preventing application of the methodology used by Ottensmeyer \& Whitehead (2003) to generate unit size; as such, unit size comparisons between the two studies should be viewed cautiously. Mean unit size was similarly lower in the Strait of Gibraltar study (de Stephanis et al. 2008b) than in the current study, although limited inferences can be drawn as results were not scaled by the proportion of distinctive individuals. Mean association indices for social units in the Strait of Gibraltar study ranged from $0.39 \pm 0.04$ to $0.87 \pm 0.04$ and were similar to the current study; de Stephanis et al. (2008b) further distinguished between units with high mean association indices (presumably units with AIs $\geq 0.76 \pm 0.07$ ) as single "line units," and those with lower mean association indices (presumably units with AIs $\leq 0.63 \pm 0.00$ ) as consisting of multiple line units. Unfortunately, the only other multi-year study on short-finned pilot whales (Heimlich-Boran 1993) utilized different methodology and cannot be directly compared to the current study; however, following assumptions that $85 \%$ of the study population was considered distinctive and that clustering methods yielded similar results, Ottensmeyer \& Whitehead (2003) estimated that the majority of Heimlich-Boran's (1993) "pods" contained 11 or fewer individuals. 
Interpreting the social and ecological significance of clusters and units

Results presented here indicate that units represent persistent social entities; however, the social and ecological significance of these units remains unclear. As mentioned earlier, previous studies have suggested that pilot whales may exhibit natal group philopatry, a type of stable matrilineal social structure implying relatedness between members of both sexes within the natal group (Heimlich-Boran 1993, Ottensmeyer \& Whitehead 2003, de Stephanis et al. 2008b). Short-finned pilot whales in the current study demonstrated a strong degree of social cohesion characteristic of pods of killer whales in the coastal eastern North Pacific; however, genetic relatedness of unit members in Hawai' $i$ is unknown. While it is tempting to infer genetic relatedness among Hawai ${ }^{\prime} i$ unit members based on similarities in group composition (i.e., groups of mixed age and sex) and association strength (i.e., in association more than $50 \%$ of the time) to that of killer whale pods, even mother-calf pairs can only cautiously be assumed.

Although groups encountered in the field were often of mixed age and sex, qualitative assignment of age and sex to individuals within each social unit indicated that there may be some segregation between adult males and female/calf pairs, or that adult males may disperse from their natal groups (Table 2.10). More than half of the social units did not have calves or juveniles documented in association with an adult; however, the majority of social units where calves and juveniles were present also contained adult males, suggesting social dynamics differ among units. The largest social unit defined in the study, Unit B1, was the only unit where adult males were not identified; conversely, Unit B1 also contained almost twice as many female/calf pairs as the other units. In 
discussing the structure of B1 it is important to note that Units B1 and B2 were initially defined as a single unit; however, pronounced differences in association levels within this unit supported unit division. In contrast to Unit B1, three of Unit B2's members were thought to be adult males and no adult females, juveniles or calves were identified in the unit. Thus, while Units B1 and B2 both appear to exhibit some degree of within-unit age and sex-based segregation, they also maintain inter-unit associations, suggesting bonds between units are socially important. The inter-unit association between Units B1 and B2 is supported by the fact that multiple units have been documented in association and may help explain why individuals off the island of Hawai' $i$ were commonly observed in groups of mixed sex and age.

The age and sex-based segregation observed within several of the units in Hawai' $i$ is seemingly in contrast to a study of long-finned pilot whales in the Strait of Gibraltar, where five of the six units for which the sex of some unit members was known contained both males and females (de Stephanis et al. 2008b). Additionally, although no information was provided regarding the possible age of the genetically-sexed individuals within the Strait of Gibraltar (or the presence of calves or juveniles within units), malefemale associations were found to be the most common (de Stephanis et al. 2008b). Differences in age and sex-based segregation may indicate a difference between the social structure of long-finned and short-finned pilot whales, or may simply indicate a difference among populations.

Genetic analysis of relatedness within grinds of long-finned pilot whales in the Faroe Islands identified multigenerational matrilines (membership range: 2-27, 
mean $=4.5, n=11$ ), with mother-calf relationships documented between both adult males and adult females, providing some evidence for natal group philopatry (Fullard et al. 2000). Based on the assumption by Fullard et al. (2000) that the size of the matrilines identified in the Faroese grinds would likely increase with the identification of shared ancestors (by allowing related matrilines to be joined into extended matrilines), Ottensmeyer \& Whitehead (2003) suggested that units of long-finned pilot whales in Nova Scotia represented extended matrilines. Similarly, de Stephanis et al. (2008b) suggested that line units identified in the Strait of Gibraltar study population represented stable matrilines comparable to those found in within pods of killer whales in the coastal eastern North Pacific (Bigg et al. 1990).

Although complimentary genetic and behavioral studies have not been conducted on the same pilot whale population as they have with killer whales (Bigg et al. 1990, Ford et al. 2011), genetic evidence of natal group philopatry occurring in long-finned pilot whale populations in both the northern and southern hemispheres (Amos et al. 1993a, Fullard et al. 2000, Oremus 2008), and behavioral evidence of persistent social groups of mixed age and sex in long-finned (Ottensmeyer \& Whitehead 2003, de Stephanis et al. 2008b) and short-finned pilot whales (Heimlich-Boran 1993), provide preliminary evidence that long-finned pilot whales exhibit natal group philopatry. However, the suggestion by Amos et al. (1993) and Fullard et al. (2000) that grinds of long-finned pilot whales represent an extended matrilineal group demonstrating persistent associations similar to pods of killer whales in the coastal eastern North Pacific has been questioned (Connor 2000, Ottensmeyer \& Whitehead 2003, Oremus 2008). Indeed, 
Oremus (2008) identified multiple unrelated matrilines within stranded groups of longfinned pilot whales in New Zealand; while differences in study populations and possible inherent differences in social structure cannot be ignored, the use of microsatellite markers facilitated direct comparisons between New Zealand and portions of the Faroese Islands study. As such, Oremus (2008) suggested that while natal group philopatry has been demonstrated within matrilines, multiple matrilines in association do not necessarily indicate relatedness. This is an important distinction between pilot whale social structure(s) and that of killer whales in the coastal eastern North Pacific, and may indicate an intermediate social structure between sperm whales and killer whales.

\section{Implications for conservation and management}

Short-finned pilot whales in Hawaiian waters are currently managed as a single stock and it is not known whether population subdivision exists (Carretta et al. 2011). Shipboard (Barlow 2006) and aerial surveys (Mobley et al. 2000) have indicated that short-finned pilot whales are abundant throughout the main Hawaiian Islands, however, these abundance estimates assume that the whales surveyed exist as a single population, rather than multiple independent demographic units, as has been found for several species of odontocetes in Hawai'i (Baird et al. 2008a, b, 2009, McSweeney et al. 2009, Aschettino et al. 2011, Courbis 2011, Martien et al. 2011). As Baird et al. (2008a) suggested, applying abundance estimates from the entire Hawaiian EEZ to portions of the population potentially demonstrating restricted ranges may result in an underestimate of the level of anthropogenic risks affecting that population; thus, detailed knowledge of population structure is necessary to inform management decisions. The presence of a 
small, core resident population of short-finned pilot whales off the island of Hawai' $i$ could therefore indicate an elevated risk to anthropogenic threats such as high levels of commercial and recreational vessel traffic, targeted tourist activities such as dolphin watching and swim-with-dolphin programs (Danil et al. 2005), and increased exposure to mid-frequency naval sonar (Southall et al. 2006). Additionally, the island of Hawai'i has the highest level of commercial and sports troll fisheries in the main Hawaiian Islands (Baird et al. 2008a), and short-finned pilot whales have been observed being either mildly or seriously injured (as defined by Anderson 2008) in deep-set longline (DSLL) fisheries operating within and outside of the Hawaiian EEZ on eight occasions between 2004 and 2008 (McCracken 2009, Forney 2010, Carretta et al. 2011). Although only one of the DSLL injuries occurred within the Hawaiian EEZ during the years of observation effort (2004-2008), observer coverage ranged from $20 \%$ to $28 \%$, suggesting the number of individuals taken in DSLL fisheries is higher.

In addition to management concerns associated with individuals demonstrating restricted ranges, Williams \& Lusseau (2006) noted the importance of considering social structure when formulating effective management plans. Using social network analysis, Williams \& Lusseau (2006) simulated removal of random and targeted individuals from the coastal eastern North Pacific population of killer whales known to demonstrate natal group philopatry. Results of Williams \& Lusseau's (2006) analysis indicated that while removal of random individuals did not fracture the social network, targeted removal of individuals (as would be expected in a live-capture scenario) caused the network to splinter into smaller groups. Short-finned pilot whales in Hawaiian waters are not at risk 
of live capture; however, this analysis does suggest that, as a strongly matrifocal species similar to killer whales, loss of key individuals within the social unit (e.g., as a result of fishery interactions) could weaken unit stability. As a small resident population demonstrating strong group cohesiveness, short-finned pilot whales off the island of Hawai'i many warrant special management considerations. 


\section{Literature Cited}

Abend, A. G., \& Smith, T. D. (1999). Review of distribution of the long-finned pilot whale (Globicephala melas) in the North Atlantic and Mediterranean. NOAA Technical Memorandum NMFS-NE-117.

Aguilar, A., Jover, L., \& Borrell, A. (1993). Heterogeneities in organochlorine profiles of Faroese long-finned pilot whales: indication of segregation between pods? In G.P. Donovan, C.H. Lockyer, \& A.R. Martin (Eds.). Report of the International Whaling Commission (Special Issue) 14, 359-367.

Amos, B., Barrett, J., \& Dover, G. A. (1991). Breeding system and social structure in the Faroese pilot whale as revealed by DNA fingerprinting. In A. R. Hoelzel (Ed.). Report of the International Whaling Commission (Special Issue), 13, 255-268.

Amos, B., Bloch, D., Desportes, G., Majerus, T.M.O., Bancroft, D.R., Barrett, J.A., \& Dover, G.A. (1993b). A review of the molecular evidence relating to social organisation and breeding system in the long-finned pilot whale. Report of the International Whaling Commission (Special Issue) 14, 209-217.

Amos, B., Schlötterer, C., \& Tautz, D. (1993a). Social structure of pilot whales revealed by analytical DNA profiling. Science, 260, 670-672.

Andersen, L.W. (1988). Electrophoretic differentiation among local populations of the long-finned pilot whale, Globicephela melaena, at the Faroe Islands. Canadian Journal of Zoology, 66, 1884-1892.

Andersen, L.W. (1993). Further studies on the population structure of the long-finned pilot whale, Globicephala melas, off the Faroe Islands. Report of the International Whaling Commission (Special Issue) 14, 219-231.

Andersen, M.S., Forney, K.A., Cole, T.V.N., Eagle, T., Angliss, R., Long, K., Barre... Engleby, L. (2008). Differentiating serious and non-serious injury of marine mammals: report of the serious injury technical workshop, 10-13 September 2007, Seattle, Washington. NOAA Technical Memorandum NMFS-OPR-39.

Andrews, K. R., Karczmarski, L., Au, W. W. L., Rickards, S. H., Vanderlip, C. A., Bowen, B. W. ...Toonen, R. J. (2010). Rolling stones and stable homes: social structure, habitat diversity and population genetics of the Hawaiian spinner dolphin (Stenella longirostris). Molecular Ecology, 19, 732-748.

Aschettino, J. M., Baird, R. W., McSweeney, D. L., Schorr, G. S., Huggins, J. L., Martien, K. K., ...West, K. L. (2011). Population structure of melon-headed whales (Peponocephala electra) in the Hawaiian Archipelago: evidence of 
multiple populations based on photo-identification. Marine Mammal Science. doi: 10.1111/j.1748-7692.2011.00517.x

Auger-Méthé, M., \& Whitehead, H. (2007). The use of natural markings in studies of long-finned pilot whales (Globicephala melas). Marine Mammal Science, 23, 7793.

Augusto, J. F., Rachinas-Lopes, P., \& dos Santos, M. E. (2011). Social structure of the declining resident community of common bottlenose dolphins in the Sado Estuary, Portugal. Journal of the Marine Biological Association of the United Kingdom. doi:10.1017/S0025315411000889

Baird, R. W. (2000). The killer whale: Foraging specializations and group hunting. In J. Mann, R. C. Connor, P. L. Tyack, \& H. Whitehead (Eds.). Cetacean societies: field studies of dolphins and whales. (pp. 127-153). Chicago: The University of Chicago Press

Baird, R. W. (2009). A review of false killer whales in Hawaiian waters: biology, status, and risk factors. Report prepared for the U.S. Marine Mammal Commission under Order No. E40475499.

Baird, R. W., \& Dill, L. M. (1995). Occurence and behavious of transient killer whales: seasonal and pod-specific variability, foraging behaviour, and prey handling. Canadian Journal of Zoology, 73, 1300-1311.

Baird, R. W., Gorgone, A. M., McSweeney, D. J., Webster, D. L., Salden, D. R., Deakos, M. H., ... Mahaffy, S. D. (2008b). False killer whales (Pseudorca crassidens) around the main Hawaiian Islands: long-term site fidelity, inter-island movements, and association patterns. Marine Mammal Science, 24, 591-612.

Baird, R. W., Gorgone, A. M., McSweeney, D. J., Ligon, A. D., Deakos, M. H., Webster, D. L., ... Mahaffy, S. D. (2009). Population structure of island-associated dolphins: evidence from photo-identification of common bottlenose dolphins (Tursiops truncatus) in the Main Hawaiian Islands. Marine Mammal Science, 25, 251-274.

Baird, R. W., Schorr, G. S., Mahaffy, S. D., Aschettino, J. A., \& Cullins, T. (2011). Movements and spatial use of satellite-tagged odontocetes in the western main Hawaiian Islands: results of field work undertaken off $\mathrm{O}^{\prime}$ ahu in October 2010 and Kaua'i in February 2011. Annual progress report under Grant No. N00244-10-10048 from the Naval Postgraduate School.

Baird, R. W., Schorr, G. S., Webster, D. L., Mahaffy, S. D., Douglas, A. B., Gorgone, A. M., \& McSweeney, D.J. (2006). A survey for odontocete cetaceans off Kaua'i and $\mathrm{Ni}$ 'ihau, Hawai' $\mathrm{i}$, during October and November 2005: evidence for population 
structure and site fidelity. Report to Pacific Islands Fisheries Science Center, NOAA Fisheries, under Order No. AB133F05SE5197 with additional support from the Marine Mammal Commission and Dolphin Quest.

Baird, R. W., Schorr, G. S., Webster, D. L., McSweeney, D. J., Hanson, M. B., \& Andrews, R. D. (2008c). Multi-species cetacean satellite tagging to examine movements in relation to the 2008 Rim-of-the-Pacific (RIMPAC) naval exercise. A quick look report on the results of tagging efforts undertaken under Order No. D1000115 from the Woods Hole Oceanographic Institution.

Baird, R. W., Webster, D. L., Mahaffy, S. D., McSweeney, D. J., Schorr G. S., \& Ligon, A. D. (2008a). Site fidelity and association patterns in a deep-water dolphin: rough-toothed dolphins (Steno bredanensis) in the Hawaiian Archipelago. Marine Mammal Science, 24, 535-553.

Baird, R. W., \& Whitehead, H. (2000). Social organization of mammal-eating killer whales: group stability and dispersal patterns. Canadian Journal of Zoology, 78, 2096-2105.

Barlow, J. (2006). Cetacean abundance in Hawaiian waters estimated from a summer/fall survey in 2002. Marine Mammal Science, 22, 446-464.

Baker, C. S., Perry, A., \& Herman, L. M. (1987). Reproductive histories of female humpback whales, Megaptera novaeangliae, in the North Pacific. Marine Ecology Progress Series, 41, 103-14.

Balbuena, J. A., \& Raga, J. A. (1994). Intestinal helminthes as indicators of segregation and social structure of pods of long-finned pilot whales (Globicephala melas) off the Faeroe Islands. Canadian Journal of Zoology, 72, 443-448.

Barlow, J. (2006). Cetacean abundance in Hawaiian waters estimated from a summer/fall survey in 2002. Marine Mammal Science, 22, 1-19.

Bellière, E. N., Esperón F., Fernández A., Arbelo, M., Muñoz, M. J., \& SánchezVizcaíno, J. M. (2010). Phylogenetic analysis of a new Cetacean morbillivirus from a short-finned pilot whale stranded in the Canary Islands. Research in Veterinary Science, 90 (2), 324-328.

Bejder, L., Fletcher, D., \& Bräger, S. (1998). A method for testing association patterns of social animals. Animal Behaviour, 56, 719-725.

Bernard, H. J., \& Reilly, S. B. (1999). Pilot whales, Globicephala Lesson, 1828. In S. H. Ridgway, \& R. Harrison (Eds.). Handbook of marine mammals, Vol. 6. (pp. 245279). Orlando, FL: Academic Press.

Best, P. B. (1979). Social organization of sperm whales, Physeter macrocephalus. In H. 
E. Winn, \& B. L. Olla (Eds.). Behavior of marine animals, Vol. 3. (pp. 227-289). Plenum, New York: Plenum Press.

Bigg, M. (1982). An assessment of killer whale (Orcinus orca) stocks off Vancouver Island, British Columbia. Report of the International Whaling Commission 32, $655-666$.

Bigg, M. A., Olesiuk, P. F., Ellis, G. M., Ford, J. K. B., \& Balcomb, K. C. (1990). Social organization and genealogy of resident killer whales (Orcinus orca) in the coastal waters of British Columbia and Washington State. In P.S. Hammond, S. A. Mizroch, \& G. P. Donovan (Eds.). Report of the International Whaling Commission (Special Issue 12), 383-405.

Bloch, D., Desportes, G., Mouritsen, R., Skaaning, S., \& Stefansson, E. (1993). An introduction to studies of the ecology and status of the long-finned pilot whale (Globicephala melas) off the Faroe Islands, 1986-1988. Report of the International Whaling Commission (Special Issue 14), 1-32.

Bower, J. R., Seki, M.P, Young, R.E., Bigelow, K.A., Hirota, J., \& Flament, P. (1999). Cephalopod paralarvae assemblages in Hawaiian Islands waters. Marine Ecology Progress Series, 185, 203-212.

Boyle, P., \& Rodhouse, P. (2005). Cephalopods: ecology and fisheries. Oxford: Blackwell Publishing.

Bryant, P. J., Lafferty, C. M., \& Lafferty, S. K. (1984). Reoccupation of Laguna Guerrero Negro, Baja California, Mexico, by gray whales. In M. L. Jones, S. L. Swartz, \& S. Leatherwood (Eds.). The gray whale, Eschrichtius robustus. (pp. 375-387). Orlando, FL: Academic Press.

Caldwell, M. C., \& Caldwell, D. K. (1966). Epimeletic (care-giving) behavior in Cetacea. In K. S. Norris (Ed.). Whales, dolphins, and porpoises. (pp. 755-789). Berkeley and Los Angeles: University of California Press.

Cairns, S. J., \& Schwager, S. J. (1987). A comparison of association indices. Animal Behaviour, 35, 1454-1469.

Cañadas, A., \& Sagarminaga, R. (2000). The northeastern Alboran Sea, an important breeding and feeding ground for the long-finned pilot whale (Globicephala melas) in the Mediterranean Sea. Marine Mammal Science, 16, 513-529.

Carretta, J. V., Forney, K. A., Oleson, E., Martien, K., Muto, M. M., Lowry, M. S., ... Hill, M. C. (2011). U.S. Pacific marine mammal stock assessments: 2010. NOAA Technical Memorandum NMFS-SWFSC-476.

Caurant, F., Amiard-Triquet, C., \& Amiard, J.-C. (1993). Factors influencing the 
accumulation of metals in pilot whales (Globicephala melas) off the Faroe Islands. Report of the International Whaling Commission (Special Issue) 14, 369390.

Caurant F., Amiard, J.-C., Amiard-Triquet, C., \& Sauriau, P. G. (1994). Ecological and biological factors controlling the concentrations of trace elements $(\mathrm{As}, \mathrm{Cd}, \mathrm{Cu}$, $\mathrm{Hg}, \mathrm{Se}, \mathrm{Zn}$ ) in delphinids Globicephala melas from the North Atlantic. Marine Ecology Progress Series, 103, 207-219.

Chivers, S. J., Baird, R. W., McSweeney, D. J., Webster, D. L., Hedrick, N. M., \& Salinas, J. C. (2007). Genetic variation and evidence for population structure in eastern North Pacific false killer whales (Pseudorca crassidens). Canadian Journal of Zoology, 85, 783-794.

Chivers, S. J., LeDuc R. G., \& Baird R. W. (2003). Hawaiian island populations of false killer whales and short-finned pilot whales revealed by genetic analyses. In Abstracts of the 15th Biennial Conference on the Biology of Marine Mammals, Greensboro, NC, December 2003.

Christal, J., Whitehead, H., \& Lettevall, E. (1998). Sperm whale social units: variation and change. Canadian Journal of Zoology, 76, 1431-1440.

Clapham, P. (2000). The humpback whale: seasonal feeding and breeding in a baleen whale. In J. Mann, R. C. Connor, P. L. Tyack, \& H. Whitehead (Eds.). Cetacean societies: field studies of dolphins and whales. (pp 173-196). Chicago: University of Chicago Press.

Clapham, P. J., Baraff, L. S., Carlson, C. A., Christian, M. A., Mattila, D. K., Mayo, C. A., ... Pittman, S. (1993). Seasonal occurrence and annual return of humpback whales in the southern Gulf of Maine. Canadian Journal of Zoology, 71, 440-43.

Clarke, M. R. (1996). Cephalopods as prey. III. Cetaceans. Philosophical Transactions of the Royal Society of London, Series B, 351, 1053-1065.

Clarke, M., \& R. Young. (1998). Description and analysis of cephalopod beaks from stomachs of six species of odontocete cetaceans stranded on Hawaiian shores. Journal of the Marine Biological Association of the United Kingdom, 78, 623641.

Connor, R. (2000). Group living in whales and dolphins. In J. Mann, R.C. Connor, P.L. Tyack, \& H. Whitehead (Eds.). Cetacean societies: field studies of dolphins and whales. (pp 199-218). Chicago: University of Chicago Press.

Connor, R., Wells, R. S., Mann, J., \& Read, A. J. (2000). The bottlenose dolphin. Social relationships in a fission-fusion society. In J. Mann, R.C. Connor, P.L. Tyack, \& H. Whitehead (Eds.). Cetacean societies: field studies of dolphins and whales. (pp 
91-127). Chicago: University of Chicago Press.

Courbis, S. S. (2011). Population structure of island-associated pantropical spotted dolphins (Stenella attenuata) in Hawaiian waters. (Doctoral dissertation, Portland State University).

Croft, D. P., Krause, J., \& James, R. (2004). Social networks in the guppy (Poecilia reticulata). Proceedings of the Royal Society B, 271, S516-S519.

Danil, K., Maldini, D., \& Marten, K. (2005). Patterns of use of Maku'a Beach, O'ahu, Hawai' $i$, by spinner dolphins (Stenella longirostris) and potential effects of swimmers on their behavior. Aquatic Mammals, 31, 403-412.

de Stephanis, R., García-Tíscar, S., Verborgh, P., Esteban-Pavo, R., Pérez, L., MinvielleSebastia, L., \& Guinet, G. (2008a). Diet of the social groups of long-finned pilot whales (Globicephala melas) in the Strait of Gibraltar. Marine Biology, 154, 603612.

de Stephanis, R., Verborgh, P., Perez, S., Esteban, R., Minvielle-Sebastia, L., \& Guinet, C. (2008b). Long-term social structure of long-finned pilot whales (Globicephala melas) in the Strait of Gibraltar. acta ethologica, 11, 81-94.

Duffield, D. A., \& Wells, R. S. (1991). The combined application of chromosome protein and molecular data for the investigation of social unit structure and dynamics in Tursiops truncatus. In A.R. Hoelzel (Ed.). Report of the International Whaling Commission (Special Issue 13), 155-169.

Durrell, J. L., Sneddon, I. A., O’Connell, N. E., \& Whitehead, H. (2004). Do pigs form preferential associations? Applied Animal Behaviour Science, 89 (1-2), 41-52.

Efron, B., \& Stein, C. (1981). The Jackknife Estimate of Variance Source: The Annals of Statistics, 9 (3), 586-596.

Fehring, W. K., \& Wells, R. S. (1976). A series of strandings by a single herd of pilot whales on the west coast of Florida. Journal of Mammalogy, 57, 191-94.

Ford, M.J., Hanson, M. B., Hempelmann, J. A., Ayres, K. L., Emmons, C. K., Schorr, G. S.,..Balcomb-Bartok, K. (2011). Inferred paternity and male reproductive success in a killer whale (Orcinus orca) population. Journal of Heredity, 102, 537-553.

Forney, K. A. (2010). Serious injury determinations for cetaceans caught in Hawaii longline fisheries during 1994-2008. NOAA Technical Memorandum NOAATM-NMFS-SWFSC-462.

Frantzis, A. (1998). Does acoustic testing strand whales? Nature, 392, 29. 
Fullard, K., Early, G., Heide-Jørgensen, M. P., Bloch, D., Rosing-Asvid A., \& Amos W. (2000). Population structure of long-finned pilot whales in the North Atlantic: a correlation with sea surface temperature? Molecular Ecology, 9, 949-958.

Gero, S., Bejder, L., Whitehead, H., Mann, J., \& Connor, R. C. (2005). Behaviourally specific preferred associations in bottlenose dolphins, Tursiops sp. Canadian Journal of Zoology, 83, 1566-1573.

Ginsberg, J. R., \& Young, T. P. (1992). Measuring association between individuals or groups in behavioural studies. Animal Behaviour, 44, 377-379.

Gray, J. E. (1846). Description of Cetaceous Animals, with figures of the new species and their skulls. In The Zoology of the voyage of H.M.S. Erebus and Terror under the command of Captain Sir James Clark Ross, R.N.F.R.S., during the years 1839 to 1843. (pp. 13-53). London: E.W. Janson.

Greenwood, P. J. (1980). Mating systems, philopatry, and dispersal in birds and mammals. Animal Behaviour, 28, 1140-1162.

Haenel, N. J. (1986). General notes on the behavioral ontogeny of Puget Sound killer whales and the occurrence of allomaternal behavior. In B. Kirkevold and J. S. Lockard (Eds.). Behavioral Biology of Killer Whales. (pp. 285-300). New York: Alan R. Liss.

Hammond, P. S., Mizroch, S. A., \& Donovan, G. P. (Eds.). (1990). Individual recognition of cetaceans: Use of photo-identification and other techniques to estimate population parameters. Reports of the International Whaling Commission (Special Issue 12),440 pp.

Hartman, K.L., Geelhoed, S.C.V., Visser, F., \& Azevedo, J.N. (2009). Temporal residency patterns of Risso's dolphins (Grampus griseus) off Pico island, Azores. In: Proceedings of the 18th Biennal Conference on the Biology of Marine Mammals, Quèbec, Canada.

Hartman, K. L., Visser, F., \& Hendriks, A. J. E. (2008). Social structure of Risso's dolphins (Grampus griseus) at the Azores: a stratified community based on highly associated social units. Canadian Journal of Zoology, 86, 294-306.

Heimlich-Boran, J. R. (1993). Social organization of the short-finned pilot whale, Globicephala macrorhynchus, with special reference to the comparative social ecology of delphinids. (Doctoral dissertation, Cambridge University, England).

Herman, L. M., \& Antinoja, R. C. (1977). Humpback whales in the Hawaiian breeding waters: population and pod characteristics. Scientific Reports of the Whales Research Institute 29, 59-85. 
Hinde, R.A. (1976). Interactions, relationships and social structure. Man, 11, 1-17.

International Whaling Commission. (1994). Report of the workshop on mortality of cetaceans in passive fishing nets and traps. In Perrin, W. F., Donovan, G., \& Barlow, J. (Eds.). Gillnets and cetaceans: Incorporating the proceedings of the symposium and workshop on the mortality of cetaceans in passive fishing nets and traps. (pp. 6-71). Reports of the International Whaling Commission (Special Issue 15), $629 \mathrm{pp}$.

Ivkovich, T., Filatova, O. A., Burdin, A. M., Sato, H., \& Hoyt, E. (2009). The social organization of resident-type killer whales (Orcinus orca) in Avacha Gulf, Northwest Pacific, as revealed through association patterns and acoustic similarity. Mammalian Biology, 75, 198-210.

Karczmarski, L., Würsig, B., Gailey, G., Larsen, K. W., \& Vanderlip, C. (2004). Spinner dolphins in a remote Hawaiian atoll: social grouping and population structure. Behavioral Ecology, 16, 675-685.

Kasuya, T., Mayashita, T., \& Kasamatsu, F. (1988). Segregation of two forms of shortfinned pilot whales off the Pacific coast of Japan. Scientific Reports of the Whales Research Institute, 39, 77-90.

Kemp, N. J. (1996). Incidental catches of small cetaceans. In M. P. Simonds and J. Hutchinson (Eds.). The conservation of whales and dolphins: Science and practice. (pp. 129-128). Chichester: Wiley.

Krause, J., \& Ruxton, G.D. (2002). Living in groups. Oxford: Oxford University Press.

Lusseau, D. (2007). Why are male social relationships complex in the Doubtful Sound bottlenose dolphin population? PLoS ONE, 2(4), e348.

Lusseau, D., Schneider, K., Boisseau, J., Haase, P., Slooten, E., \& Dawson, S. M. (2003). The bottlenose dolphin community of Doubtful Sound features a large proportion of long-lasting associations. Can geographic isolation explain this trait? Behavioral Ecology and Sociobiology, 54, 396-405.

Lusseau, D., Whitehead H., \& Gero, S. (2008). Incorporating uncertainty into the study of animal social networks. Animal Behaviour, 75, 1809-1815.

Mann, J. (2000). Unraveling the dynamics of social life. In J. Mann, R.C. Connor, P.L. Tyack, \& H. Whitehead (Eds.), Cetacean societies: Field studies of dolphins and whales. (pp. 45-64). Chicago: University of Chicago Press.

Mazzuca, L., Atkinson, S., Keating, B., \& Nitta, E. (1999). Cetacean mass strandings in the Hawaiian Archiepelago, 1957-1998. Aquatic Mammals, 25.2, 105-114. 
Martien, K. M., Baird, R. W., \& Hedrick, N. M. (2011). Population structure of island associated dolphins: Evidence from mitochondrial and microsatellite markers for common bottlenose dolphins (Tursiops truncatus) around the main Hawaiian Islands. Marine Mammal Science. doi:10.1111/j.1748-7692.2011.00506.x

Martin, A. R., \& da Silva, V. M. F. (2004). River dolphins and flooded forest: seasonal habitat use and sexual segregation of botos Inia geoffrensis in an extreme cetacean environment. Journal of Zoology, 263, 295-305.

MATLAB version 7.1, 2003, computer software. The MathWorks Inc, Natick, MA.

McCracken M., \& Forney, K. A. (2010). Preliminary assessment of incidental interactions with marine mammals in the Hawaii longline deep and shallow set fisheries. NMFS, Pacific Islands Fisheries Science Center Working Paper WP-10001. 27p.

McSweeney, D. J., Baird, R. W., \& Mahaffy, S. D. (2007). Site fidelity, associations and movements of Cuvier's (Ziphius cavirostris) and Blainville's (Mesoplodon densirostris) beaked whales off the island of Hawai'i. Marine Mammal Science, 23, 666-687.

McSweeney, D. J., Baird, R.W., Mahaffy, S. D., Webster, D. L., \& Schorr, G. S. (2009). Site fidelity and association patterns of a rare species: pygmy killer whales (Feresa attenuata) in the main Hawaiian Islands. Marine Mammal Science, 25, 557-572.

Merriman, M. G., Markowitz, T. M., Harlin-Cognato, A. D., \& Stockin, K. A. (2009). Aquatic Mammals, 35(4), 511-522. doi 10.1578/AM.35.4.2009.511

Miyashita, T., Kasuya, T., \& Mori, K. (Eds.). (1990). An examination of the feasibility of using photo-identification techniques for a short-finned pilot whale stock off Japan. Reports of the International Whaling Commission (Special Issue 12), 425428.

Mobley, J. R., Spitz, S.S., Forney, K.A., Grotefendt, R.A., \& Forestell, P.H. (2000). Distribution and abundance of odontocete species in Hawaiian waters: Preliminary results of 1993-98 aerial surveys. National Marine Fisheries Service Southwest Fisheries Science Center Administrative Report LJ-00-14C. 26 pp

Möller, L. M., Allen, S. J., \& Harcourt, R. G. (2002). Group characteristics, site fidelity and abundance of bottlenose dolphins (Tursiops aduncus) in Jervis Bay and Port Stephens, southeastern Australia. Australian Mammalogy, 24,11-21.

Newman, M.E.J. (2004). Analysis of weighted networks. Physical Review E, 70, 056131. 
Newman, M.E.J. (2006). Modularity and community structure in networks. Proceedings of the National Academy of Sciences of the United States of America, 103, 85778582.

Norris, K.S., \& Schilt, C.R. (1988). Cooperative societies in three-dimensional space: On the origins of aggregations, flocks and schools, with special reference to dolphins and fish. Ethology and Sociobiology, 9, 149-79.

Olesiuk, P., Bigg, M. A., \& Ellis, G. M. (1990). Life history and population dynamics of resident killer whales (Orcinus orca) in the coastal waters of British Columbia and Washington State. Reports of the International Whaling Commission (Special Issue 12), 209-243.

Olson, P.A. (2009). Pilot whales (Globicephala melas and G. macrorhynchus). In W.F. Perrin, B. Wursig, \& J.G.M. Thewissen (Eds.). Encyclopedia of marine mammals, Second Edition. Amsterdam: Academic Press.

Oremus, M. (2008). Genetic and demographic investigation of population structure and social system in four delphinid species. (Doctoral dissertation, University of Auckland, New Zealand).

Ottensmeyer, C. A. (2001). Social structure of long-finned pilot whales from photoidentification techniques (Globicephala melas). (Master's thesis, Dalhousie University, Canada).

Ottensmeyer, C. A., \& Whitehead, H. (2003). Behavioral evidence for social units in long-finned pilot whales. Canadian Journal of Zoology, 81, 1327-1338.

Palmeirim, J. M., \& Rodrigues, L. (1995). Dispersal and philopatry in colonial animals: The case of Miniopterus schreibersii. Symposia of the Zoological Society of London, 67, 219-31.

Pepper, J. W., Mitani, J. C., \& Watts, D. P. (1999). General gregariousness and specific social preferences among wild chimpanzees. International Journal of Primatology, 20, 613-632.

Porter, J.W. (1979). Pseudorca strandings. Oceans, 10, 8-15.

Reeves, R. R., Stewart, B. S., Clapham, P. J., \& Powell, J. A. (2002). National Audubon Society guide to marine mammals of the world. New York: Alfred A. Knopf.

Richardson, W. J., Greene, C.R. Jr., Malme, C.I., \& Thompson, D.H. (1995). Marine mammals and noise. San Diego: Academic Press.

Roussel, R, E. (1999). Les cétacés dans la partie orientale du Détroit de Gibraltar au printemps: indications d'écologie. (Master's thesis, Ecole Pratique des Hautes 
Etudes, France).

Schorr, G. S., Baird, R. W., Webster, D. L., McSweeney, D. J., Hanson, M. B., Andrews, R. D., \& Barlow, J. (2007). Spatial distribution of Blainville's beaked whales, Cuvier's beaked whales, and short-finned pilot whales in Hawai' $i$ using dorsal finattached satellite and VHF tags: implications for management and conservation. Talk presented at the 17th Biennial Conference on the Biology of Marine Mammals, Cape Town, South Africa, November-December 2007.

Sergeant, D.E. (1962). The biology of the pilot or pothead whale, Globicephala melaena (Traill) in Newfoundland waters. Bulletin - Fisheries Research Board of Canada, 132,1-84.

Sellas, A. B., Wells, R. S., \& Rosel, P. E. (2005). Mitochondrial and nuclear DNA analyses reveal fine scale geographic structure in bottlenose dolphins (Tursiops truncatus) in the Gulf of Mexico. Conservation Genetics 6, 715-728.

Shane, S.H., \& McSweeney, D. (1990). Using photo-identification to study pilot whale social organization. Reports of the International Whaling Commission (Special Issue 12), 259-263.

Smolker, R.A., Richards, A.F., Connor, R.C., \& Pepper, J.W. (1992). Sex differences in patterns of association among Indian Ocean bottlenose dolphins. Behavior, 123, 38-69.

Southall, B.L., Braun, R., Gulland, F.M.D., Heard, A.D., Baird, R.W., Wilkin, S.M., \& Rowles, T.K. (2006). Hawaiian melon-headed whale (Peponocephala electra) mass stranding event of July 3-4, 2004. NOAA Technical Memorandum NMFSOPR-31.

Traill, T.S. (1809). Description of a new species of whales, Delphinus melas. Nicholson's Journal of Natural Philosophy, Chemistry and the Arts, 22, 81-83.

Trillmich, F. (2009). Sociobiology. In W.F. Perrin, B. Würsig, and J.G.M Thewissen (Eds.). Encyclopedia of marine mammals, Second Edition. Amsterdam: Academic Press.

Verborgh, P., de Stephanis, R., Perez, S., Jaget, Y., Barbraud, C., \& Guinet, C. (2009). Survival rate, abundance, and residency of long-finned pilot whales in the Strait of Gibraltar. Marine Mammal Science, 25, 523-536.

Wada, S. (1988). Genetic differentiation between forms of short-finned pilot whales off the Pacific coast of Japan. The Scientific Reports of the Whales Research Institute, 39, 91-101.

Wade, P. R., \& T. Gerrodette. (1993). Estimates of cetacean abundance and distribution 125 
in the eastern tropical Pacific. Reports of the International Whaling Commission, 43, 477-493.

Watkins, W.A., Moore, K.E., \& Tyack, P. (1985). Sperm whale acoustic behaviors in the southeast Caribbean. Cetology, 49, 1-15.

Weilgart, L.S., \& Whitehead, H. (1990). Vocalizations of the North Atlantic pilot whale (Globicephala melas) as related to behavioral contexts. Behavioral Ecology and Sociobiology, 26, 399-402.

Wells, R.S. (1986). Population structure of bottlenose dolphins: Behavioral studies of bottlenose dolphins along the central west coast of Florida. Contract Report to National Marine Fisheries Service, Southeast Fisheries Center. Contract. No. 45WCNF-5-00366.

Wells, R.S. (1991). The role of long-term study in understanding the social structure of a bottlenose dolphin community. In K. Pryor and K.S. Norris (Eds.). Dolphin societies: Discoveries and puzzles. (pp. 195-225). Berkeley: University of California Press.

Wells, R.S., Scott, M.D., \& Irvine, A.B. (1987). In H. Genoways (Ed.). The social structure of free-ranging bottlenose dolphins. Current Mammalogy, Vol. 1. (pp. 247-305). New York: Plenum Press.

Wells, R.S., \& Scott, M.D. (1990). Estimating bottlenose dolphin population parameters from individual identification and capture-release techniques. Reports of the International Whaling Commission (Special Issue 12), 407-415.

Whitehead, H. (1996). Babysitting, dive synchrony, and indications of alloparental care in sperm whales. Behavioural Ecology and Sociobiology, 38, 237-244.

Whitehead, H. (1999). Testing association patterns of social animals. Animal Behaviour 57, F26-29.

Whitehead, H. (2001). Analysis of animal movement using opportunistic individual identifications: application to sperm whales. Ecology, 82, 1417-1432

Whitehead, H. (2007). Selection of models of lagged identification rates and lagged association rates using AIC and QAIC. Communications in Statistics-Simulation and Computation, 36, 1233-1246.

Whitehead, H. (2008a). Precision and power in the analysis of social structure using associations. Animal Behaviour, 75: 1093-1099

Whitehead, H. (2008b). Analyzing animal societies: quantitative methods for vertebrate social analysis. University of Chicago Press, Chicago. 
Whitehead, H. (2009). SOCPROG programs: analyzing animal social structures. Behavioral Ecology and Sociobiology, 63, 765-778.

Whitehead, H., \& Dufault, S. (1999). Techniques for analyzing vertebrate social structure using identified individuals: review and recommendations. Advances in the Study of Behavior, 28, 33-74.

Whitehead, H., Gowans, S., Faucher, A., \& McCarrey, S. (1997). Status of the northern bottlenose whale, Hyperoodon ampullatus, in the Gully, Nova Scotia. Canadian Field-naturalist, 111, 287-92.

Whitehead, H., Reeves, R.R., \& Tyack, P.L. (2000). Science and the conservation, protection, and management of wild cetaceans. In J. Mann, R.C. Connor, P.L. Tyack, \& H. Whitehead (Eds.). Cetacean societies: Field studies of dolphins and whales. (pp. 308-339). Chicago: University of Chicago Press.

Whitehead, H., \& Weilgart, L. (2000). The sperm whale: social females and roving males. In J. Mann, R.C. Connor, P.L. Tyack, \& H. Whitehead (Eds.). Cetacean societies: Field studies of dolphins and whales. (pp. 154-172). Chicago: University of Chicago Press.

Williams, R., \& Lusseau, D. (2006). A killer whale social network is vulnerable to targeted removals. Biology Letters 2, 497-500.

Wilson, E.O. (1975). Sociobiology: The New Synthesis. Cambridge, MA: Harvard University Press.

Würsig, B., \& Jefferson, T.A. (1990). Methods of photo-identification for small cetaceans. Reports of the International Whaling Commission (Special Issue 12), 43-52.

Würsig, B., \& Würsig, M. (1977). The photographic determination of group size, composition and stability of coastal porpoises (Tursiops truncatus). Science, 198, 755-756.

Würsig, B., \& Würsig, M. (1979). Behavior and ecology of the bottlenose dolphin, Tursiops truncates, in the South Atlantic. Fishery Bulletin, 77, 871-890.

Yonekura, M., Matsui, S., \& Kasuya, T. (1980). On the external characters of Globicephala macrorhynchus off Taiji, Pacific coast of Japan. The Scientific Reports of the Whales Research Institute 32, 67-95. 


\section{Appendix A: Group size}

When comparing group size estimates among studies of long-finned pilot whales, group sizes were not appreciably different for encounters delineated using the $200 \mathrm{~m}$ boundary and $\leq 5$ inter-individual distance, with a mean $=20, \mathrm{SD} \pm 17$, range $=2-135$ for Ottensmeyer \& Whitehead (2003), and a mean $=14, \mathrm{SD} \pm 18$, range $=2-150$ for de Stephanis et al. (2008b). However, the 1,000m chain rule used by the Cañadas \& Sagarminaga (2000) study reported a larger average group size (mean=41.1, SD \pm 58.4 ) and membership range (1-350). A logarithmic transformation of the data in the Cañadas \& Sagarminaga (2000) study reduced the average group size to 20.9 individuals, although they reported that $10.1 \%$ of the sightings contained $\geq 100$ individuals, suggesting that larger group sizes might be more strongly associated with sparsely distributed groups. The average group size for the current study (mean=20.7) is therefore in line with the other studies presented here; however, the average group size range (1-53) is noticeably smaller despite having a more relaxed definition of encounter than all but one of the studies. The smaller group size range documented off the island of Hawai'i could indicate a difference between the two pilot whale species (all comparisons were with studies of long-finned pilot whales), a difference in local ecology, or a difference in social structure. Additional field effort off the island of Hawai'i from 2008 has since documented two encounters with maximum group size estimates of 230 and 240 individuals, indicating that while it may be uncommon, larger aggregations do exist. As Ottensmeyer (2001) noted, the modifications Heimlich-Boran (1993) made to the original sighting data prevented any comparison of group-size estimations. 
Over half of the 86 photographed encounters for which coverage estimates were available reported $<50 \%$ coverage; while not representative of the entire data set (61\% of all directed research encounters), this value does suggest that in the majority of encounters a portion of individuals who were present were likely not documented. However, use of a coverage index in lieu of $\%$ coverage provided a consistent metric for coding encounters from different sources and allowed results to be more directly compared with other studies; therefore, rather than restricting encounters used in the study based on multiple metrics, some of which were only applicable to a portion of the data set, a single measure was used. 


\section{Appendix B: Evolving fingerprints: working with natural markings}

By nature, the markings that form the foundation of photo-identification studies are not fixed elements of an individual's appearance, but dynamic characteristics that often reflect events in an individual's life history. The potential for a constellation of markings on the dorsal fin to change, either with the addition of new markings, the loss of markings through the addition of a more dramatic mark-change event, or the alteration of an existing mark shape are real concerns that affect the accuracy of photo-identification results in describing populations. In a photo-identification study of melon-headed whales around the main Hawaiian Islands between 2002 and 2009, Aschettino et al. (2011) found mark changes to 36 distinctive, well-photographed individuals (10.9\%), four of which underwent several independent mark-change events over the course of the study; mark changes were estimated to occur at a rate of once per 9.2-13.8 years (6.7-10.3 years for the Hawai'i resident population and 15.2-21.0 years for the main Hawaiian Islands population). A missed-match rate of 5\% of distinctive individuals was found in the melon-headed whale study (Aschettino et al. 2011); missed matches included situations in which a single individual was assigned to two separate catalog IDs, and in which right side and left side photos assigned to the same ID were, in fact, different individuals. Mark changes were documented on over half $(55 \%)$ of the pygmy killer whales resighted off the island of Hawai' $i$, resulting in a total of 71 modifications to the dorsal fin (including five occasions in which the total number of notches decreased due to the merging of notches); mark-change events were estimated to occur at rate of once every 3.9-6.1 years (McSweeney et al. 2009). Mark changes were also documented in 17 
(24.3\%) of rough-toothed dolphins re-sighted around the main Hawaiian Islands (estimated rate of mark change once every 2.42 years), and in $26(32.5 \%)$ of the resighted false killer whales, with an estimated rate of mark change of once every 6.9-8.8 years (Baird et al. 2008a, b). Ottensmeyer (2001) reported mark changes resulting in additional nicks or notches to three individuals over the two-year study period; no loss of marks were observed and only minor changes to the dorsal fin were implied.

Damage to the leading and the trailing edge of the dorsal fin can result in a diversity of mark shapes and sizes, creating much speculation over the origin of these markings. Heimlich-Boran (1993) described 24 categories of dorsal fin disfigurements found in all age and sex classes within the population of short-finned pilot whales, and speculated that nicks and scratches could be caused by predators or objects such as boat propellers, but were most likely caused by conspecifics; whether these interactions were aggressive in nature is unknown. Ottensmeyer (2001) suggested that the origin of the markings could bias the study if aggressive or social individuals were more likely to acquire notches than other members of the population, or if certain age and/or sex classes had a higher probability of being marked (such as adult males). Heimlich-Boran (1993) found that adult males were significantly more recognizable than immature short-finned pilot whales. 


\section{Appendix C: Distinctiveness of the study population and the influence of photo- identification on fine-scale and population-wide analysis}

Techniques such as those used to study social structure that rely on characteristics of individuals to make wider assumptions about the study population require that individuals be consistently and reliably identifiable through time; therefore, only distinctive individuals with good-quality photos are typically used in analyses. Würsig \& Jefferson (1990) acknowledged misidentifying poorly-marked individuals and realizing the error only after higher quality photos were obtained. However, by definition, analyses restricted to only distinctive individuals are not truly representative of the entire study population (though studies may necessarily make this assumption), and potential biases associated with these results need to be addressed. As individuals acquire markings throughout their lives, distinctiveness is generally acknowledged to increase with age (Ottensmeyer \& Whitehead 2003) and individuals included in the current study are largely considered to be adults or sub-adults. Given that distinctiveness is loosely correlated with age, restricting slightly and non-distinctive individuals from analyses may result in the complete or partial exclusion of one or more entire age classes. The exclusion of any portion of the population from analysis is less than ideal, and while conclusions drawn from these results will only be truly representative of distinctive members of the population, effort should be made to include anecdotal information on individuals not included in all analyses to provide a more complete depiction of the study population. 
Estimating the proportion of the study population considered distinctive is important in determining how representative results are of the entire population, and for allowing results to be scaled accordingly to eliminate conservative bias. Accuracy of the population distinctiveness estimate is dependent on the quality of photos taken in the field, the scales used to assign distinctiveness and photo quality ratings and the skill-level of the photo-identification technician. Until the advent of digital photography, photoidentification studies relied heavily on the development of negatives or slides that would typically be examined using a light board and optical loupe, or alternatively would be projected onto a smooth surface and traced to provide a hard copy of the dorsal fin image (Würsig \& Jefferson 1990). Of the five primary pilot whale photo-identification studies reviewed for the current study (see Table A.1), four exclusively employed non-digital cameras, and one (de Stephanis et al. 2008b) used slides for the first portion of the study (examined using a light table and loupe and later scanned into a computer) and digital photographs analyzed on a computer screen for the latter portion. Pilot whale studies employing slides and negatives were analyzed using a variety of methods. Both Shane \& McSweeney (1990) and Miyashita et al. (1990) initially examined slides and negatives using a magnifying loupe before sketching outlines of individual dorsal fins for catalog analysis. Heimlich-Boran (1993) used a video processor to magnify images and identify quality photos that were then printed out for analysis, and Ottensmeyer \& Whitehead (2003) scanned selected negatives to be used with the computer-based matching program Finscan. With the exception of Ottensmeyer \& Whitehead (2003) none of the pilot whale 
studies used computer-assisted matching programs, and the majority used physical rather than digital images.

Table A.1 Photo-identification studies of pilot whales

\begin{tabular}{|c|c|c|c|c|c|}
\hline Study & $\begin{array}{c}\text { de } \\
\text { Stephanis } \\
\text { et al. } \\
(\mathbf{2 0 0 8 b})\end{array}$ & $\begin{array}{c}\text { Ottensmeyer \& } \\
\text { Whitehead } \\
(\mathbf{2 0 0 3 )}\end{array}$ & $\begin{array}{c}\text { Heimlich- } \\
\text { Boran (1993) }\end{array}$ & $\begin{array}{c}\text { Shane \& } \\
\text { McSweeney } \\
\text { (1990) }\end{array}$ & $\begin{array}{c}\text { Miyashita \& } \\
\text { Kasuya (1990) }\end{array}$ \\
\hline Species & G. melas & G. melas & $\begin{array}{c}\text { G. } \\
\text { macrorhynchus }\end{array}$ & $\begin{array}{c}\text { G. } \\
\text { macrorhynchus }\end{array}$ & $\begin{array}{c}\text { G. } \\
\text { macrorhynchus }\end{array}$ \\
\hline Location & $\begin{array}{l}\text { Strait of } \\
\text { Gibraltar }\end{array}$ & $\begin{array}{l}\text { St. Lawrence } \\
\text { Bay, Nova } \\
\text { Scotia }\end{array}$ & $\begin{array}{c}\text { Tenerife, } \\
\text { Canary Islands }\end{array}$ & $\begin{array}{c}\text { Hawai'i and } \\
\text { Catalina }\end{array}$ & Japan \\
\hline Duration & $\sim 7$ years & 26 months & 22 months & $\begin{array}{c}4 \text { winters- } \\
\text { Catalina } \\
5 \text { days over } 2 \\
\text { years- Hawai' } i\end{array}$ & $\begin{array}{l}14 \text { sightings } \\
\text { from } 5 \text { cruises }\end{array}$ \\
\hline $\begin{array}{c}\text { Association } \\
\text { index }\end{array}$ & HWI & HWI and SR? & $\begin{array}{l}\text { SR (Ratio } \\
\text { Index) }\end{array}$ & NA & NA \\
\hline $\begin{array}{c}\text { Mean } \\
\text { group size }\end{array}$ & $14, \mathrm{SD} \pm 18$ & $20, \mathrm{SD} \pm 17$ & NA* & Not reported & Not reported \\
\hline $\begin{array}{l}\text { Distinctive- } \\
\text { ness of } \\
\text { population }\end{array}$ & $\begin{array}{l}\text { Correction } \\
\text { Factor: } \\
1.42(95 \% \\
\mathrm{CI}=1.32- \\
1.52) * * *\end{array}$ & $\begin{array}{c}\text { Overall: } \\
33.6 \%, \\
\text { SE }=4.1 \% \\
\text { By encounter: } \\
35.2 \%, \\
\text { SE }=3.6 \%\end{array}$ & $\sim 85 \% * *$ & $\begin{array}{c}33.5 \% \pm 4.43 \%- \\
\text { Catalina } \\
45.3 \% \pm 2.89 \%- \\
\text { Hawai'i } \\
\text { (error type not } \\
\text { reported) }\end{array}$ & Not reported \\
\hline
\end{tabular}

*Field estimates of group size not reported

$* *$ Not reported, based on estimate of non-distinctive individuals

***“"Inverse of the proportion of identifiable individuals" (de Stephanis et al. 2008b)

The current study used only digital photographs visually displayed full-screen on 19 inch computer monitors and processed without the aid of photo-identification software. The variety of media and matching techniques utilized by the pilot whale studies mentioned above make robust comparisons among studies difficult.

Technological advances in digital cameras and computer-based image visualization software allow individuals to be captured at greater resolution than previously available, and for images to be digitally manipulated in ways not available to physical print photos 
or slides and negatives. The ability to digitally enlarge photos and enhance contrast, brightness and color balance allow the identification of fine-scale markings in the dorsal fin and scarring patterns on the dorsal fin and body to be seen that would otherwise be lost to low-contrast photos. While the advantages of digital manipulation increase the rate of successful matches that might otherwise be considered "close" and thus provide a more accurate view of the study populations, digital manipulation also creates a discrepancy between results obtained through pre-digital methods. Estimations of the proportion of the population considered distinctive are dependent on the definition of distinctiveness, which may vary depending on the detail visible in the photo; although distinctiveness ratings ideally would remain independent of photo quality, an increase in overall photo quality from higher resolution digital photos could influence distinctiveness ratings. Indeed, the use of digital photo-manipulation techniques in the current study has allowed individuals with virtually no markings on the dorsal fin or body to be identified between years. Verborgh et al. (2009) reported that an increase in photo quality over a long-term photo-identification study of long-finned pilot whales allowed previously unidentified individuals to be entered into the catalog and slightly-distinctive individuals to be re-sighted.

Unfortunately, no standardized method was used to estimate the distinctiveness of the different pilot whale populations reviewed here, making comparisons difficult. Assuming equal photographic coverage of all individuals, Ottensmeyer \& Whitehead (2003) calculated the ratio of the number of good-quality photos of distinctive individuals to the number of good-quality photos of all individuals, regardless of distinctiveness, 
while de Stephanis et al. (2008a) calculated the inverse of this ratio and added a correction factor. Ottensmeyer \& Whitehead (2003) reported a population distinctiveness estimate of 33.4\% ( $\mathrm{SE}=3.6 \%$ ), while de Stephanis et al. (2008a) did not provide a percent estimate of distinctive individuals but listed a correction factor of $1.42(95 \% \mathrm{CI}=1.32-$ 1.52) for the entire data set, assumed here to equal $70.0 \%$ (95\% CI=65.8-75.8). Verborgh et al. (2009) annually estimated the percent of well-marked long-finned pilot whales in the Strait of Gibraltar between 1999-2005, ranging from 33.1\% (95\% CI=30.8-35.7) in 2004 to $40.2 \%$ (95\% CI=34.0-49.1) in 1999, after a correction factor using 1,000 bootstrap replications was applied. While distinctiveness estimates between the Verborgh et al. (2009) study and Ottensmeyer \& Whitehead (2003) study are similar, the distinctiveness estimate from the de Stephanis et al. (2008a) study is substantially higher. Heimlich-Boran (1993) did not provide an estimate of the proportion of the population of short-finned pilot whales off Tenerife considered distinctive; however, he estimated that, on average, $15 \%(14.8, \mathrm{SE} \pm 0.7)$ of the study population was unrecognizable using either dorsal fin markings or scarring patterns (calculated by taking the difference between the group size estimate and number of identifiable individuals (range $0-34 \%, n=35$ ). Shane \& McSweeney (1990) calculated a distinctiveness estimate of $45.3 \%( \pm 2.89)$ for the island of Hawai' $i$ on three days based on the ratio of identifiable individuals to the total number of good-quality photographs regardless of distinctiveness (type of error factor not reported). Although Shane \& McSweeney (1990) did not provide details of the methods used to calculate the Santa Catalina Island population distinctiveness estimate, estimates of $33.5 \%( \pm 4.43)$ to $35.0 \%( \pm 3.27)$ were lower than those from Hawai' $i$, and differing 
photo qualities were cited as a possible explanation for this discrepancy (type of error factor not reported).

The method used to estimate population distinctiveness in the current study, by calculating the ratio of distinctive individuals with good-quality photographs to all individuals with good-quality photographs, is different from those of the other pilot whale studies referenced here, and follows previous studies of several cetacean species off Hawai'i (see Baird et al. 2008a, b, McSweeney et al. 2009, Aschettino et al. 2011). Encounters were processed such that all possible photos were allocated to an individual regardless of photo quality, and only the best photo was given a photo quality rating for use in subsequent analysis; thus, poor-quality photos were not separated from those of higher quality within an individual's sighting record, and individual photos were not scored due to the volume of photos present. However, such thorough sorting provided a nearly-complete record of individuals present within an encounter, allowing individuals to be accounted for regardless of distinctiveness. Through the aid of digital photomanipulation techniques, encounters were sorted completely; all individuals, regardless of distinctiveness (including calves), were assigned catalog IDs, provided photo quality was deemed sufficient to be able to re-sight that individual. It is reasonable to assume that, were each of the studies reviewed here able to be repeated with higher resolution photographs and digital processing, both the re-sighting rate and distinctiveness estimates would increase slightly, as evidenced by comparing results here to the Shane \& McSweeney (1990) study. 
Although higher than the other pilot whale studies reviewed here, the proportion of the study population estimated to be distinctive is likely conservative, as slightly distinctive individuals have been repeatedly (and in some cases consistently) re-sighted among years using good and excellent-quality photos, as have individuals with clean fins. In some cases, match confirmation required additional markings beyond the leading or trailing edge of the dorsal fin, such as saddle pigmentation patterns or persistent scars; however, scarring was only used to aid in confirmation of a match, and never to deny a match, since it was not known which scars were ephemeral. Auger-Méthé \& Whitehead (2007) noted in a study of natural markings among long-finned pilot whales in Nova Scotia that all pilot whales sampled had at least one mark present and averaged 19 markings representing five different types (though few were permanent), supporting observations from the current study that with frequent re-sighting rates ephemeral scars can be used to aid in match confirmation. 